UNIVERSITY OF OKLAHOMA

GRADUATE COLLEGE

\title{
THE EFFECTS OF SHORT-TERM RESISTANCE TRAINING AND SUBSEQUENT DETRAINING ON NEUROMUSCULAR FUNCTION, MUSCLE CROSS-SECTIONAL AREA, AND LEAN MASS
}

\author{
A DISSERTATION \\ SUBMITTED TO THE GRADUATE FACULTY \\ in partial fulfillment of the requirements for the \\ Degree of \\ DOCTOR OF PHILOSOPHY
}

By

PABLO B. COSTA

Norman, Oklahoma

2011 
THE EFFECTS OF SHORT-TERM RESISTANCE TRAINING AND SUBSEQUENT DETRAINING ON NEUROMUSCULAR FUNCTION, MUSCLE CROSS-SECTIONAL AREA, AND LEAN MASS

A DISSERTATION APPROVED FOR THE DEPARTMENT OF HEALTH AND EXERCISE SCIENCE

BY

Dr. Joel T. Cramer, Chair

Dr. Trina L. Hope

Dr. Travis W. Beck

Dr. Jeffrey R. Stout

Dr. E. Laurette Taylor 
(C) Copyright by PABLO BRANDO COSTA 2011 All Rights Reserved. 


\section{ACKNOWLEDGEMENTS}

First, I would like to thank my dissertation committee for all of the help, involvement, and continued support through this endeavor. I would like to express my sincere appreciation for the mentorship I have received by Dr. Cramer. I have been extremely fortunate to be given the opportunity to work with him. This project would not have been possible without his guidance, inspiration and efforts, and for that I will forever be very thankful.

I would also like to thank my friends, former and current fellow colleagues, graduate students, former students, and staff, who all have directly or indirectly helped me with this process during my educational experience. Specifically, I would like to thank my lab partners. Without them, this project would not have been possible.

Finally, I would like to thank my family for all of their support throughout the years. They have always been my motivating force and the reason for what I have done and what I have achieved. 


\section{TABLE OF CONTENTS}

ACKNOWLEDGEMENTS .............................................. iv

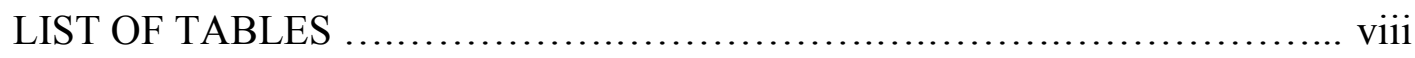

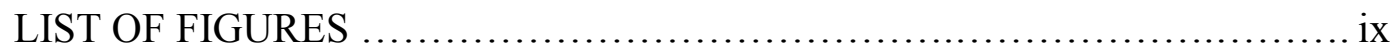

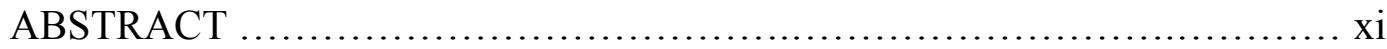

CHAPTER 1: INTRODUCTION ..................................... 1

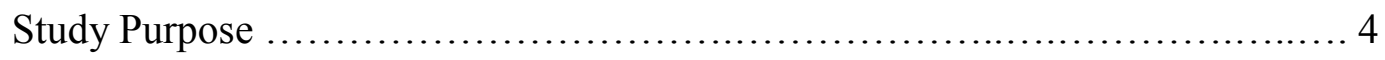

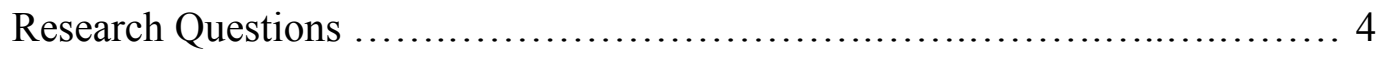

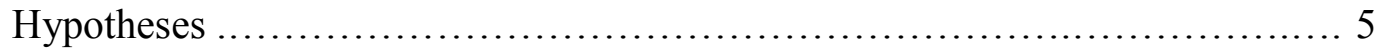

Operational Definitions ............................................. 6

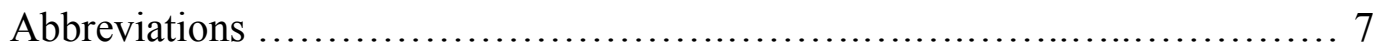

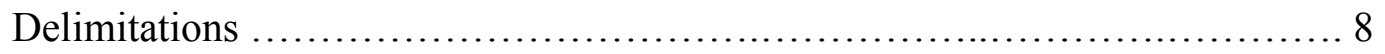

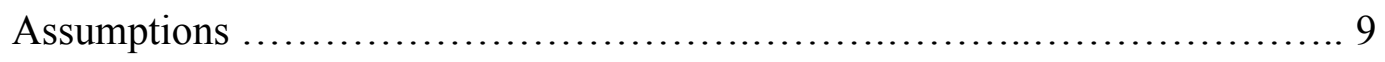

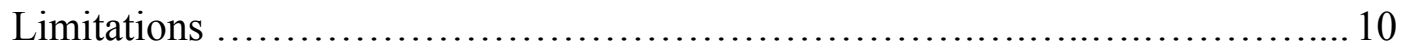

CHAPTER 2: REVIEW OF LITERATURE $\ldots \ldots \ldots \ldots \ldots \ldots \ldots \ldots \ldots \ldots \ldots \ldots \ldots . \ldots \ldots$

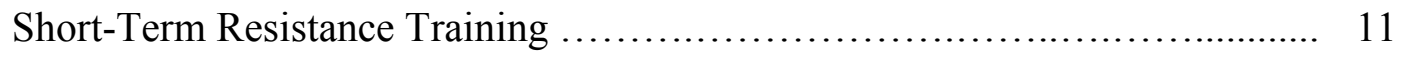

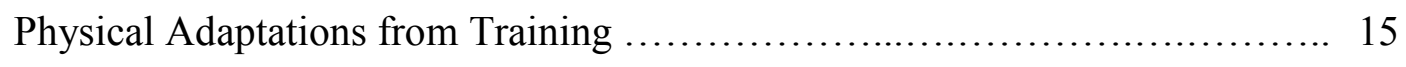

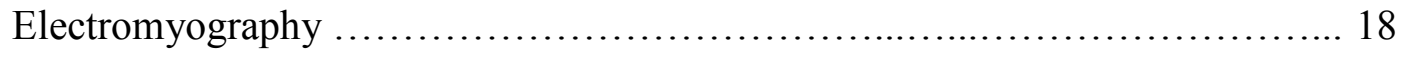

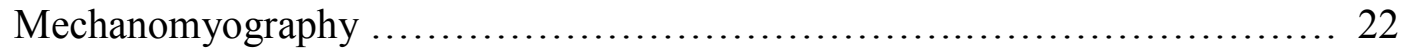

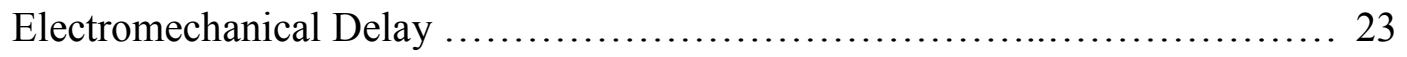


Contralateral Strength Gains ............................................. 23

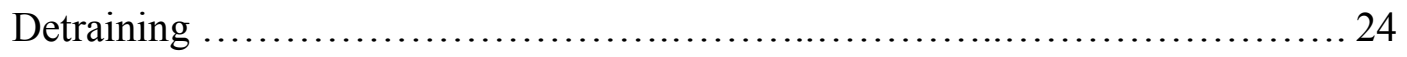

CHAPTER 3: METHODS …............................................ 27

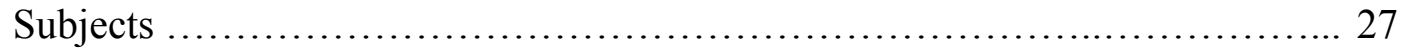

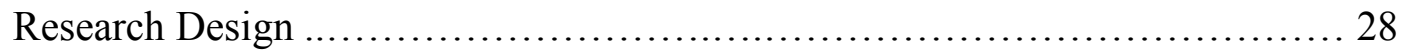

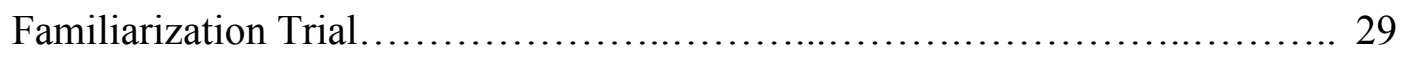

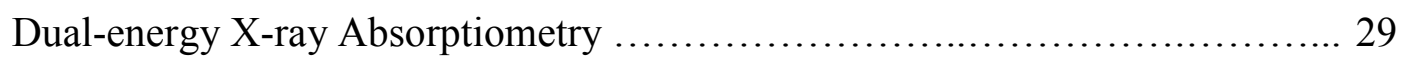

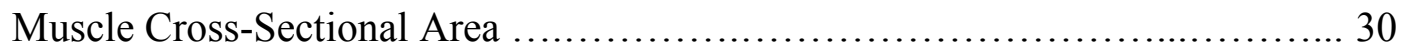

Isokinetic Assessments ..................................................... 31

Dynamic Constant External Resistance Assessments ....................................... 32

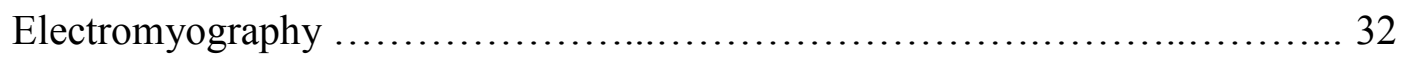

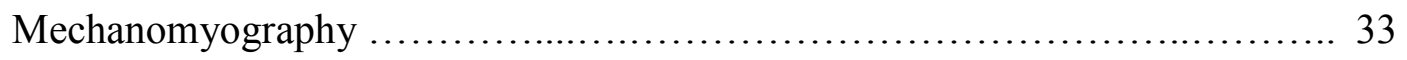

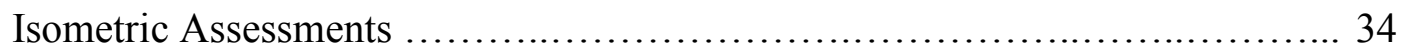

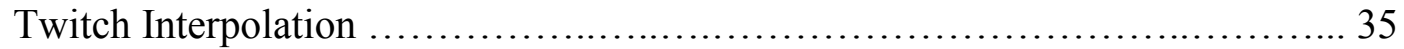

Electromechanical Delay .................................................... 36

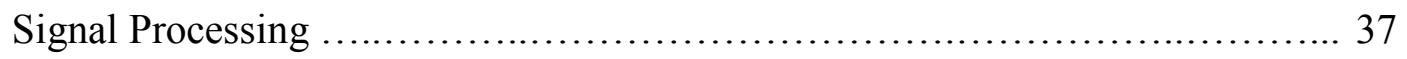

Isokinetic and Dynamic Constant External Resistance Training Protocol ....... 38

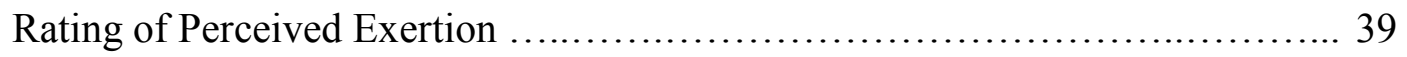

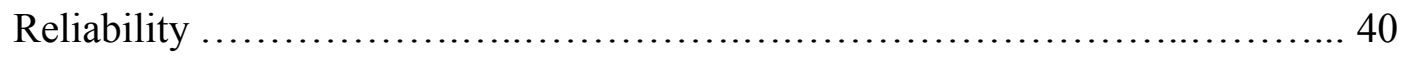

Statistical Analyses ........................................................ 40

CHAPTER 4: RESULTS .................................................. 43

Anthropometric and Body Composition Characteristics ....................... 43

Isokinetic Assessments .................................................. 43

Dynamic Constant External Resistance Assessments ............................ 44

Isometric Assessments ................................................ 45 
Muscle Activation ....................................................... 45

Electromyography ........................................................ 45

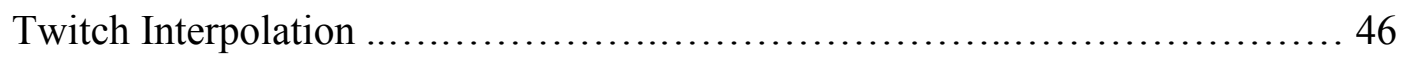

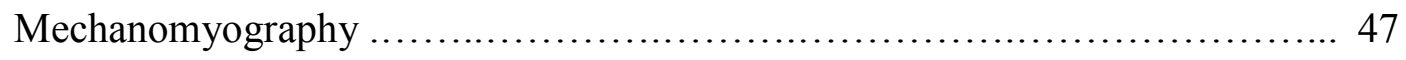

Electromechanical Delay ................................................... 47

Rating of Perceived Exertion ............................................ 47

CHAPTER 5: DISCUSSION ............................................ 49

Anthropometric and Body Composition Characteristics ........................ 49

Isokinetic Assessments ................................................. 50

Dynamic Constant External Resistance Assessments .......................... 50

Isometric Assessments .......................................................... 53

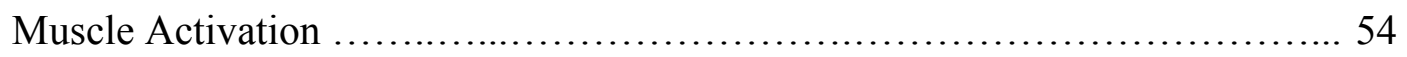

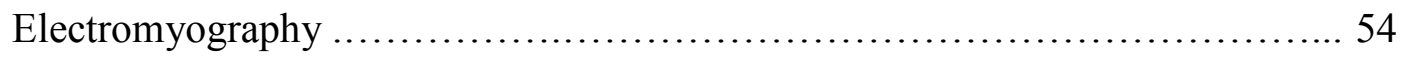

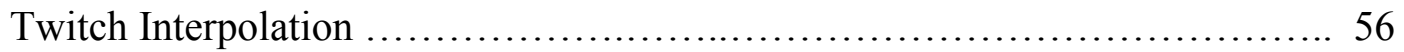

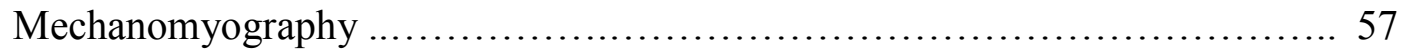

Electromechanical Delay ............................................... 57

Rating of Perceived Exertion ......................................... 58

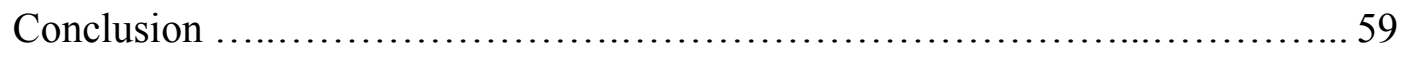

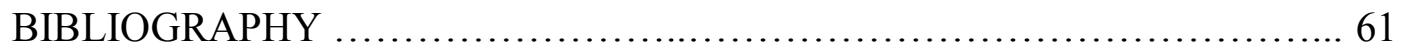

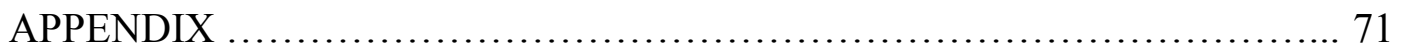

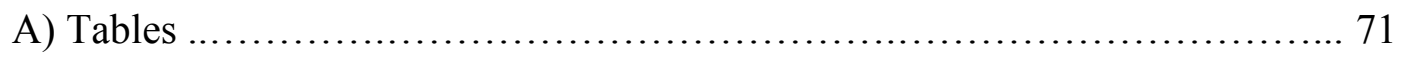

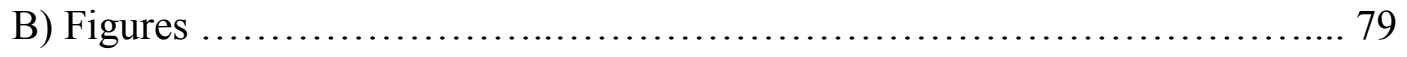

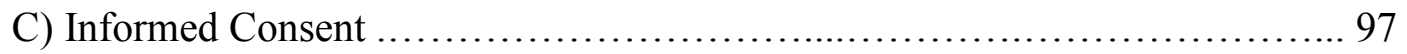

D) Pre-exercise Testing Health and Exercise Status Questionnaire .............. 100 


\section{LIST OF TABLES}

Table 1. Subjects' demographics

Table 2. Reliability results

Table 3. Means ( \pm SE) for anthropometric and body composition data

Table 4. Means $( \pm \mathrm{SE})$ for isokinetic strength testing

Table 5. Means ( \pm SE) for dynamic constant external resistance 1-RM

Table 6. Means $( \pm \mathrm{SE})$ for isometric maximal voluntary contraction

Table 7. Means ( \pm SE) for mechanomyographic amplitude

Table 8. Means ( $\pm \mathrm{SE}$ ) for electromechanical delay 


\section{LIST OF FIGURES}

Figure 1. Study design flowchart

Figure 2. Regions of interest around the right thigh

Figure 3. Isokinetic assessment set-up

Figure 4. Dynamic constant external resistance assessment set-up

Figure 5. Electromyography electrodes and mechanomyography accelerometers placements

Figure 6. Isometric force assessment set-up

Figure 7. Category-Ratio scale rating of perceived exertion

Figure 8 . Isokinetic peak torque at $90^{\circ} \cdot \mathrm{s}-1$

Figure 9. Isokinetic peak torque at $180^{\circ} \cdot \mathrm{s}-1$

Figure 10. Isokinetic peak torque collapsed across time, group, and velocity

Figure 11. Isokinetic peak torque collapsed across time, group, and limb

Figure 12. Dynamic constant external resistance strength 
Figure 13. Electromyographic amplitude collapsed across quadriceps muscles, group, and time

Figure 14. Electromyographic amplitude collapsed groups and velocities for the BF muscles

Figure 15. Electromyographic amplitude collapsed across group and time for the BF muscles

Figure 16. Voluntary activation collapsed across group and time

Figure 17. Set rating of perceived exertion collapsed across both training groups

Figure 18. Session rating of perceived exertion collapsed across both training groups 


\begin{abstract}
THE EFFECTS OF SHORT-TERM RESISTANCE TRAINING AND SUBSEQUENT DETRAINING ON NEUROMUSCULAR FUNCTION, MUSCLE CROSS-SECTIONAL AREA, AND LEAN MASS
\end{abstract}

Pablo B. Costa

The University of Oklahoma 2011

Supervising Professor: Joel T. Cramer, PhD

A resistance training program has been the hallmark of exercise and rehabilitation treatment, and the neuromuscular system undergoes numerous adaptations following this type of training intervention. Recently, interest has shifted to short-term resistance training. Short-term resistance training has been shown to increase muscle strength and isokinetic (ISOK) performance after only a few days of training; however, the specific mechanisms of such adaptations to different modes of short-term training have not been fully understood. Therefore, the purpose of this study was to examine and compare the effects of three days of dynamic constant external resistance (DCER) and ISOK training and subsequent 
detraining on thigh muscle cross-sectional area (TMCSA) and thigh lean mass (TLM), ISOK peak torque (PT), DCER strength, isometric force, surface electromyography (EMG), and surface mechanomyography (MMG) of the leg extensors during maximal leg extension muscle actions, percent voluntary activation (\%VA), and the electromechanical delay (EMD). A mixed factorial design was used to examine the effects of three days of short-term resistance training. Thirty-one apparently-healthy untrained men (mean \pm SD age $=22.2 \pm 4.2$ yrs; body mass $=77.9 \pm 12.9 \mathrm{~kg}$; height $=173.9 \pm 5.4 \mathrm{~cm}$ ) were randomly assigned to a DCER training group, ISOK training group, or control (CONT) group. Subjects visited the laboratory eight times, the first visit was a familiarization session, the second visit was a pre-training assessment, the subsequent three visits were for training (if assigned to a training group), and the last three visits were the post-training assessments. Testing included assessments of body composition, DCER, ISOK, and isometric strength, EMG, MMG, \%VA, and EMD. One training group performed ISOK leg extension exercise and the other performed DCER leg extension exercise for three sets of ten repetitions each of the three days of training. A third group took part in a CONT condition and did not train. Rating of perceived exertion (RPE) was obtained after each training set (set RPE) and after every training session (session RPE). The dependent variables in this study were (a) body mass (BM); (b) body fat percentage (BF\%); (c) thigh fat percentage (TF\%); (d) thigh lean mass (TLM); (e) thigh muscle cross-sectional area (TMCSA); (f) isokinetic PT; (g) DCER strength; (h) isometric force; (i) EMG; (j) MMG; (k) $\%$ VA at 30, 50, 70, and 100\% of maximum MVC; (l) EMD; and (m) RPE. No 
changes in $\mathrm{BF} \%$, TLM, or TMCSA were found. However, BM decreased for all groups from pre- to post-training assessment one. There were no changes for ISOK PT, but PT was greater for the right than left leg and at $90^{\circ} \cdot \mathrm{s}^{-1}$ than $180^{\circ} \cdot \mathrm{s}^{-1}$. DCER strength increased from pre- to post-training assessment 1 in both limbs for the DCER group only, and remained elevated during post-training assessments 2 and 3 . In addition, DCER strength was higher for the right leg than left leg. No changes were found for isometric strength. Surface EMG amplitude for the rectus femoris and vastus lateralis did not change, but was higher at $180^{\circ} \cdot \mathrm{s}^{-1}$ than $90^{\circ} \cdot \mathrm{s}^{-1}$. Surface EMG for the biceps femoris was higher at post-training assessment 3 than pretraining assessment, post-training assessment 1 , and post-training assessment 2 . In addition, biceps femoris EMG was higher at $180^{\circ} \cdot \mathrm{s}^{-1}$ than $90^{\circ} \cdot \mathrm{s}^{-1}$. No changes were found for $\% \mathrm{VA}$, but increased from 30 to $100 \%$ of MVC intensity. Surface MMG amplitude for the rectus femoris and vastus lateralis did not change, but was higher at $180^{\circ} \cdot \mathrm{s}^{-1}$ than $90^{\circ} \cdot \mathrm{s}^{-1}$. No changes were found for EMD. Set RPE did not change over the training sessions, but increased from the first until the last set within all sessions for both training groups. Session RPE did not change over the training sessions. The primary finding of this study was that DCER strength can be increased with three days of training. Another important finding of the current study is that short-term resistance training induces a cross-education effect increasing the strength in the untrained limb. This has important implications for injury rehabilitation, where in the initial period post-injury strength gains on an injured limb can possibly be obtained with short-term contralateral resistance training. Strength gains observed after DCER resistance training were due to an 
unidentified factor. The findings of the current study may indicate an advantage of DCER over ISOK resistance training programs when conducted over a relatively short period of time. Traditional DCER resistance training appears to be a better and more cost-effective option when rapid increases in strength are desired and a longer amount of time is not available. These findings have important implications in clinical rehabilitation settings, sports injury prevention, as well as in other allied health fields such as physical therapy, occupational therapy, and athletic training. To our knowledge, the current study is the first to demonstrate recently-acquired strength can be maintained for a two-week period in trained and untrained limbs. Therefore, future studies should examine the effects of short-term resistance training on injury prevention and rehabilitation. 


\section{CHAPTER 1:}

\section{INTRODUCTION}

Resistance training has been the hallmark of exercise and rehabilitation programs. Recently, interest has been shifted to short-term resistance training (25). Allied health professionals, such as physical therapists and athletic trainers, may benefit from a rapid increase in strength of a patient or athlete recovering from injury $(7,17,25)$. In theory, if an individual's strength can be increased within a short amount of time, they are more likely to comply with a rehabilitation program and perhaps decrease the risk of reinjury (7). Consequently, short-term resistance training has been shown to increase muscle strength and isokinetic performance after only days of training $(11,17,25,80)$. Those who are injured could benefit greatly from this type of training because often they receive limited physical rehabilitation treatments because of minimal insurance coverage or lack of compliance $(17,25)$, or simply because not enough time is available before they need to return to play. If patients do not improve quickly, the risk of injury reoccurrence may increase (25). In addition, if short-term resistance training can improve performance quickly, patient compliance may increase, reduce risk of reinjury, and offer an alternative to more expensive and oftentimes invasive procures $(17,25)$. Because of this potential for short-term resistance training to improve muscular performance in a relatively shorter period of time, it would have 
important implications for professionals working in rehabilitation setting $(7,17$, 25).

Increases in muscular strength following a resistance training program can be attributed to neural and hypertrophic factors $(35,64,69,82,83,90)$. Voluntary strength increases due to not only the quantity and quality of muscle mass but also to the extent that the muscle mass is able to activate (83). In general, neural factors are believed to account for most of the increases in strength in the early stage of a resistance training program, whereas hypertrophic factors gradually become prevalent after approximately several weeks of training $(35,57,60,61,69,70,83)$. Hence, initial improvements in strength and muscular performance reported following short-term resistance training are generally attributed to neural adaptation instead of muscle fiber hypertrophy $(3,69)$. For example, Akima et al. (1999) reported increases in PT after two weeks of resistance training but no changes in muscle cross-sectional area (CSA) or fiber area suggesting strength increases occurred without muscle hypertrophy (3). Nevertheless, Akima et al. (1999) suggested future studies should investigate the mechanisms underlying strength gains obtained with short-term resistance training (3).

A physiological question often asked in exercise science human research is how much of a muscle can be activated. Surface electromyography (EMG) records action potentials generated during muscle activation and can be used as a noninvasive measure of muscular activation $(6,38)$. Thus, most studies have used EMG techniques to examine neural factors and their effects during or after a resistance training program (3). In addition, muscle activation can be examined by 
comparing the amount of voluntary excitation relative to the maximal excitation of the motor neuron pool (88). This is performed by comparing the increment in muscle force produced when an electrical stimulus is delivered to a muscle during a voluntary contraction, with the force increment produced when this same stimulus is delivered to the resting muscle in a procedure known as twitch interpolation (TI) $(4,67,88)$. Hence, the TI technique has been used in research assessing muscle force production $(4,8,95)$ and neural adaptations to resistance training $(34,61,71$, 86).

The principle of training called reversibility, or detraining, occurs when a complete cessation or substantial reduction in training causes a partial or complete reversal of the adaptations induced by training $(72,73)$. Detraining occurs after an individual stops a training program $(5,43,46,56,72,73,75,93)$. Most of the increase in strength found with resistance training is lost after several weeks of training $(19,43,46,56,75,93)$. However, Colliander and Tesch (1992) revealed that a resistance training program that incorporates combined concentric and eccentric leg extension repetitions retained more of the recent strength gains than the concentric-only repetition (19). Because isokinetic muscle actions are primarily concentric in nature, it is unknown whether dynamic constant external resistance (DCER) training, which uses coupled concentric and eccentric muscle actions, and isokinetic training would affect detraining differently. In addition, Farthing (2003) found eccentric muscle action training elicited greater strength gains than concentric training (39). 


\section{Study Purpose}

Traditionally, isokinetic muscle actions have been used on rehabilitation and testing scenarios. Several studies have examined the effects of isokinetic training on strength and/or muscle CSA and isokinetic training allows development of maximum tension throughout the range of motion (3). However, DCER training would offer a more accessible, convenient, cost-effective, and practical method of training, in addition to perhaps providing a greater stimulus to elicit increases in strength (62). Therefore, the purpose of this study was to examine and compare the effects of three days of DCER and isokinetic training and subsequent detraining on thigh muscle CSA and thigh lean mass, isokinetic peak torque (PT), DCER strength, isometric force, surface electromyography (EMG), and surface mechanomyography (MMG) of the leg extensors during maximal leg extension muscle actions, percent voluntary activation $(\% \mathrm{VA})$, and the electromechanical delay (EMD).

\section{Research Questions}

1) Is short-term resistance training capable of increasing strength, improving voluntary activation of skeletal muscle, and surface EMG of the leg extensors?

a. Does short-term resistance training using isokinetic or DCER muscle actions affect strength similarly?

b. Are increases in strength specific to training modalities? 
2) Can any possible improvements be attributed to changes in muscle activation or thigh muscle CSA and volume?

a. Does short-term resistance training using isokinetic or DCER muscle actions affect muscle CSA similarly?

3) Do any possible improvements in muscle performance last a period of up to two weeks?

a. Does short-term resistance training using isokinetic or DCER muscle actions affect detraining similarly?

4) Can any possible improvements in muscle performance affect the contralateral limb?

a. Does short-term resistance training using isokinetic or DCER muscle actions affect the contra-lateral limb similarly?

\section{Hypotheses}

1) It is hypothesized both modes of training will increase strength. However, greater magnitude of changes will be observed on tests that are similar to training modality.

2) It is hypothesized DCER training will increase muscle CSA to a greater extent than isokinetic training due to the eccentric loading present in DCER whereas isokinetic training will incorporate concentric—only muscle actions. 
3) It is hypothesized any strength increases will still be seen one week, but not two, after training ends. The DCER may cause strength to remain more elevated than the isokinetic training.

\section{Operational Definitions}

Electromechanical Delay (EMD) - a time delay existing from the onset of muscle activation to the onset of force development.

Maximal Voluntary Contractions $(M V C)$ - the maximum force one can voluntarily exert by a muscle or group of muscles.

Voluntary Activation - the percentage of muscle mass that can be recruited voluntarily, without means of tissue stimulation.

Surface Electromyography (EMG) - the recording of neural activation of the contracting muscle fibers from the surface of the skin.

Mechanomyography - the recording of lateral oscillations of muscle fibers occurring during a muscle contraction.

Twitch Interpolation - Involves delivering an electrical stimulus to a nerve while the participant attempts to produce a maximum voluntary contraction. 
Expressing the interpolated twitch as a percentage of the twitch evoked in the resting muscle can be used to quantify the amount of muscular activation.

Muscle Strength - the amount of force produced by a muscle or group of muscles.

Maximum Repetition - Greatest amount of weight moved through a complete repetition during a given exercise.

\section{Abbreviations}

$\% \mathrm{VA}-$ percent voluntary activation

$\mathrm{BF}$ - biceps femoris

CONT - control

DCER - dynamic constant external resistance

EMD - electrical mechanical delay

EMG - electromyography

ISOK - isokinetic 


\section{MMG - mechanomyography}

MCSA - muscle cross-sectional area

$\mathrm{MVC}$ - maximal voluntary contraction

$\mathrm{RF}$ - rectus femoris

$\mathrm{RM}$ - repetition maximum

$\mathrm{RPE}$ - rating of perceived exertion

TI - twitch interpolation

TMCSA - thigh muscle cross-sectional area

VL - vastus lateralis

\section{Delimitations}

1) The inclusion of apparently healthy but minimally-active males who are naïve to the intent of the study into the designated groups. 
2) Participants with a history of chronic resistance training ( $>1$ day/week) in the previous 12 months prior to the study were excluded.

3) All individuals with any degenerative neuromuscular or joint disorders, or sustained injury in the previous six months were also excluded from the study.

\section{Assumptions}

Theoretical Assumptions

1) All participants will understand the testing protocol.

2) The information provided by the participants in the health history questionnaires will be honest and accurate.

3) All equipment will be calibrated and accurate for all testing assessments.

4) The twitch interpolation technique is a valid method of determining voluntary skeletal muscle activation.

5) Maximal effort will be given by the participants during each training session and testing trial.

6) All equipment will function properly for all training and testing sessions.

\section{Statistical Assumptions}

1) The population from which the samples are drawn is normally distributed.

2) The sample is randomly selected and the group assigned is done in random fashion. 
3) The data meets the assumption of sphericity (circularity). Sphericity requires that the repeated measures data demonstrate both homogeneity of variance and homogeneity of covariance.

\section{Limitations}

1) Subject selection will be based on volunteer participation and, therefore, will not be a truly random sample.

2) Medical information will be obtained through self-report.

3) Muscular assessment will be limited to the quadriceps and may not be generalized to other muscle groups.

4) As subject population will be volunteers, subjects participating in the study may be interested in physical performance, and thus, not representative of a normal population. 


\section{CHAPTER 2:}

\section{REVIEW OF LITERATURE}

The neuromuscular system undergoes numerous adaptations following a resistance training program $(3,35,64,69,70,82,90)$. However, the specific mechanisms of such adaptations in short-term training are not fully understood (17). Research suggests early adaptations to resistance training programs are related to improvements in neuromuscular efficiency, which is perhaps an increased capacity to activate skeletal muscle voluntarily $(3,17,25,61,80)$. Thus, acute strength gains in untrained subjects following a short-term resistance training program appear to originate from neural adaptations (11).

\section{Short-term Resistance Training}

Evidence has shown that improvements in muscle performance can be observed in a shorter period than what is typically used in longer traditional training programs $(3,25,69)$. For example, Prevost et al. (1999) investigated velocity-specific short-term training for two days (80). Participants performed 3 sets of 10 repetitions of leg extensions at the velocities of 30 and $270^{\circ} \cdot \mathrm{s}^{-1}$ for two training sessions and were tested at the velocities of 30,150 , and $270^{\circ} \cdot \mathrm{s}^{-1}(80)$.

Investigators found $22.1 \%$ increases in $\mathrm{PT}$ at $270^{\circ} \cdot \mathrm{s}^{-1}$ after training at $270^{\circ} \cdot \mathrm{s}^{-1}$, but 
no changes at the testing velocities of 30 and $150^{\circ} \cdot \mathrm{s}^{-1}(80)$. No significant changes in PT were observed for training at 30 and $150^{\circ} \cdot \mathrm{s}^{-1}(80)$. Because improvements were only seen in one velocity, and muscle hypertrophy would most likely yield strength increases at the other velocities, investigators suggested that neural adaptations play a major role in strength improvements which are specific to a training velocity (80). Interestingly, it was mentioned that increases in PT generated by the two days of training were of a similar magnitude to the increases reported after several weeks of training by other investigators (80).

Brown and Whitehurst (2003) investigated the effects of short-term resistance training sessions on rate of velocity development (RVD) and PT (11). Participants were assigned to a control, slow, or fast group (11). The intervention groups performed isokinetic training at a slow or fast velocity for two days consisting of three sets of eight repetitions (11). Investigators reported no PT changes from pre- to post-testing at either velocity (11). However, significant velocity-specific changes were observed for RVD (limb acceleration) such that the slow velocity group experienced decreases in RVD at the slow velocity whereas the fast velocity group exhibited decreases in RVD at the fast velocity (11). Improvements in RVD were attributed to neural adaptations and occur similarly in men and women (11). In addition, these results indicated that limb acceleration can be improved independent of PT increases (11).

Coburn et al. (2006) investigated short-term resistance training effects after three sessions of velocity specific training on PT and EMG signal (17). Subjects were randomly assigned to a slow-velocity, fast-velocity, or a control group and 
performed 4 sets of 10 repetitions of maximal, concentric, isokinetic leg extensions at 30 or $270^{\circ} \cdot \mathrm{s}^{-1}$. PT increased for both training groups. However, the slower velocity training group increased PT at both velocities whereas PT increased only at the faster velocity for the faster velocity training group. No changes in PT were observed for the control group and no changes in EMG amplitude were reported for any of the groups at any of the velocities. The authors concluded 3 sessions of slow or fast velocity isokinetic resistance training were sufficient to increase PT and the lack of EMG amplitude changes suggested increases in leg extension PT were not caused by increases in muscle activation (17).

Cramer et al. (2007) examined the effects of eight days of creatine supplementation and three days of isokinetic resistance on muscle PT, power output, and neuromuscular function (25). Training involved three sets of ten repetitions of isokinetic leg extension muscle actions at $150^{\circ} \cdot \mathrm{s}^{-1}$. The results of this study indicated $6 \%$ and $13 \%$ increases in peak torque in the placebo and creatine group, respectively. No changes in EMG amplitude, but significant increases in EMG median frequency, suggest training-induced increases in motor unit firing rate, instead of motor unit recruitment, were responsible for the improvements in muscle performance (25). Nevertheless, the authors explain that factors such as a decrease in reciprocal coactivation of the hamstrings, for example, could not be discounted (25). The authors concluded that three days of isokinetic resistance training were sufficient to induce significant improvements in strength and acceleration (25). 
Beck et al. (2007) investigated the effects of short-term resistance training on isometric and isokinetic PT and muscle activation (7). Training involved two days of short-term isokinetic resistance training of the dominant forearm flexors and extensors. Six sets of ten repetitions of concentric isokinetic muscle actions at $180^{\circ} \cdot \mathrm{s}^{-1}$ were performed. Subjects were tested for isometric PT and PT at the three velocities of 60,180 , and $300^{\circ} \cdot \mathrm{s}^{-1}$ and for EMG amplitude of the agonist and antagonist muscles. The authors reported no significant changes in forearm flexion and extension PT or EMG amplitude for the agonist and antagonist muscles. It was also suggested that responses to training might be influenced by number of training sessions, training volume, and muscle(s) being tested (7).

Christie and Kamen (2010) examined the effects of short-term training adaptations in young and older participants who were randomly assigned to a control or training group (16). Training involved six training sessions of dorsiflexor exercises and testing was conducted pre- and post-training assessments two weeks apart. The dorsiflexor exercise protocol consisted of three sets of ten 5-second maximal voluntary contractions (MVC), three times per week for a two-week period. Training subjects had a $17.8 \%$ increase in MVC from pre- to post-training. Young and older participants in the training group demonstrated a 17.4 and 19.8\% increase in MVC force, respectively. In addition, central activation as calculated by the ratio between maximal force prior to and following stimulation was approximately .99 in both pre- and post-training assessments for all subjects indicating all participants were able to fully activate their muscles voluntarily. 
Thus, the authors suggested observed differences in maximal voluntary force due to training were not due to an inability to activate the muscle fully (16).

\section{Physical Adaptations from Training}

Moritani and deVries (1979) examined the relative contributions of both neural and hypertrophic factors in muscle strength gains after 8 weeks of resistance training (69). The participants' training lasted 8 weeks and consisted of 10 repetitions twice a day three times per week (69). Maximal strength tests were conducted every two weeks and training load was adjusted to maintain a load equivalent to $2 / 3$ of the maximum load for the forearm flexors. All participants had increased their strength throughout the study and EMG changes were shown to be primarily responsible during the early stages of training while hypertrophic responses gradually increased its contribution over time (69). It was reported that that increases in muscle activation accounted for up to $90 \%$ of strength gains made after only six training sessions (69). Interestingly, a significant increase in strength of the subjects' contralateral untrained forearm flexors was also observed, which was also attributed to neural factors (69).

Moritani and deVries (1980) examined neural and hypertrophic factors in five young and five older men during eight weeks of resistance training (70). Participants trained the dominant forearm flexors three times per week for eight weeks while the contralateral non-dominant forearm of each subjected served as a control. The young and older men displayed similar significant increases in 
strength with neural factors being the primary contributing factor for the older men whereas neural factors contributed to strength gains in the initial stage and hypertrophic factors after 4 weeks of training for the younger men. The authors reported that neural factors based on EMG analysis contributed approximately $90 \%$ to increases in strength after two weeks of resistance training (70).

Akima et al. (1999) investigated the effects of two weeks of resistance training on isometric and isokinetic PT, muscle CSA, muscle fiber area and fiber types, and contractile activity (3). The investigators reported significant increases in PT at $60,90,120,180$, and $240^{\circ} \cdot \mathrm{s}^{-1}$ after training at $120^{\circ} \cdot \mathrm{s}^{-1}$ for 9 sessions (two weeks) of isokinetic resistance training (3). However, the authors observed no changes in muscle CSA but found significant increases in muscle strength and contractile activity. The authors suggested that the strength increases observed were due to greater muscle activation as opposed to muscle hypertrophy (3). It was concluded that after short-term resistance training, gains in muscle strength occur because of an increase in muscle contractile activity instead of morphological changes (3). In addition, other studies have also shown strength gains with no increases in muscle $\operatorname{CSA}(57,60)$.

Changes in muscle CSA have typically not been shown with short-term resistance training $(3,57,60,70)$, but structural changes can occur in the early phase of training (90). Staron et al. (1994) examined the effects of 8 weeks of resistance training on skeletal muscle adaptations in men and women (90). Participants took part in lower extremity resistance training twice a week, had their hormonal levels analyzed, performed dynamic strength tests biweekly, and had 
muscle biopsies that were extracted at the start and every two weeks (90).

Investigators reported an increase in absolute and relative strength after 4 weeks of training for both genders (90). In addition, the resistance training program caused decreases in the percentage of type IIb fibers after two weeks of training in women and 4 weeks of training in men (90). The investigators suggested that fiber type conversion from type IIb to type IIa and other skeletal muscle adaptations might have contributed to strength gains observed during the early phase of training (90).

Although hypertrophic factors are not believed to be the main sources of strength gains in the initial phase of a resistance training program $(3,35,57,60$, 70), increases in muscle CSA might still occur. For instance, DeFreitas et al. (2010) investigated the effects of eight weeks of resistance training and compared three methods for assessing muscle CSA (29). Subjects trained three days per week in a program designed to elicit hypertrophy for the leg extensor muscles. Participants were tested for muscle CSA twice before training initiated and were re-tested every two weeks throughout the course of the study. All three methods of assessment revealed a significant increase in muscle CSA over time. In addition, significant increases in muscle CSA were observed after only two weeks of training (six visits) with all three methods of assessment. The authors reported that detectable increases in muscle CSA can be observed after only weeks of training and that field methods can be used to detect these changes.

Because of this dissociation between increases in strength and changes in muscle size, it can be concluded that resistance training induces some form of neural adaptation (35). These studies $(3,11,25,69,80)$ have collectively shown 
that rapid neuromuscular adaptations may occur in response to short-term resistance training. Hence, neural adaptations, and not muscle hypertrophy, have been implicated as the main basis for improvements in muscle performance after short-term resistance training programs $(3,11,25,61,69,80)$. Thus, acute strength gains in untrained subjects following a short-term resistance training program appear to be neural in origin (11).

\section{Electromyography}

Increases in muscular strength following a resistance training program can be attributed to neural and hypertrophic factors $(35,64,69,82,83,90)$. Neural factors include muscle recruitment and discharge frequency modulation (19). Hence, voluntary strength increases due to not only the quantity and quality of muscle mass but also to the extent that the muscle mass is able to activate (83). In addition to an increase in muscle activation of agonist muscles, adaptations may occur in synergists and antagonists muscles (83). Neural adaptations include an increased activation of agonist and/or synergistic muscles responsible for a given muscle action, improved coordination, motor unit synchronization, and reduced coactivation of antagonistic muscles $(35,69)$. Increases in muscle fiber size (muscle CSA) and muscle fiber length are considered as the hypertrophic factor $(19,69)$. In addition, research evidence suggest the quantity and quality of the connective tissue are also affected by resistance training and, hence, affect tension development (35). These adaptations in the connective tissue may improve force transmittal from the 
sarcomere to the skeletal system and may also explain the increase in strength induced by training such that less force is dissipated by the surrounding tissue (35).

Surface EMG has been used as a noninvasive assessment to quantify neuromuscular activation $(7,17,24,32,36,70,83,91)$. The EMG amplitude has been suggested to provide a global measurement of muscle activation $(6,38)$. This EMG signal is generated by a summation of the action potentials from the active motor units underneath the recording area of the electrodes (38). Surface EMG is used to record these electrical muscle action potentials passing through the electrode recording areas during skeletal muscle action (25). Most studies have used EMG techniques to examine neural factors and their effects during or after a resistance training program $(3,83)$. Hence, the use of surface EMG may provide information on the neuromuscular adaptations that may occur following a shortterm resistance training program (25). The advantage of this method of assessment is that it provides a non-invasive global estimate of muscle activation.

Nevertheless, Cramer et al. (2007) and Coburn et al. (2006) examined the effects of three sessions of isokinetic training and reported no effects of short-term resistance training on EMG amplitude (17, 25). Thus, Coburn et al. (2006) suggested increases in PT without accompanying increases in EMG can be possible because of a decrease in the antagonist's muscle coactivation induced by the training program and/or an increased ability in coordinating stabilizing/synergistic muscles (17). Conversely, Knight and Kamen (2001) compared a 6-week resistance training program in young vs. older adults and found significant increases in maximal force 
that were accompanied by increases in motor unit discharge as early as in one week (61). A decreased coactivation could theoretically increase force production (94).

A procedure known as TI allows investigators to examine the muscular and neural adaptations after resistance training $(34,88,89,94)$. The procedure can be performed by comparing the increment in muscle force produced when an electrical stimulus is delivered to a muscle during a voluntary contraction, with the force increment produced when this same stimulus is delivered to the muscle at rest $(4$, $67,88)$ and is used to examine motor unit excitation. When this supramaximal stimulus is applied to a nerve of an active muscle during a voluntary contraction, motor units not already recruited generate a twitch in response to the stimulus $(9$, 47). As neural drive to the muscle increases, fewer motor units would be available for recruitment and the superimposed twitch consequently becomes lower and is eventually undetectable if the muscle can be fully activated (88). Thus, if the electrical stimulus does not induce an additional torque, the muscle can be considered fully activated, whereas voluntary activation is considered submaximal when stimulation causes an increase in torque (35). For this reason, the higher the increase in force made by the interpolated twitch during a contraction, the lower the extent of voluntary drive or the higher the failure of voluntary drive (4). The extent of voluntary activation is quantified by the ratio of the superimposed torque during the MVC to the evoked torque measured at rest and is expressed as a percentage [(1 $-($ superimposed torque $\div$ control torque $) \times 100]$ (4). Furthermore, the TI technique allows for the quantification of the percentage of voluntary activation of a specific muscle or muscle groups $(4,67,88)$. 
If increased muscle activation is an adaptation of training, it is implied that, because of insufficient motivation or some other form of inhibition preventing full activation, untrained individuals cannot activate the motor units in primary muscles during an MVC (83). Ekblom (2010) suggested muscle activation is not optimally controlled by the central nervous system and thus, an individual's ability to voluntarily fully activate a muscle group is often limited (34). Hence, it has been suggested maximal voluntary activation increases following resistance training, as determined by the TI technique $(34,88)$. Possible causes for this increase in voluntary activation include an increase in motor unit firing rate $(42,59)$, increased activity measured by EMG $(45,51,63,69,75,77)$, neuromuscular cross-education $(13,54,55,69,79,99)$, and enhanced reflex potential $(1,68,84)$. However, several studies have reported no change in percent of voluntary activation as assessed by the TI technique following resistance training $(10,12,14,26,41,48,49,58,85$, 94). Lack of changes were hypothesized to be attributed to voluntary muscle activation being complete (maximally activated) prior to training, training and testing were conducted using different muscle actions (i.e. dynamic and isometric), and some muscles display only small deficit in voluntary activation leaving only a small window of improvement (88).

While untrained subjects have been shown to be capable of fully activating their muscles voluntarily before a training program (16), another study revealed increases in voluntary activation as a result of a resistance training program (34). Ekblom (2010) examined the effects and mechanisms of resistance training of plantar flexor muscles on voluntary activation (34). Participants were assigned to a 
resistance training or control group where training consisted of 15 sessions of unilateral plantar flexor exercises. Strength was measured and voluntary activation calculated using TI during concentric and eccentric plantar flexions before and after the 5-week training period. Investigators reported similar improvements in plantar flexor concentric and eccentric strength and voluntary activation during concentric and eccentric maximal voluntary muscle actions whereas no changes were observed for the control group. In addition, a significant association between increases in strength and increases in voluntary activation was reported for the training group. The authors concluded that the increase in voluntary strength was attributed in part to an increase in voluntary activation induced by training (34).

\section{Mechanomyography}

Another method used to noninvasively examine neural adaptations following short-term resistance training is MMG (25). Surface MMG quantifies the mechanical lateral oscillations or vibrations of muscle fiber contraction (25). It has been suggested that the MMG signal can reflect motor unit recruitment $(2,76)$. To date only one study has investigated the effects of short-term training on MMG (25). For instance, Cramer et al. (2007) examined the effects of three days of isokinetic short-term resistance training on strength, power output, and neuromuscular function (25). Although the authors reported increases in PT, no changes were found in MMG amplitude (25). In addition, the authors did not 
dismiss other neuromuscular adaptations such as a decrease in reciprocal coactivation of the hamstrings (25).

\section{Electromechanical Delay}

Enoka (1988) has suggested adaptations in the connective tissue may improve force transmittal from the sarcomere to the skeletal system (35). Consequently, this may also explain the increases in strength induced by resistance training such that less force is dissipated by the surrounding tissue (35). One neuromuscular assessment that is used to examine force transmittal from muscle to bone and has been associated with musculotendinous stiffness changes is EMD (23, 65). Häkkinen et al. (1983) found no changes in EMD calculated under reflex contraction before and after 16 weeks of resistance training (44). In contrast, Kubo et al. (2001), reported decreases in EMD during isometric MVC's after 12 weeks of isometric training (65). The authors concluded that 12 weeks of isometric training led to an increase in stiffness, consequently decreasing EMD values (65). This increase in stiffness and corresponding decrease in EMD were suggested to be an advantage for increasing the rate of force development.

\section{Contralateral Strength Gains}

If training with the intent of muscle strength gain is performed on one limb, voluntary strength can be increased on the contralateral side in an effect termed 
contralateral strength training effect (15). The concept of strength occurring via increases cross-transfer has been known experimentally since 1894 (18). This concept that unilateral resistance training of a limb can increase the strength of the contralateral limb is also known as cross-education $(18,74)$. A meta-analysis concluded that overall, unilateral resistance training led to -2.7 to $21.6 \%$ changes in the initial strength of the untrained limb, with a mean improvement of $7.8 \%$, which was $35.1 \%$ of the effect on the trained limb (74). To our knowledge, no studies have investigated the effects of short-term resistance training on the strength of the contralateral limb. Nevertheless, the mechanisms for contralateral strength gains are unclear and there is no consensus on proposed mechanisms (74). Central neural adaptations (i.e. excitation of the cortex), increased motoneuron output, and improved postural stabilization have been hypothesized to be the causes for eliciting contralateral strength gains $(15,74,81)$.

\section{Detraining}

The principle of training called reversibility indicates that a complete cessation or substantial reduction in training causes a partial or complete reversal of the adaptations initially induced by training leading to detraining $(72,73)$. Detraining is defined as the partial or complete loss of anatomical, physiological, and performance adaptations induced by training (72) and occurs after an individual withdraws from a training program $(5,37,43,46,53,56,72,75,93)$. Physiological changes in the muscle due to detraining include a decrease in 
capillary density, arterial-venous oxygen difference, mitochondrial ATP production, muscle fiber CSA, and force production $(72,73)$. Most of any increases in strength found with resistance training are lost after several weeks of detraining $(19,37,43,46,56,75,93)$. Detraining can be categorized as short- or long-term detraining (72). Short-term detraining is described as less than four weeks of insufficient training stimulus (72). One study by Hortobagyi et al. (1993) found that two weeks of detraining of resistance-trained athletes did not cause a significant decrease in maximal bench press, squat, isometric, or concentric isokinetic strength (53). However, eccentric muscle strength and surface EMG activity decreased significantly (53). Longer periods of detraining may lead to greater decreases in strength (73). By comparison, strength gains that have been recently acquired may be lost at different rates with recently acquired strength being lost at a greater rate than strength-trained athletes $(72,87)$. Finally, Andersen et al. (2005) reported quadriceps muscle CSA, concentric PT, and EMG during concentric muscle actions decreased after three months of detraining, but with no decreases in eccentric PT (5).

Shaver (1975) investigated the effects of recently-acquired strength on 1,4, 6 , and 8 weeks of detraining on the trained and untrained limb (87). Subjects took part in three sessions of high-intensity, low-repetition, unilateral DCER training for six weeks. Following the six-week training period, subjects in the training group were then randomly assigned groups that stopped training for $1,4,6$, and 8 weeks. The author reported strength increases for all training groups in both trained and untrained arms. No significant changes were observed for the control group. All 
training groups retained some of their strength in both arms following detraining. However, it was reported that the groups taking part in 4,6 , and 8 weeks of detraining resulted in greater strength loss in both arms. It was concluded that traditional DCER resistance training was capable of increasing isometric elbowflexion strength by 12.6 and $8.9 \%$ in both the trained and untrained limb, respectively. In addition, recently-acquired strength gains were maintained with 1, but not 4,6 , and 8 weeks of detraining. Nevertheless, all strength scores were still higher than those of pre-tests (87).

Colliander and Tesch (1992) investigated and compared the effects of 12 weeks of resistance training and 12 weeks of detraining using concentric-only and combined concentric and eccentric muscle actions of the leg extensors (19). Interestingly, the group performing coupled concentric and eccentric muscle actions had a greater overall increase in PT after training and detraining than the concentric-only group (19). Colliander and Tesch (1992) suggested strength decreases observed during detraining were not likely due to atrophy, but perhaps a reduction in neural drive or motor unit activation and hypothesized eccentric muscle actions is capable of inducing greater motor unit activation than concentric muscle actions (19). Previous long-term studies have reported the rate of strength loss during detraining is greater in muscle actions that are different from the modality of muscle actions performed during training $(46,75)$. Because isokinetic muscle actions are primarily concentric in nature, it is unknown whether DCER training, which uses combined concentric and eccentric muscle actions, and isokinetic training would affect detraining differently. 


\section{CHAPTER 3:}

\section{METHODS}

\section{Subjects}

Participants were recruited via flyers posted on the campus of the University of Oklahoma and by word of mouth. Thirty-one healthy men between the ages of 18 and 35 who were naïve to the intent of the experiment volunteered to participate in this study (Table 1). Prior to any testing, all subjects read and signed an informed consent form and completed a health status questionnaire. Any individuals with degenerative neuromuscular or joint disorders or injuries distal to the waist within six months prior to screening were also excluded from the study. Subjects were untrained in resistance training within six months prior to the start of the study. Those who reported engaging in one or more lower-body resistance training exercises for six months prior to the start of the study were excluded. Subjects were asked to maintain their daily activities, but refrain from any exercise and/or nutritional supplements throughout the course of the study. In addition, individuals who had been taking nutritional supplements three months prior to screening were not allowed to volunteer. This study was approved by The University of Oklahoma Institutional Review Board for the protection of human subjects. 


\section{Research Design}

A mixed factorial design with repeated measures on the factor "time" (prevs. post-training) by "group" (DCER, ISOK, and CONT) was used to examine the effects of three days of DCER versus ISOK training with the leg extensors (Figure 1). Participants were randomly assigned to a DCER training group, ISOK training group, or CONT group. Participants visited the laboratory on 8 occasions separated by $48-168$ hours. The first visit was a familiarization session, the second visit was a pre-training assessment, the subsequent three visits were for training, and the last three visits were the post-training assessments (Figure 1). Pre-training assessments were performed 48 hours prior to the start of training. The dependent variables in this study were (a) BM; (b) BF\%; (c) TF\%; (d) TLM; (e) TMCSA; (f) isokinetic PT; (g) DCER strength; (h) isometric force; (i) EMG; (j) MMG; (k) percent of voluntary muscle activation (\%VA) at $30,50,70$, and $100 \%$ of maximum MVC; (1) EMD; and (m) RPE. After the three training sessions, post-training assessments were performed in an identical manner to the pre-training assessments. In order to examine the time course of the effects of the different training modes, post-training assessments were performed 48 hours, 1 week, and 2 weeks after the final training session. All pre- and post-training assessments were conducted at approximately the same time of day. 


\section{Familiarization Trial}

During the familiarization visit, subjects underwent screening and upon approval, they read and signed an Informed Consent Form and Pre-exercise Testing Health and Exercise Status Questionnaire (Appendix C and D, respectively). After providing consent, subjects were familiarized with the ISOK and DCER leg extension machines and exercises to allow the inexperienced participants to become better accustomed to the proper exercise technique execution. The familiarization visit included anthropometric assessments (BM, HT, and body composition) followed by the maximal isometric force, ISOK PT, and DCER strength tests (in this order). These assessments and tests were performed in an identical manner during the pre-and post-training assessments. Data obtained during the familiarization trial and pre-training assessments were used to determined test-retest reliability.

\section{Dual-energy X-ray Absorptiometry}

Dual-energy X-ray absorptiometry (DEXA) (Lunar Prodigy Advance 300532, General Electric Healthcare, Madison, WI) was used to assess BF\%, TF\%, and TLM. Each day prior to testing, a quality assurance phantom was scanned to ensure calibration. Before each assessment, the subjects' HT, BM, sex, and race were entered into the computer program DEXA software program (enCORE ${ }^{\mathrm{TM}}$ 2006, version 10.50.086). The subjects were positioned supine on the DEXA table with hands pronated and flat on the table. Total body mode was selected for each 
scan, and scanning thickness was determined by the DEXA software. Thigh lean mass was determined using regions of interest around the right thigh. Region of interest markers were placed by the primary investigator (P.B.C.) using the DEXA software crossing diagonally the femoral neck and horizontally through the inferior border of the femur condyles (Figure 2).

\section{Muscle Cross-Sectional Area}

Thigh muscle CSA (TMCSA) of the thigh was estimated by measuring circumference and correcting for subcutaneous fat $(69,70)$. In short, the circumference of the thigh was measured, the radius calculated, and TMCSA was estimated by subtracting the mean of four skinfolds (69). Thigh circumference was measured at the midpoint between the inguinal crease and the proximal border of the patella (98). Circumference was measured to the nearest millimeter using a tension-gauged measuring tape (Gullick II; Country Technology, Inc., Gays Mills, WI). Skinfold thickness was measured using four skinfolds from the anterior, lateral, posterior, and medial region of the thigh, and measured to the nearest millimeter using Lange calipers (Santa Cruz, CA), midway between the proximal border of the patella and the inguinal crease (98). The skinfold values were averaged after three measurements were taken at each site. Muscle CSA was estimated using the equation by Moritani and deVries $(69,70)$ :

$$
\text { CSA }=\pi\left[\frac{\text { Circumference }}{2 \pi}-\frac{\sum_{i=1}^{4} s k f_{i}}{4}\right]^{2}
$$


where Circumference is defined as the circumference of the thigh, and skf is defined as the thigh skinfold thickness of each of the four sites.

\section{Isokinetic Assessments}

Maximal concentric ISOK PT of the left and right leg extensors was measured using a calibrated Biodex System 3 ISOK dynamometer (Biodex Medical Systems, Inc., Shirley, NY) at the randomly-ordered velocities of 90 and $180^{\circ} \cdot \mathrm{s}^{-1}$. Subjects were in a seated position with restraining straps over the pelvis, trunk, thigh, and ankle in accordance with the Biodex User's Guide (Biodex Pro Manual, Applications/Operations. Biodex Medical Systems, Inc., Shirley, NY. 1998). The input axis of the dynamometer was aligned with the axis of rotation of the knee (Figure 3). Prior to the ISOK assessment, each participant's range of motion was individually determined and limb weight measured for subsequent gravity correction. Three submaximal warm-up repetitions of increasing intensities (i.e., approximately 25,50 , and $75 \%$ of the subject's perceived maximum) preceded three maximal muscle actions at each velocity. During the tests, loud verbal encouragement was provided by the investigator such that each subject was instructed to "kick out" as hard as possible throughout the entire range of motion. A 1-min rest was allowed between velocities (78). 


\section{Dynamic Constant External Resistance Assessments}

The maximal strength of both leg extensors were assessed using a DCER Nautilus leg extension machine (Nautilus, Inc. Vancouver, WA) (Figure 4). The input axis of the machine was aligned with the axis of rotation of the knee. The distal anterior portion of the leg superior to the ankle was used as the load bearing point. Three submaximal warm-up sets of increasing tester-selected intensities (i.e., $6-8,3-5$, and 1-2 repetitions) preceded the maximal strength attempt. When one attempt was successful, the load was increased by $2-5 \mathrm{~kg}$ until a failed repetition occurred. A failed repetition was defined as the inability to complete the full range of motion with the assigned load. During the tests, loud verbal encouragement was provided by the investigator. Each subject was instructed to provide maximal effort throughout the entire range of motion. The greatest load moved through a complete leg extension range of motion was considered the one repetition maximum 1-RM. A 1-min rest was allowed between each successive attempt $(66,97)$.

\section{Electromyography}

Pre-amplified, bipolar surface EMG electrodes (EL254S, Biopac Systems Inc.; Santa Barbara, CA, gain = 350) with a fixed center-to-center inter-electrode distance of $20 \mathrm{~mm}$ were taped over the rectus femoris (RF), vastus lateralis (VL), and biceps femoris (BF) muscles of the right leg (Figure 5). For the RF, the electrodes were placed at $50 \%$ of the distance between the inguinal crease and the superior border of the patella. For the VL, the electrodes were placed at the anterior 
border of the iliotibial band along the muscle's longitudinal axis at $50 \%$ of the distance from the greater trochanter to the lateral epicondyle of the femur. Finally, the electrodes for the BF were placed at the midpoint of the distance between the ischial tuberosity and the lateral epicondyle of the tibia. A single pre-gelled, disposable electrode (Ag-Ag Cl, Quinton Quick Prep, Quinton Instruments Co., Bothell, WA) was placed on the spinous process of the $7^{\text {th }}$ cervical vertebrae to serve as a reference electrode. Prior to electrode placement, the skin was shaved to remove hair and the recording sites were carefully abraded with an abrasive pad and cleaned using isopropyl alcohol to reduce the inter-electrode impedance. All electrodes were placed in accordance with the recommendations of Hermens et al. (50). The EMG signals (recorded in microvolts) were differentially amplified with a bandwidth of 1 to $500 \mathrm{~Hz}$, input impedance of 2M (differential), common mode rejection ratio of $110 \mathrm{~dB}$, maximum input voltage of $10 \mathrm{~V}$, sampling rate of 1,000 (ISOK PT) and 10,000 (\%VA and EMD) Hz, and gain of 1,000 (EMG100C; Biopac Systems, Inc., Santa Barbara, CA). After the electrodes were removed, a permanent marker was used to mark the positions of the electrodes for replacement during subsequent post-training assessments.

\section{Mechanomyography}

The MMG signals were detected with active miniature accelerometers (EGAS-FS-10-/VO5, Intran Inc., Fairfield, NJ) that were pre-amplified with a gain of 200 , frequency response of $0-200 \mathrm{~Hz}$, sensitivity of $70 \mathrm{mV} / \mathrm{ms}^{-2}$, and range of \pm 
$98.1 \mathrm{~ms}^{-2}$. The accelerometers were placed over the RF and VL muscles, respectively, and fixed to the skin with double-sided foam tape (3M, ST. Paul, MN). MMG accelerometers were placed superior to the EMG electrodes (Figure 5). After the accelerometers were removed, a permanent marker was used to mark the positions of the electrodes for replacement during subsequent post-training assessments.

\section{Isometric Assessments}

Two isometric MVC's were recorder using a Biodex System 3 ISOK dynamometer (Biodex Medical Systems, Inc., Shirley, NY) configured for isometric mode and modified with an in-line load cell (Omegadyne LC402, Stamford, CT) (Figure 6). Each participant was seated in the dynamometer with restraining straps over the pelvis, trunk, thigh, and ankle in accordance with the Biodex User’s Guide (Biodex Pro Manual, Applications/Operations. Biodex Medical Systems, Inc., Shirley, NY. 1998). The input axis of the dynamometer was aligned with the axis of rotation of the knee and the leg was fixed at an angle of $90^{\circ}$ below the horizontal plane. During the tests, loud verbal encouragement was provided by the investigator such that each subject was instructed to "kick out" as hard as possible for approximately 4-6 seconds. A 1-min rest was allowed between each assessment. The highest force output between the two trials was selected as the representative MVC value. 
After the MVC trials, each subject performed submaximal isometric step muscle actions at 30,50 , and $70 \%$ of the peak MVC. The order of the submaximal isometric step muscle actions was randomly-ordered during each experimental trial. During the isometric step, participants were asked track their force production on a computer monitor placed in front of them that displayed in real-time, digitized force signals overlaid onto a programmed template. Horizontal lines were programmed as templates on the computer monitor that served as the target force lines. The isometric step muscle action templates and real-time force overlay were programmed and displayed using (LabView 8.5, National Instruments, Austin, TX). A 1-min rest was allowed between each isometric assessment.

\section{Twitch Interpolation}

The twitch interpolation technique was used to determine $\% \mathrm{VA}$ at 30,50 , 70 and $100 \%$ of MVC. Transcutaneous electrical stimuli were delivered to the femoral nerve using a high-voltage (maximal voltage $=400 \mathrm{~V}$ ), constant-current stimulator (Digitimer DS7AH, Herthfordshire, UK). A small bipolar electrode was pressed over the lateral portion of the femoral triangle. Single stimuli were administered to the femoral nerve at a low current (amperage $=20 \mathrm{~mA}$ ) to determine the optimal probe location by the investigator based on visually inspecting a computer monitor displaying the compound muscle action potential (M-wave) and Hoffmann reflex (H-reflex) of the RF muscle. Once the best location was determined and marked, the maximal M-wave was achieved with incremental 
(5 mA) amperage increases until a plateau in the peak-to-peak (p-p) M-wave was observed after three successive amperage increases. To ensure a supramaximal stimulus, $120 \%$ of the stimulus intensity (mA) that elicited the maximal M-wave was used during the evoked twitches and TI procedures. A single stimulus was defined as a 200- $\mu$ s duration square wave impulse, while a doublet consisted of two single stimuli delivered successively at $100 \mathrm{~Hz}$. Doublets were administered with the supramaximal stimulus intensity during the MVC trials to increase the signal-to-noise ratio and minimize the series elastic effects on force production (30). In accordance with the TI procedure, supramaximal stimuli were administered 3-5 seconds into the MVC plateau (superimposed twitch) and again 3-5 seconds after the MVC trial at rest (control twitch). The extent of voluntary activation was quantified by the following equation $(4,67)$ :

$$
\% V A=\left[1-\left(\frac{\text { Superimposed Twitch }}{\text { Control Twitch }}\right)\right] \times 100
$$

where the Superimposed Twitch is the force increase during the MVC at the time of stimulation and the Control Twitch is the response in the relaxed muscle.

\section{Electrical Mechanical Delay}

Prior to the maximal MVC procedures, five, single, 200- $\mu$ s duration, square-wave, supramaximal transcutaneous electrical stimuli (each separated by 5 seconds) were delivered to the femoral nerve at rest in order to examine the EMD. An average of the three most common twitches was used. The EMD was defined as 
the time (ms) elapsed between the onset of the M-wave and the onset of the twitch response recorded from the load cell mounted onto the dynamometer apparatus. After the electrical artifact was identified prior to the M-wave by an experienced investigator (P.B.C.), the onsets of the M-wave and twitch recordings were automatically determined off-line using custom-written software (LabView 8.5, National Instruments, Austin, TX) that provided interactive graphs viewing the force and EMG signals in $20 \mathrm{~ms}$ windows for an accurate visual representation. The thresholds for automatic M-wave and twitch detection were defined as the EMG and unfiltered force signals increasing to 3 standard deviation units above their respective baselines. This threshold was determined after extensive pilot testing and was adopted for all subjects' signals. In addition, after each automatic detection, the investigator (P.B.C.) visually inspected the location of the onsets for accuracy in separate graphing windows for the EMG and force signals. The automatic onset detection system accurately identified the onsets for all of the twitches evoked in this study.

\section{Signal Processing}

ISOK torque, EMG, and MMG signals were sampled at 1,000 Hz during ISOK PT assessments and at 10,000 Hz during MVC force, EMD, and \%VA assessments. Signals were recorded simultaneously with a Biopac data acquisition system (MP150WSW, Biopac Systems, Inc.; Santa Barbara, CA) during each assessment from the dynamometer interfaced with a laptop computer (Inspiron 
8200, Dell Inc., Round Rock, TX) using proprietary software (AcqKnowledge version 3.7, Biopac Systems, Inc., Santa Barbara, CA) and stored on a personal computer for off-line analysis. Torque, force, EMG, and MMG signals were processed off-line with custom-written software (LabView 8.5, National Instruments, Austin, TX). ISOK PT was calculated as the highest 0.25 -s average torque value for the repetition that yielded the highest PT value. Consequently, the same (concurrent) 0.25 -s epochs were selected for all EMG and MMG signals. Isometric MVC force $(\mathrm{N})$ was calculated as the highest average force value that occurred during a 0.05 -s epoch. The force value for the TI was calculated during a 0.25 -s epoch immediately prior to the stimulation for all submaximal and the two MVC (ITT MVC) trials. EMG and MMG signals were filtered with a bandpass (zero phase $4^{\text {th }}$ order Butterworth filter) of $10-500 \mathrm{~Hz}$ and $5-100 \mathrm{~Hz}$, respectively. The amplitudes of the EMG and MMG signals were quantified by calculating the root-mean-square (RMS) values for each signal epoch.

\section{Isokinetic and Dynamic Constant External Resistance Training Protocol}

After a rest period of 48 hours following the pre-training assessment, the training groups performed three ISOK or DCER training sessions separated by 48 hours. Participants in the training groups performed 4 sets of 10 repetitions of maximal muscle actions. For the ISOK training group, a velocity of $90^{\circ} \cdot \mathrm{s}^{-1}$ was used, whereas moderate speed was used for the DCER training group. Each training session began with ten warm-up repetitions at approximately $25 \%$ of the 
resistance used for the DCER training session and $25 \%$ of the individual's perceived maximal for the ISOK training session. Approximately $80 \%$ of the $1-\mathrm{RM}$ obtained during the DCER maximal strength assessment was used as the starting load for the DCER group. A 2-minute rest period was allowed between each training set. Training load for the DCER group was continually increased and adjusted as each participant was able to tolerate a given load with ease in order to assure that the subject reached failure at approximately the $10^{\text {th }}$ repetition. Participants of the ISOK training program were seated and strapped to the machine similarly to the manner used during the maximal ISOK. All participants taking part in either ISOK or DCER training interventions were supervised during all training sessions.

\section{Rating of Perceived Exertion}

Rating of perceived exertion (RPE) was used to compare effort between the DCER and ISOK training modes $(27,31,33,40,92)$. Prior to the start of the study, subjects received instructions on how to use the RPE scale to rate their perceived exertion. A Category-Ratio scale (CR-10) was used, where " 0 " is classified as rest (no effort) and "10" is classified as maximal effort (most stressful exercise ever performed) (Figure 7). The CR-10 has been slightly modified to reflect American English (e.g. easy and hard instead of light and strong, respectively) (40). Subjects were asked to provide a number on the scale to rate their overall effort immediately after each set was completed and after the entire training session. These RPE 
assessments were conducted during each session by showing the scale and asking subjects "How would you rate your effort?" and "How would you rate your entire workout?" immediately after each set of training and after each training session, respectively. Therefore, in this study, "set RPE" was defined as the RPE reported by the subject after each set, while "session RPE" was defined as the RPE reported each day after the training session was completed.

\section{Reliability}

Thirty-one men were measured 48 hours apart using the same pre- and posttraining assessment procedures (but with no training intervention) to determine test-retest reliability. One-way ANOVA was used to assess systematic variability, intra-class correlation coefficients were used to assess relative reliability, and standard errors of measurement were used to assess absolute reliability (96).

\section{Statistical Analyses}

Four one-way factorial ANOVAs were used to compare the means at baseline for age, BM, HT, BF\%, TF\%, TLM, and TMCSA among the DCER, ISOK, and CONT groups. Six two-way mixed factorial ANOVAs (time [pre- vs. post-training assessment 1 vs. post-training assessment 2 vs. post-training assessment 3] $\times$ group [ISOK vs. DCER vs. CONT]) were used to analyze the anthropometric, body composition, EMD and MVC data. A three-way mixed 
factorial ANOVA (time [training session 1 vs. training session 2 vs. training session 3] $\times$ group [ISOK vs. DCER] $\times$ set [1 vs. 2 vs. 3 vs. 4]) was used to analyze RPE assessed after each set during training. A two-way mixed factorial ANOVA was used to analyze training session RPE (time [training session 1 vs. training session 2 vs. training session 3] $\times$ group [ISOK vs. DCER]). One three-way mixed factorial ANOVA (time [pre- vs. post-training assessment 1 vs. post-training assessment 2 vs. post-training assessment 3] $\times$ group [ISOK vs. DCER vs. CONT]) $\times \operatorname{limb}$ [right vs. left]) was used to analyze 1-RM data. A four-way mixed factorial ANOVA (time [pre- vs. post-training assessment 1 vs. post-training assessment 2 vs. post-training assessment 3] $\times$ group $[$ ISOK vs. DCER vs. CONT] $\times$ velocity [90 vs. $\left.180^{\circ} \cdot \mathrm{s}^{-1}\right] \times \operatorname{limb}$ [right vs. left]) was used to analyze ISOK PT. A three-way mixed-factorial ANOVA (time [pre- vs. post-training assessment 1 vs. post-training assessment 2 vs. post-training assessment 3] $\times$ group [ISOK vs. DCER vs. CONT]) $\times$ intensity $[30 \%$ vs. $50 \%$ vs. $70 \%$ vs. $100 \%]$ ) was used to analyze the TI data. A four-way mixed factorial ANOVA (time [pre- vs. post-training assessment 1 vs. post-training assessment 2 vs. post-training assessment 3] $\times$ group [ISOK vs. DCER vs. CONT] $) \times$ muscle $[$ RF vs. VL $] \times$ velocity $\left[90\right.$ vs. $\left.\left.180^{\circ} \cdot \mathrm{s}^{-1}\right]\right)$ was used to analyze quadriceps EMG and MMG. A three-way mixed factorial ANOVA (time [pre- vs. post-training assessment 1 vs. post-training assessment 2 vs. post-training assessment 3] $\times$ group [ISOK vs. DCER vs. CONT]) $\times$ velocity [90 vs. $\left.\left.180^{\circ} \cdot \mathrm{s}^{-1}\right]\right)$ was used to analyze the BF EMG. When appropriate, follow-up analyses were performed using lower-order two- and one-way repeated measured ANOVAs, and paired sample $t$-tests. An alpha level of $p \leq 0.05$ will be considered statistically 
significant for all comparisons. Predictive Analytics SoftWare (PASW) version 18.0.0 (SPSS Inc., Chicago, IL) was used for all statistical analyses. 


\section{CHAPTER 4:}

\section{RESULTS}

\section{Anthropometric and Body Composition Characteristics;}

There were no significant differences among groups for anthropometric measurements (age, BM, HT, BF\%, TF\%, TLM, and TMCSA) at baseline ( $p>$ 0.05) (Table 1). Reliability results for $\mathrm{BF} \%, \mathrm{TF} \%$, TLM, TMCSA, MVC force, ISOK PT, TI, EMD, and DCER are presented in Table 2. Table 3 displays the means $( \pm \mathrm{SE})$ for all anthropometric data. There was no two-way interaction for time $\times$ group for $\mathrm{BM}, \mathrm{BF} \%, \mathrm{TF} \%$, TLM, or TMCSA $(p>0.05)$. However, there was a significant main effect for time for body mass $(p<0.05)$. Post-hoc pairwise comparisons for the marginal means (collapsed across groups) indicated a mean decrease of $0.6( \pm 2.3) \mathrm{kg}$ from pre- to post-training assessment one for all three groups $(p<0.05)$. There were no other significant anthropometric changes for BM, $\mathrm{BF} \%, \mathrm{TF} \%$, TLM, or TMCSA $(p>0.05)$.

\section{Isokinetic Assessments}

Table 4 contains the means $( \pm \mathrm{SE}$ ) for ISOK PT assessments for the right and left legs. There was no four-way interaction for time $\times$ group $\times$ velocity $\times \operatorname{limb}$, no three-way interactions for time $\times \operatorname{limb} \times$ velocity, time $\times$ group $\times$ velocity, time 
$\times$ group $\times \operatorname{limb}$, time $\times$ group $\times \operatorname{limb}$, or group $\times$ velocity $\times \operatorname{limb}$, and no two-way interactions for time $\times \operatorname{limb}$, group $\times$ time, or group $\times \operatorname{limb}(p>0.05)$. However, there were significant two-way interactions for time $\times$ velocity, limb $\times$ velocity, and group $\times$ velocity $(p<0.05)$. Figures 8 and 9 display the mean percent change $(\Delta \%)$ change for leg extension isokinetic PT for the right leg and left legs at $90^{\circ} \cdot \mathrm{s}^{-1}$

and $180^{\circ} \cdot \mathrm{s}^{-1}$, respectively. Post-hoc pairwise comparisons for the marginal means (collapsed across time and group, group and limb, and time and limb) indicated that PT for the right leg was significantly higher than the left leg (Figure 10) and PT was significantly higher at $90^{\circ} \cdot \mathrm{s}^{-1}$ than $180^{\circ} \cdot \mathrm{s}^{-1}$ (Figure 11) $(p<0.05)$.

\section{Dynamic Constant External Resistance Assessments}

Table 5 contains the means ( \pm SE) for 1-RM strength in the right and left legs. There was no three-way interaction for time $\times$ group $\times \operatorname{limb}(p>0.05)$, no two-way interaction for group $\times \operatorname{limb}(p>0.05)$, but there were significant two-way interactions for time $\times$ group and time $\times \operatorname{limb}(p<0.05)$. Post-hoc pairwise comparisons for the marginal means (collapsed across limb) indicated that 1-RM increased from pre- to post-training assessment 1 in both limbs for the DCER group only, and remained elevated during post-training assessments 2 and $3(p<0.05)$ (Figure 12). There were no differences in 1-RM strength for the DCER group between post-training assessments 1 and 2, or between post-training assessments 2 and $3(p>0.05)$. In addition, post-hoc pairwise comparisons for the marginal means (collapsed across group) indicated that 1-RM was higher for the right leg 
than left leg $(p<0.05)$. No other changes were found for the ISOK- training or CONT groups $(p>0.05)$.

\section{Isometric Assessments}

There was no interaction for time $\times$ group and no main effect for times or group $(p>0.05)$. Table 4 displays the means $( \pm \mathrm{SE})$ for isokinetic MVC for all groups.

\section{Muscle Activation}

\section{Surface Electromyography}

There was no four-way interaction for time $\times$ group $\times$ muscle $\times$ velocity, no three-way interactions for time $\times$ muscle $\times$ velocity, time $\times$ group $\times$ velocity, time $\times$ group $\times$ muscle, time $\times$ muscle $\times$ velocity, or group $\times$ muscle $\times$ velocity, and no two-way interactions for time $\times$ muscle, time $\times$ group, time $\times$ velocity, group $\times$ muscle, velocity $\times$ muscle, or velocity $\times$ group for the EMG amplitude of the RF and VL $(p>0.05)$. However, there was a significant main effect for velocity $(p<$ 0.05). Post-hoc pairwise comparisons for the marginal means (collapsed across time, group, and muscle) indicated EMG amplitude was significantly higher at $180^{\circ} \cdot \mathrm{s}^{-1}$ than $90^{\circ} \cdot \mathrm{s}^{-1}(p<0.05)$. Figure 13 displays the means $( \pm \mathrm{SE})$ for EMG amplitude collapsed across quadriceps muscles, groups, and time. 
For the $\mathrm{BF}$, there was no three-way interaction for time $\times$ group $\times$ velocity, and no two-way interactions for time $\times$ velocity, time $\times$ group, or group $\times$ velocity $(p>0.05)$. However, there were significant main effects for time and main effect for velocity $(p<0.05)$. Post-hoc pairwise comparisons for the marginal means (collapsed across group and velocity) indicated that EMG amplitude for the BF at post-training assessment 3 was significantly greater than pre-training assessment, post-training assessment 1 , and post-training assessment $2(p<0.05)$. In addition, post-hoc pairwise comparisons for the marginal means (collapsed across group and time) indicated that EMG amplitude for the BF was significantly greater at $180^{\circ} \cdot \mathrm{s}^{-1}$ than $90^{\circ} \cdot \mathrm{s}^{-1}(p<0.05)$. Figure 14 displays the mean $( \pm \mathrm{SE})$ for EMG amplitude collapsed across groups and velocities for the BF muscles. Figure 15 displays the mean ( $\pm \mathrm{SE}$ ) for EMG amplitude collapsed across groups and time for the BF muscles.

\section{Twitch Interpolation}

There was no significant three-way interaction for time $\times$ group $\times$ intensity, and no two-way interactions for time $\times$ intensity, group $\times$ intensity, or time $\times$ group $(p>0.05)$. However, there was a significant main effect for intensity $(p<0.05)$.

Post-hoc pairwise comparisons for the marginal means (collapsed across group and time) indicated voluntary activation significantly increased from 30 to $100 \%$ of MVC intensity $(p<0.05)$. Figure 16 displays the mean $( \pm$ SE) for voluntary activation collapsed across groups and time. 


\section{Mechanomyography}

Table 7 contains the means ( \pm SE) for MMG amplitude for all groups, muscles, and velocities. There was no four-way interaction for time $\times$ group $\times$ muscle $\times$ velocity, no three-way interactions for time $\times$ muscle $\times$ velocity, time $\times$ group $\times$ muscle, time $\times$ group $\times$ velocity, or time $\times$ muscle $\times$ velocity, no two-way interactions for time $\times$ muscle, time $\times$ group, time $\times$ velocity, group $\times$ muscle, muscle $\times$ velocity, or group $\times$ velocity $(p>0.05)$, but there was a significant threeway interaction for muscle $\times$ velocity $\times$ group $(p<0.05)$. Post-hoc pairwise comparisons for the marginal means (collapsed across time) indicated a significant main effect for velocity $(p<0.05)$. MMG amplitude was significantly higher at $180^{\circ} \cdot \mathrm{s}^{-1}$ than $90^{\circ} \cdot \mathrm{s}^{-1}$ for all groups $(p<0.05)$.

\section{Electromechanical Delay}

There was no significant interaction for time $\times$ group $(p>0.05)$. In addition, there were no significant main effects for time or group $(p>0.05)$. Table 8 displays the means $( \pm \mathrm{SE})$ for EMD for all groups.

\section{Rating of Perceived Exertion}

There was no three-way interaction for time $\times$ group $\times$ set, and no two-way interactions for time $\times$ set or time $\times$ group for set RPE $(p>0.05)$. However, there 
was a significant set $\times$ group interaction for training $(p<0.05)$. Post-hoc pairwise comparisons for the marginal means (collapsed across time) indicated a significant main effect for set RPE $(p<0.05)$ (Figure 17). RPE increased significantly ( $p<$ 0.05) from the first until the last set within all sessions for both training groups. For session RPE, there was no two-way interaction for time $\times$ group and no main effect for time or main effect for group $(p>0.05)$ (Figure 18). 


\section{CHAPTER 5:}

\section{DISCUSSION}

\section{Anthropometric and Body Composition Characteristics}

The only significant finding for anthropometric and body composition was a change in BM from pre- to post-training assessment. There was a decrease in BM for all groups from pre-training assessment to post-training assessment 1 . No other changes in anthropometric or body composition occurred. These findings were in agreement with short-term resistance training studies, in which no significant hypertrophy or other body composition changes have been reported $(3,11,17,25$, 80). For example, Akima et al. (1999) reported no increases in muscle CSA or fiber area after two weeks of resistance training. In contrast, DeFreitas et al. (2010) reported increases in muscle CSA after six resistance training sessions (29). However, in addition to taking part in six training sessions compared to three in the present study, subjects trained in three lower body exercises involving agonist and antagonist muscle groups (29), which may explain the difference between the present findings and those of DeFreitas (2010) (29). 


\section{Isokinetic Assessments}

No training-related PT changes were observed for any of the groups. In addition, PT values followed the well-established force-velocity relationship such that PT was higher during the slower $\left(90^{\circ} \cdot \mathrm{s}^{-1}\right)$ than faster $\left(180^{\circ} \cdot \mathrm{s}^{-1}\right)$ velocity $(20$ 22). The unique aspect of the present study was that both DCER and ISOK modes of training were used and neither resulted in increased ISOK strength. Overall, these results are consistent with studies that have reported no increases in PT after short-term ISOK training $(7,11,80)$. Brown and Whitehurst $(2003)$ reported no changes in PT after two days of leg extensors ISOK training (11). Likewise, Beck et al. (2007) reported no changes in PT after two days of forearm flexors and extensors ISOK training (7). The results of the current study are partially in agreement with the findings of Prevost et al. (1999), who reported no increases in PT after two days of ISOK training at the velocities of 30 and $150^{\circ} \cdot \mathrm{s}^{-1}(80)$. However, these findings are in contrast with previous studies reporting ISOK PT increases after short-term ISOK training $(17,25)$.

\section{Dynamic Constant External Resistance Assessments}

Perhaps the most important finding of the present study was the increases in DCER strength acquired in the DCER group. DCER strength increased similarly in both limbs for the DCER groups. To our knowledge, this was the first study to report DCER strength gains with short-term resistance training while also considering the detraining period of two weeks. In addition, the DCER group 
retained the strength gains during post-training assessments 2 and 3 over a twoweek period. Typical increases in strength obtained in longer resistance training programs are diminished after several weeks of training $(19,43,46,56,75,93)$. Colliander and Tesch (1992) compared the effects of resistance training and detraining using concentric-only and combined concentric and eccentric muscle actions of the leg extensors and reported that the group performing coupled concentric and eccentric muscle actions had a greater overall increase in PT after training and detraining than the concentric-only group. (19). These authors suggested that a resistance training program incorporating combined concentric and eccentric repetitions of leg extension can retain more of the obtained strength gains than the training program with concentric-only repetitions (19). Likewise, Farthing (2003) found eccentric muscle action training elicited greater strength gains than concentric training (39). Similarly, Knight et al. (2001) suggested that isotonic muscle actions may be more effective at increasing torque because isokinetic resistance is accommodating, hence, it decreases with fatigue (62). These findings $(19,39,62)$, along with the findings of the current study may indicate an advantage of DCER over ISOK resistance training programs when conducted over a relatively short period of time. Moreover, reliability results from the present study demonstrate that the ICC's were higher and SEM's lower for the DCER than ISOK testing, which may have explained the observed changes in DCER vs. ISOK findings.

For the DCER training group, despite training only the right leg; both limbs increased strength and maintained these strength gains over the two-week 
detraining period. Unilateral resistance training of a limb can increase the strength of the contralateral limb in a concept termed cross-education (74). Increases in the contralateral, untrained limb, have been extensively reported in the literature (15, 74). Perhaps an important finding of the current study is that short-term resistance training also elicits this cross-education effect. This has important implications for injury rehabilitation, where in the initial period post-injury strength gains on an injured limb can possibly be obtained with short-term contralateral resistance training. Contralateral strength gains have been hypothesized to be attributed to central neural adaptations (i.e. excitation of the cortex), increased motoneuron output, and improved postural stabilization $(15,74,81)$.

Strength gains were also maintained during the two-week detraining period in the DCER group. Although in the present study subjects were untrained, these findings were similar to those of Hortobagyi et al. (1993), who found that two weeks of detraining of resistance-trained athletes did not cause a significant decrease in maximal bench press, squat, isometric, or concentric isokinetic strength (53). Similarly, Shaver (1975) reported that recently acquired strength can be maintained in both trained and untrained limb for up to one week (87). To our knowledge, the current study is the first to demonstrate that short-term increases in strength can be maintained for a two-week period and in trained and untrained limbs. In contrast, other authors have suggested strength gains that have been recently acquired may diminish faster than in strength-trained athletes $(72,87)$. Therefore, the history experience with resistance training (novice versus well- 
trained athletes) should be considered when interpreting the results of a short-term resistance training program and its potential lasting effects.

\section{Isometric Assessments}

Isometric MVC force did not change for any of the groups in the present study. These results are similar to those found by Beck et al. (2007) who reported no changes in isometric PT after two days of forearm ISOK training (7). These results are in contrast with those of Christie and Kamen (2010), who compared the effects of short-term training in young and older subjects (16). These authors reported increases in MVC force after six sessions of isometric dorsiflexor exercises (16). The discrepancies between their findings and the results of the current study may be due to the number of training sessions and/or specificity, in which participants trained and tested in the same mode of muscle action (isometric) compared to the current study in which participants in trained in either DCER or ISOK muscle actions. Christie and Kamen (2010) trained their subjects for six training sessions whereas in the present study, participants only took part in three training sessions (16). The specificity principle was also demonstrated in the present study by the increase in DCER strength in the DCER training group only. The study by Rutherford et al. (1986) also demonstrated the specificity principle (81). The authors reported large improvements in training load for dynamic leg extensions that were not reflected by a comparable magnitude of increases in isometric strength (81). 


\section{Muscle Activation}

\section{Electromyography}

No changes in RF or VL EMG amplitude occurred in the present study. These results are in agreement with previous short-term resistance training studies reporting no change in muscle activation $(7,17,25,52)$. For example, Beck et al. (2007) reported no changes in EMG amplitude after two days of forearm flexors and extensors ISOK training (7). Coburn et al. (2006) reported increases in PT, but no changes in EMG amplitude after three days of short-term isokinetic training (17). The authors suggested that gains in PT after training were not caused by increases in muscle activation (17). Similarly, Holtermann et al. (2005) reported increases in isometric MVC strength but no increases in EMG after five days of isometric training (52). Likewise, Cramer et al. (2007) found no changes in EMG amplitude, but reported increases in PT (25). Coburn et al. (2006) suggested increases in PT without accompanying increases in EMG can be possible because of a decrease in the antagonist's muscle coactivation induced by the training program and/or an increased ability in coordinating stabilizing/synergistic muscles (17). Thus, an increase in PT torque without a concomitant increase in EMG amplitude could be due to other neural changes, such as synchronization of motor units and/or optimization of motor unit firing rates (52) or a decrease in reciprocal coactivation of the antagonist muscles (25). 
Beck et al. (2007) reported no changes in EMG amplitude of the antagonist muscles after two days of forearm flexors and extensors training ISOK (7). However, EMG amplitude for the BF muscles increased at the post-training assessment 3 in the current study. Other studies have also found an increase in antagonist coactivation as a result of training $(28,89,94)$. A decreased coactivation could theoretically increase force production, but evidence for mechanisms of increased agonist activation and decrease antagonist activation is equivocal (94). An increase in reciprocal coactivation of the BF after training could be interpreted as a protective mechanism in an effort to maintain, rather than compromise, joint stability $(28,94)$. Future studies should further investigate the effects of antagonist muscle coactivation on short-term resistance training.

Longer duration studies have reported increases in EMG activity (69). For example, Moritani and deVries (1979) reported increases in muscle activation EMG after four weeks of training (69).No changes in EMG were found in the present study. The results of the current study along with the findings of previous studies $(17,25)$ suggest a greater duration of training may be necessary to induce detectable increases in muscle activation. By comparison, Hortobagyi et al. (1993) reported two weeks of detraining of resistance-trained athletes caused a significant decrease in surface EMG activity (53). Similarly, Andersen et al. (2005) reported EMG during concentric muscle actions decreased after three months of detraining (5). Finally, the results in the current study indicate EMG amplitude was greater at $180^{\circ} \cdot \mathrm{s}^{-1}$ than $90^{\circ} \cdot \mathrm{s}^{-1}$ for all groups. These findings are also consistent with those of 
Cramer et al. 2007) who reported EMG amplitude increased from $30^{\circ} \cdot \mathrm{s}^{-1}$ to $150^{\circ} \cdot \mathrm{s}^{-}$ ${ }^{1}$ to $270^{\circ} \cdot \mathrm{s}^{-1}(25)$.

\section{Twitch Interpolation}

There were no changes in \%VA activation in the present study as determined by the TI technique. These results are similar to those found by Tillin et al. 2011), who reported no changes in \%VA after four weeks of isometric training (94). Likewise, although using a different method to determine muscle activation, Christie and Kamen (2010) also reported no changes in central activation after six days of isometric training (16). In addition, the authors reported all subjects were able to fully activate their muscles voluntarily and thus, suggested increases in MVC isometric force were not due to an increased ability to activate their muscles fully (16). The results of the current study are also in agreement with studies that have reported no changes in percent of voluntary activation as assessed by the TI technique following resistance training $(10,12,14,26,41,48,49,58,85,94)$. Lack of changes in muscle activation are hypothesized to be attributed to complete voluntary muscle activation prior to training, training and testing were conducted using different muscle actions (i.e. dynamic and isometric), and some muscles display only small deficit in voluntary activation leaving only a small window of improvement (88). The mean \%VA in the present study ranged from $85-87 \%$ for all groups over all assessments. Perhaps longer training and/or higher training volume (i.e. more exercises) are necessary to increase \%VA. 


\section{Mechanomyography}

No changes in mechanomyography were found in the present study. These findings are similar to those found by Cramer et al. (2007). In that study, the authors reported no changes in MMG amplitude after two days of isokinetic shortterm resistance training with and without eight days of creatine supplementation (25). In addition, the results in the current study indicate MMG amplitude was greater at $180^{\circ} \cdot \mathrm{s}^{-1}$ than $90^{\circ} \cdot \mathrm{s}^{-1}$ for all groups. These findings are also consistent with those of Cramer et al. 2007) who reported MMG amplitude increased from $30^{\circ} \cdot \mathrm{s}^{-1}$ to $150^{\circ} \cdot \mathrm{s}^{-1}$ to $270^{\circ} \cdot \mathrm{s}^{-1}(25)$. Since the authors reported increases in PT but not increases in EMG or MMG amplitude, it was suggested that these increases in strength from training were due to increases in motor unit firing rate rather than motor unit recruitment (25).

\section{Electromechanical Delay}

In the present study, no changes on EMD were found in any of the groups. To our knowledge, this was the first study to investigate the effects of short-term resistance training on EMD. Similarly, Häkkinen et al. (1983) found no changes in EMD calculated under reflex contraction before and after 16 weeks of resistance training (44). In contrast, Kubo (2001), reported decreases in EMD during voluntary muscle actions after 12 weeks of isometric training (65). Potential sources of discrepancies between the results of the current study and those of Kubo 
et al (2001) could be study duration and EMD stimulation and detection procedures. Nevertheless, the authors concluded that 12 weeks of isometric training led to an increase in stiffness, consequently decreasing EMD values (65). Hence, it can be hypothesized that increases in strength observed in the DCER training group of the current study may not have been attributed to changes in the stiffness changes in the series elastic component.

\section{Rating of Perceived Exertion}

The results revealed RPE increased from the first to the fourth set within each training session. However, there were no differences among the three days of training. In addition, there were no differences in RPE as acknowledged by the subjects in either the DCER or ISOK groups. These results are similar to those reported by Egan et al. (2006), who reported mean session RPE values of 7.3 for six sets of six repetitions of traditional resistance training using squats at an intensity of $80 \%$ of 1-RM (33). Likewise, Sweet et al. (2004) reported mean RPE values between 6.8 and 8.2 for 70 and $90 \%$ of leg press 1-RM, respectively (92). In addition, similar to our ISOK RPE findings, Douris (1993) reported mean RPE values of $6.5,7.1$, and 7.2 for ISOK leg flexion and extension at the velocities of 30,120 , and $300^{\circ} \cdot \mathrm{s}^{-1}$, respectively $(31)$. 


\section{Conclusion}

The primary finding of this study was that DCER strength can be increased with three days of training. Another important finding of the current study is that short-term resistance training induces a cross-education effect increasing the strength in the untrained limb. This has important implications for injury rehabilitation, where in the initial period post-injury strength gains on an injured limb can possibly be obtained with short-term contralateral resistance training. To our knowledge, the current study is the first to demonstrate recently acquired strength can be maintained for a two-week period and in trained and untrained limbs. The neuromuscular system undergoes numerous adaptations following a resistance training program $(3,35,64,69,70,82,90)$. However, the specific mechanisms of such adaptations in short-term training have not been fully understood (17). Nevertheless, evidence has shown that improvements in muscle performance can be observed in a shorter period than what is typically used in longer traditional training programs $(3,25,69)$. Although increases in strength following resistance training have been attributed to neural and hypertrophic factors $(35,64,69,82,83,90)$, no increases in TMCSA, TLM, EMG and MMG amplitude, or $\% \mathrm{VA}$, were found in the current study. Therefore, strength gains observed after DCER resistance training were due to an unidentified factor. Future studies should investigate the precise physiological components responsible for short-term strength gains. The findings of the current study may indicate an advantage of DCER over ISOK resistance training programs when conducted over a relatively short period of time. Traditional DCER resistance training appears to be a better 
and more cost-effective option when rapid increases in strength are desired and a longer period of time is not available. These findings have important implications in clinical rehabilitation settings, sports injury prevention, as well as in other allied health fields such as physical therapy, occupational therapy, and athletic training. Therefore, future studies should examine the effects of short-term resistance training on injury prevention and injury rehabilitation. In addition, because muscle endurance (i.e. number of repetitions performed) may be more representative of training volume, future studies should examine the effects of short-term training on different aspects of muscle fitness and different types of muscle actions. Furthermore, muscle imbalance has also been associated with injury risk. Therefore, future studies should also investigate the effects of short-term training to minimize muscle imbalances and the use of short-term training to reduce injury risk. 


\section{BIBLIOGRAPHY}

1) Aagaard P, Simonsen EB, Andersen JL, Magnusson P, and Dyhre-Poulsen P. Neural adaptation to resistance training: changes in evoked V-wave and H-reflex responses. J Appl Physiol. 2002;92(6):2309-18.

2) Akataki K, Mita K, and Watakabe M. Electromyographic and mechanomyographic estimation of motor unit activation strategy in voluntary force production. Electromyogr Clin Neurophysiol. 2004;44(8):489-96.

3) Akima H, Takahashi H, Kuno SY, Masuda K, Masuda T, Shimojo H, Anno I, Itai Y, and Katsuta S. Early phase adaptations of muscle use and strength to isokinetic training. Med Sci Sports Exerc. 1999;31(4):588-94.

4) Allen GM, Gandevia SC, and Mckenzie DK. Reliability of measurements of muscle strength and voluntary activation using twitch interpolation. Muscle Nerve. 1995;18(6):593-600.

5) Andersen LL, Andersen JL, Magnusson SP, and Aagaard P. Neuromuscular adaptations to detraining following resistance training in previously untrained subjects. Eur J Appl Physiol. 2005;93(5-6):511-8.

6) Basmajian JV, and De Luca CJ. Muscles Alive: Their Functions Revealed by Electromyography. Baltimore: Williams \& Wilkins, 1985.

7) Beck TW, Housh TJ, Johnson GO, Weir JP, Cramer JT, Coburn JW, Malek MH, and Mielke M. Effects of two days of isokinetic training on strength and electromyographic amplitude in the agonist and antagonist muscles. $J$ Strength Cond Res. 2007;21(3):757-62.

8) Behm D, Power K, and Drinkwater E. Comparison of interpolation and central activation ratios as measures of muscle inactivation. Muscle Nerve.

2001;24(7):925-34.

9) Belanger AY, and Mccomas AJ. Extent of motor unit activation during effort. $J$ Appl Physiol. 1981;51(5):1131-5. 
10) Brown AB, Mccartney N, and Sale DG. Positive adaptations to weight-lifting training in the elderly. J Appl Physiol. 1990;69(5):1725-33.

11) Brown LE, and Whitehurst $M$. The effect of short-term isokinetic training on force and rate of velocity development. J Strength Cond Res. 2003;17(1):88-94.

12) Cannon J, Kay D, Tarpenning KM, and Marino FE. Comparative effects of resistance training on peak isometric torque, muscle hypertrophy, voluntary activation and surface EMG between young and elderly women. Clin Physiol Funct Imaging. 2007;27(2):91-100.

13) Cannon RJ, and Cafarelli E. Neuromuscular adaptations to training. $J \mathrm{Appl}$ Physiol. 1987;63(6):2396-402.

14) Carolan B, and Cafarelli E. Adaptations in coactivation after isometric resistance training. J Appl Physiol. 1992;73(3):911-7.

15) Carroll TJ, Herbert RD, Munn J, Lee M, and Gandevia SC. Contralateral effects of unilateral strength training: evidence and possible mechanisms. $J$ Appl Physiol. 2006;101(5):1514-22.

16) Christie A, and Kamen G. Short-term training adaptations in maximal motor unit firing rates and afterhyperpolarization duration. Muscle Nerve.

2010;41(5):651-60.

17) Coburn JW, Housh TJ, Malek MH, Weir JP, Cramer JT, Beck TW, and Johnson GO. Neuromuscular responses to three days of velocity-specific isokinetic training. J Strength Cond Res. 2006;20(4):892-8.

18) Coleman AE. Effect of unilateral isometric and isotonic contractions on the strength of the contralateral limb. Res $Q .1969 ; 40(3): 490-5$.

19) Colliander EB, and Tesch PA. Effects of detraining following short term resistance training on eccentric and concentric muscle strength. Acta Physiol Scand. 1992;144(1):23-9.

20) Costa PB, Ryan ED, Herda TJ, Defreitas JM, Beck TW, and Cramer JT. Effects of static stretching on the hamstrings-to-quadriceps ratio and electromyographic amplitude in men. J Sports Med Phys Fitness. 2009;49(4):401-9. 
21) Costa PB, Ryan ED, Herda TJ, Defreitas JM, Beck TW, and Cramer JT. Effects of stretching on peak torque and the H:Q ratio. Int J Sports Med. 2009;30(1):60-5.

22) Costa PB, Ryan ED, Herda TJ, Walter AA, Defreitas JR, Stout JR, and Cramer JT. Acute effects of static stretching on peak torque and the hamstrings-toquadriceps conventional and functional ratios. Scand J Med Sci Sports. 2011;

23) Costa PB, Ryan ED, Herda TJ, Walter AA, Hoge KM, and Cramer JT. Acute effects of passive stretching on the electromechanical delay and evoked twitch properties. Eur J Appl Physiol. 2010;108(2):301-10.

24) Cramer JT, Housh TJ, Weir JP, Johnson GO, Ebersole KT, Perry SR, and Bull AJ. Power output, mechanomyographic, and electromyographic responses to maximal, concentric, isokinetic muscle actions in men and women. $J$ Strength Cond Res. 2002;16(3):399-408.

25) Cramer JT, Stout JR, Culbertson JY, and Egan AD. Effects of creatine supplementation and three days of resistance training on muscle strength, power output, and neuromuscular function. J Strength Cond Res. 2007;21(3):668-77.

26) Davies J, Parker DF, Rutherford OM, and Jones DA. Changes in strength and cross sectional area of the elbow flexors as a result of isometric strength training. Eur J Appl Physiol Occup Physiol. 1988;57(6):667-70.

27) Day ML, Mcguigan MR, Brice G, and Foster C. Monitoring exercise intensity during resistance training using the session RPE scale. J Strength Cond Res. 2004;18(2):353-8.

28) De Boer MD, Morse CI, Thom JM, De Haan A, and Narici MV. Changes in antagonist muscles' coactivation in response to strength training in older women. $J$ Gerontol A Biol Sci Med Sci. 2007;62(9):1022-7.

29) Defreitas JM, Beck TW, Stock MS, Dillon MA, Sherk VD, Stout JR, and Cramer JT. A comparison of techniques for estimating training-induced changes in muscle cross-sectional area. J Strength Cond Res. 2010;

30) Desbrosses K, Babault N, Scaglioni G, Meyer JP, and Pousson M. Neural activation after maximal isometric contractions at different muscle lengths. Med Sci Sports Exerc. 2006;38(5):937-44. 
31) Douris PC. The effect of isokinetic exercise on the relationship between blood lactate and muscle fatigue. J Orthop Sports Phys Ther. 1993;17(1):31-5.

32) Ebersole KT, Housh TJ, Johnson GO, Perry SR, Bull AJ, and Cramer JT. Mechanomyographic and electromyographic responses to unilateral isometric training. J Strength Cond Res. 2002;16(2):192-201.

33) Egan A, Winchester J, Foster C, and Mcguigan M. Using session RPE to monitor different methods of resistance exercise. J Sports Sci \& Med. 2006;5(2):289-95.

34) Ekblom MM. Improvements in dynamic plantar flexor strength after resistance training are associated with increased voluntary activation and V-to-M ratio. $J$ Appl Physiol. 2010;109(1):19-26.

35) Enoka RM. Muscle strength and its development. New perspectives. Sports Med. 1988;6(3):146-68.

36) Evetovich TK, Housh TJ, Housh DJ, Johnson GO, Smith DB, and Ebersole KT. The effect of concentric isokinetic strength training of the quadriceps femoris on electromyography and muscle strength in the trained and untrained limb. J Strength Cond Res. 2001;15(4):439-45.

37) Faigenbaum AD, Westcott WL, Micheli LJ, Outerbridge AR, Long CJ, LarosaLoud R, and Zaichkowsky LD. The effects of strength training and detraining on children. Journal of Strength and Conditioning Research. 1996;10(109-14.

38) Farina $D$, Merletti R, and Enoka RM. The extraction of neural strategies from the surface EMG. $J$ Appl Physiol. 2004;96(4):1486-95.

39) Farthing JP, and Chilibeck PD. The effects of eccentric and concentric training at different velocities on muscle hypertrophy. Eur J Appl Physiol. 2003;89(6):57886.

40) Foster C, Florhaug JA, Franklin J, Gottschall L, Hrovatin LA, Parker S, Doleshal $\mathrm{P}$, and Dodge C. A new approach to monitoring exercise training. $J$ Strength Cond Res. 2001;15(1):109-15. 
41) Garfinkel S, and Cafarelli E. Relative changes in maximal force, EMG, and muscle cross-sectional area after isometric training. Med Sci Sports Exerc.

1992;24(11):1220-7.

42) Grimby L, Hannerz J, and Hedman B. The fatigue and voluntary discharge properties of single motor units in man. J Physiol. 1981;316(545-54.

43) Hakkinen K, Alen M, and Komi PV. Changes in isometric force- and relaxation-time, electromyographic and muscle fibre characteristics of human skeletal muscle during strength training and detraining. Acta Physiol Scand. 1985;125(4):573-85.

44) Hakkinen K, and Komi PV. Changes in neuromuscular performance in voluntary and reflex contraction during strength training in man. Int J Sports Med. 1983;4(4):282-8.

45) Hakkinen K, and Komi PV. Training-induced changes in neuromuscular performance under voluntary and reflex conditions. Eur J Appl Physiol Occup Physiol. 1986;55(2):147-55.

46) Hakkinen K, Komi PV, and Tesch PA. Effects of combined concentric and eccentric strength training and detraining on force-time, muscle fiber and metabolic characteristics of leg extensor muscles. Scand. J. Sports Sci. 1981;3(50-8.

47) Hales JP, and Gandevia SC. Assessment of maximal voluntary contraction with twitch interpolation: an instrument to measure twitch responses. $J$ Neurosci Methods. 1988;25(2):97-102.

48) Harridge SD, Kryger A, and Stensgaard A. Knee extensor strength, activation, and size in very elderly people following strength training. Muscle Nerve. 1999;22(7):831-9.

49) Herbert RD, Dean C, and Gandevia SC. Effects of real and imagined training on voluntary muscle activation during maximal isometric contractions. Acta Physiol Scand. 1998;163(4):361-8.

50) Hermens HJ, Frekis B, Merletti R, Stegman D, Blok J, Rau G, Klug CD, and Hägg G. SENIAM - European Recommendations for Surface Electromyography. Results of the SENIAM project. Enschede, Netherlands: Roessingh Research and Development, 1999. 
51) Higbie EJ, Cureton KJ, Warren GL, 3rd, and Prior BM. Effects of concentric and eccentric training on muscle strength, cross-sectional area, and neural activation. J Appl Physiol. 1996;81(5):2173-81.

52) Holtermann A, Roeleveld K, Vereijken B, and Ettema G. Changes in agonist EMG activation level during MVC cannot explain early strength improvement. Eur J Appl Physiol. 2005;94(5-6):593-601.

53) Hortobagyi T, Houmard JA, Stevenson JR, Fraser DD, Johns RA, and Israel RG. The effects of detraining on power athletes. Med Sci Sports Exerc. 1993;25(8):929-35.

54) Hortobagyi T, Lambert NJ, and Hill JP. Greater cross education following training with muscle lengthening than shortening. Med Sci Sports Exerc. 1997;29(1):107-12.

55) Housh TJ, Housh DJ, Weir JP, and Weir LL. Effects of unilateral concentriconly dynamic constant external resistance training. Int J Sports Med. 1996;17(5):338-43.

56) Houston ME, Froese EA, Valeriote SP, Green HJ, and Ranney DA. Muscle performance, morphology and metabolic capacity during strength training and detraining: a one leg model. Eur J Appl Physiol Occup Physiol. 1983;51(1):25-35.

57) Ikai M, and Fukunaga T. A study on training effect on strength per unit crosssectional area of muscle by means of ultrasonic measurement. Int $Z$ Angew Physiol. 1970;28(3):173-80.

58) Jones DA, and Rutherford OM. Human muscle strength training: the effects of three different regimens and the nature of the resultant changes. $J$ Physiol. 1987;391(1-11.

59) Kamen G, Knight C, Laroche D, and Asermely D. Resistance training increases vastus lateralis motor unit firing rates in young and old adults. Med Sci Sports Exerc. 1998;30(5):337.

60) Kanehisa H, and Miyashita M. Specificity of velocity in strength training. Eur $J$ Appl Physiol Occup Physiol. 1983;52(1):104-6. 
61) Knight CA, and Kamen G. Adaptations in muscular activation of the knee extensor muscles with strength training in young and older adults. $J$ Electromyogr Kinesiol. 2001;11(6):405-12.

62) Knight $\mathrm{K}$, Ingersoll $\mathrm{C}$, and Bartholomew J. Isotonic contractions might be more effective than isokinetic contractions in developing muscle strength. J Sport Rehabil. 2001;10(2):124-31.

63) Komi PV, Viitasalo JT, Rauramaa R, and Vihko V. Effect of isometric strength training of mechanical, electrical, and metabolic aspects of muscle function. Eur $J$ Appl Physiol Occup Physiol. 1978;40(1):45-55.

64) Kraemer WJ, Fleck SJ, and Evans WJ. Strength and power training: physiological mechanisms of adaptation. Exerc Sport Sci Rev. 1996;24(363-97.

65) Kubo K, Kanehisa H, Ito M, and Fukunaga T. Effects of isometric training on the elasticity of human tendon structures in vivo. J Appl Physiol. 2001;91(1):26-32.

66) Matuszak ME, Fry AC, Weiss LW, Ireland TR, and Mcknight MM. Effect of rest interval length on repeated 1 repetition maximum back squats. J Strength Cond Res. 2003;17(4):634-7.

67) Merton PA. Interaction between muscle fibres in a twitch. $J$ Physiol. 1954;124(2):311-24.

68) Milner-Brown HS, Stein RB, and Lee RG. Synchronization of human motor units: possible roles of exercise and supraspinal reflexes. Electroencephalogr Clin Neurophysiol. 1975;38(3):245-54.

69) Moritani T, and Devries HA. Neural factors versus hypertrophy in the time course of muscle strength gain. Am J Phys Med. 1979;58(3):115-30.

70) Moritani T, and Devries HA. Potential for gross muscle hypertrophy in older men. J Gerontol. 1980;35(5):672-82.

71) Morse CI, Thom JM, Davis MG, Fox KR, Birch KM, and Narici MV. Reduced plantarflexor specific torque in the elderly is associated with a lower activation capacity. Eur J Appl Physiol. 2004;92(1-2):219-26. 
72) Mujika I, and Padilla S. Detraining: loss of training-induced physiological and performance adaptations. Part I: short term insufficient training stimulus. Sports Med. 2000;30(2):79-87.

73) Mujika I, and Padilla S. Muscular characteristics of detraining in humans. Med Sci Sports Exerc. 2001;33(8):1297-303.

74) Munn J, Herbert RD, and Gandevia SC. Contralateral effects of unilateral resistance training: a meta-analysis. J Appl Physiol. 2004;96(5):1861-6.

75) Narici MV, Roi GS, Landoni L, Minetti AE, and Cerretelli P. Changes in force, cross-sectional area and neural activation during strength training and detraining of the human quadriceps. Eur J Appl Physiol Occup Physiol. 1989;59(4):310-9.

76) Orizio C, Gobbo M, Diemont B, Esposito F, and Veicsteinas A. The surface mechanomyogram as a tool to describe the influence of fatigue on biceps brachii motor unit activation strategy. Historical basis and novel evidence. Eur J Appl Physiol. 2003;90(3-4):326-36.

77) Ozmun JC, Mikesky AE, and Surburg PR. Neuromuscular adaptations following prepubescent strength training. Med Sci Sports Exerc. 1994;26(4):510-4.

78) Parcell AC, Sawyer RD, Tricoli VA, and Chinevere TD. Minimum rest period for strength recovery during a common isokinetic testing protocol. Med Sci Sports Exerc. 2002;34(6):1018-22.

79) Ploutz LL, Tesch PA, Biro RL, and Dudley GA. Effect of resistance training on muscle use during exercise. J Appl Physiol. 1994;76(4):1675-81.

80) Prevost MC, Nelson AG, and Maraj BKV. The Effect of Two Days of Velocity-Specific Isokinetic Training on Torque Production. J Strength Cond Res. 1999;13(1):35-9.

81) Rutherford OM, and Jones DA. The role of learning and coordination in strength training. Eur J Appl Physiol Occup Physiol. 1986;55(1):100-5.

82) Sale DG. Influence of exercise and training on motor unit activation. Exerc Sport Sci Rev. 1987;15(95-151. 
83) Sale DG. Neural adaptation to resistance training. Med Sci Sports Exerc. 1988;20(5 Suppl):S135-45.

84) Sale DG, Macdougall JD, Upton AR, and Mccomas AJ. Effect of strength training upon motoneuron excitability in man. Med Sci Sports Exerc.

1983;15(1):57-62.

85) Sale DG, Martin JE, and Moroz DE. Hypertrophy without increased isometric strength after weight training. Eur J Appl Physiol Occup Physiol. 1992;64(1):51-5.

86) Scaglioni G, Ferri A, Minetti AE, Martin A, Van Hoecke J, Capodaglio P, Sartorio A, and Narici MV. Plantar flexor activation capacity and H reflex in older adults: adaptations to strength training. $J$ Appl Physiol. 2002;92(6):2292-302.

87) Shaver LG. Cross transfer effects of conditioning and deconditioning on muscular strength. Ergonomics. 1975;18(1):9-16.

88) Shield A, and Zhou S. Assessing voluntary muscle activation with the twitch interpolation technique. Sports Med. 2004;34(4):253-67.

89) Simoneau E, Martin A, Porter MM, and Van Hoecke J. Strength training in old age: adaptation of antagonist muscles at the ankle joint. Muscle Nerve.

2006;33(4):546-55.

90) Staron RS, Karapondo DL, Kraemer WJ, Fry AC, Gordon SE, Falkel JE, Hagerman FC, and Hikida RS. Skeletal muscle adaptations during early phase of heavy-resistance training in men and women. $J$ Appl Physiol. 1994;76(3):1247-55.

91) Stout J, Eckerson J, Ebersole K, Moore G, Perry S, Housh T, Bull A, Cramer J, and Batheja A. Effect of creatine loading on neuromuscular fatigue threshold. $J$ Appl Physiol. 2000;88(1):109-12.

92) Sweet TW, Foster C, Mcguigan MR, and Brice G. Quantitation of resistance training using the session rating of perceived exertion method. J Strength Cond Res. 2004;18(4):796-802.

93) Thorstensson A. Observations on strength training and detraining. Acta Physiol Scand. 1977;100(4):491-3. 
94) Tillin NA, Pain MT, and Folland JP. Short-term unilateral resistance training affects the agonist-antagonist but not the force-agonist activation relationship. Muscle Nerve. 2011;43(3):375-84.

95) Todd G, Gorman RB, and Gandevia SC. Measurement and reproducibility of strength and voluntary activation of lower-limb muscles. Muscle Nerve.

2004;29(6):834-42.

96) Weir JP. Quantifying test-retest reliability using the intraclass correlation coefficient and the SEM. J Strength Cond Res. 2005;19(1):231-40.

97) Weir JP, Wagner LL, and Housh TJ. The effect of rest interval length on repeated maximal bench presses. J Strength Cond Res. 1994;8(1):58.

98) Whaley MH, Brubaker PH, and Otto RM. ACSM's Guidelines for Exercise Testing and Prescription. Philadelphia: Lippincott Williams \& Wilkins, 2006.

99) Zhou S. Chronic neural adaptations to unilateral exercise: mechanisms of cross education. Exerc Sport Sci Rev. 2000;28(4):177-84. 


\section{APPENDIX A:}

\section{TABLES}

Table 1. Sample sizes and means ( \pm SEM) for age (yr), body mass (kg), height $(\mathrm{cm})$, body fat percentage $(\%)$, thigh fat $(\%)$, thigh lean mass $(\mathrm{g})$, and thigh muscle cross-sectional area $\left(\mathrm{cm}^{2}\right)$ for the DCER, ISOK, and CONT groups.

\begin{tabular}{cccccccc}
\hline & $\begin{array}{c}\text { Age } \\
(\mathrm{yr})\end{array}$ & $\mathrm{BM}(\mathrm{kg})$ & $\mathrm{HT}(\mathrm{cm})$ & $\mathrm{BF} \%$ & $\mathrm{TF} \%$ & $\mathrm{TLM}(\mathrm{g})$ & $\begin{array}{c}\text { TMCSA } \\
\left(\mathrm{cm}^{2}\right)\end{array}$ \\
\cline { 2 - 7 } DCER & $20.3 \pm$ & $77.9 \pm$ & $173.2 \pm$ & $24.4 \pm$ & $30.3 \pm$ & $6570.3 \pm$ & $152.1 \pm$ \\
$(\mathrm{n}=$ & 0.5 & 3.6 & 2.2 & 2.5 & 2.7 & 298.5 & 9.5 \\
$11)$ & & & & & & & \\
ISOK & $23.7 \pm$ & $79.4 \pm$ & $176.3 \pm$ & $20.6 \pm$ & $25.4 \pm$ & $7064.5 \pm$ & $171.0 \pm$ \\
$(\mathrm{n}$ & 1.8 & 3.4 & 1.3 & 2.0 & 1.7 & 284.6 & 9.6 \\
$=10)$ & & & & & & & \\
CONT & $22.9 \pm$ & $77.3 \pm$ & $172.3 \pm$ & $24.8 \pm$ & $28.1 \pm$ & $6329.6 \pm$ & $151.4 \pm$ \\
$(\mathrm{n}=$ & 1.3 & 5.3 & 1.2 & 2.9 & 2.9 & 278.0 & 9.9 \\
$10)$ & & & & & & & \\
\hline
\end{tabular}

DCER $=$ dynamic constant external resistance; ISOK $=$ isokinetic; $\mathrm{CONT}=$ control; $\mathrm{BM}=$ body mass; $\mathrm{HT}=$ height; $\mathrm{BF}=$ body fat; $\mathrm{TF}=$ thigh fat; $\mathrm{TLM}=$ thigh lean mass; TMCSA = thigh muscle cross-sectional area 
Table 2. Reliability results of 31 subjects assessed 48 hours apart from pre-training assessment visit 1 to visit 2 .

\begin{tabular}{ccccc}
\hline & $p$ Value & ICC & SEM & $\begin{array}{c}\text { SEM } \\
(\% \text { pooled mean })\end{array}$ \\
\cline { 2 - 5 } BF\% & 0.37 & 0.99 & 0.88 & 3.80 \\
TF\% & 0.62 & 0.99 & 0.90 & 3.21 \\
TLM $(\mathrm{g})$ & 0.39 & 0.97 & 170.08 & 2.56 \\
TMCSA $\left(\mathrm{cm}^{2}\right)$ & 0.10 & 0.97 & 5.21 & 3.27 \\
$\mathrm{MVC}$ Force $(\mathrm{n})$ & $0.01^{*}$ & 0.88 & 54.24 & 8.97 \\
$90^{\circ} \cdot \mathrm{s}^{-1} \mathrm{PT}(\mathrm{R})(\mathrm{N} \cdot \mathrm{m})$ & $<0.01^{*}$ & 0.88 & 12.92 & 7.00 \\
$90^{\circ} \cdot \mathrm{s}^{-1} \mathrm{PT}(\mathrm{L})(\mathrm{N} \cdot \mathrm{m})$ & $0.03^{*}$ & 0.86 & 12.84 & 7.25 \\
$180^{\circ} \cdot \mathrm{s}^{-1} \mathrm{PT}(\mathrm{R})(\mathrm{N} \cdot \mathrm{m})$ & 0.13 & 0.83 & 11.3 & 8.4 \\
$180^{\circ} \cdot \mathrm{s}^{-1} \mathrm{PT}(\mathrm{L})(\mathrm{N} \cdot \mathrm{m})$ & 0.16 & 0.78 & 12.8 & 9.5 \\
TI 30\% & 0.23 & 0.46 & 8.0 & 28.61 \\
TI 50\% & 0.1 & 0.53 & 10.01 & 19.80 \\
TI 70\% & 0.14 & 0.68 & 8.09 & 11.1 \\
TI 100\% & 0.84 & 0.61 & 8.47 & 9.98 \\
$\mathrm{DCER}(\mathrm{R})(\mathrm{kg})$ & 0.08 & 0.96 & 2.1 & 2.2 \\
$\mathrm{DCER}(\mathrm{L})(\mathrm{kg})$ & $0.01 * *$ & 0.95 & 2.1 & 2.2 \\
EMD $(\mathrm{ms})$ & 0.38 & 0.27 & 0.98 & 21.3 \\
\hline
\end{tabular}

$\mathrm{BF} \%=$ body fat percentage; $\mathrm{TF} \%=$ thigh fat percentage; $\mathrm{TLM}=$ thigh lean mass; TMCSA $=$ thigh muscle cross-sectional area; $\mathrm{MVC}=$ maximum voluntary contraction; $\mathrm{L}=$ left; $\mathrm{R}=$ right; $\mathrm{PT}=$ peak torque; $\mathrm{TI}=$ twitch interpolation; DCER = dynamic constant external resistance; $\mathrm{EMD}=$ electromechanical delay; $\mathrm{ICC}=$ intraclass correlation coefficient; SEM = standard error of measurement *Denotes a significant decrease between the two visits

**Denotes a significant increase between the two visits 
Table 3. Means ( \pm SE) for anthropometric and body composition data.

\begin{tabular}{|c|c|c|c|c|c|}
\hline & & $\begin{array}{l}\text { Pre-Training } \\
\text { Assessment } 1\end{array}$ & $\begin{array}{l}\text { Post-Training } \\
\text { Assessment } 1\end{array}$ & $\begin{array}{l}\text { Post-Training } \\
\text { Assessment } 2\end{array}$ & $\begin{array}{l}\text { Post-Training } \\
\text { Assessment } 3\end{array}$ \\
\hline & DCER & $77.9 \pm 3.7$ & $77.5 \pm 3.7^{*}$ & $78.0 \pm 3.6$ & $77.7 \pm 3.6$ \\
\hline \multirow{3}{*}{$\begin{array}{l}\mathrm{BM} \\
(\mathrm{kg})\end{array}$} & ISOK & $79.4 \pm 3.6$ & $78.8 \pm 3.4^{*}$ & $78.9 \pm 3.5$ & $78.8 \pm 3.7$ \\
\hline & CONT & $77.6 \pm 5.1$ & $76.8 \pm 5.1^{*}$ & $77.0 \pm 5.2$ & $76.8 \pm 5.3$ \\
\hline & DCER & $24.4 \pm 2.5$ & $24.0 \pm 2.5$ & $24.1 \pm 2.1$ & $24.3 \pm 2.4$ \\
\hline \multirow[t]{3}{*}{$\mathrm{BF} \%$} & ISOK & $20.6 \pm 2.0$ & $20.5 \pm 2.0$ & $20.2 \pm 2.0$ & $20.4 \pm 1.9$ \\
\hline & CONT & $24.8 \pm 2.9$ & $24.7 \pm 2.9$ & $24.5 \pm 2.8$ & $24.3 \pm 2.8$ \\
\hline & DCER & $30.3 \pm 2.7$ & $30.3 \pm 2.8$ & $30.5 \pm 2.6$ & $30.2 \pm 2.7$ \\
\hline \multirow[t]{3}{*}{$\mathrm{TF} \%$} & ISOK & $25.4 \pm 1.7$ & $25.0 \pm 1.9$ & $24.8 \pm 1.8$ & $25.1 \pm 1.9$ \\
\hline & CONT & $28.1 \pm 2.9$ & $28.3 \pm 2.9$ & $28.7 \pm 2.9$ & $28.0 \pm 2.9$ \\
\hline & DCER & $6570.3 \pm 298.5$ & $6582.1 \pm 300.0$ & $6595.5 \pm 285.9$ & $6494.3 \pm 310.9$ \\
\hline \multirow[t]{3}{*}{ TLM } & ISOK & $7064.5 \pm 284.6$ & $7072.8 \pm 305.6$ & $7046.3 \pm 285.1$ & $7046.3 \pm 360.6$ \\
\hline & CONT & $6329.6 \pm 278.0$ & $6315.9 \pm 260.3$ & $6257.0 \pm 263.7$ & $6310.8 \pm 254.3$ \\
\hline & DCER & $152.1 \pm 9.5$ & $150.9 \pm 12.4$ & $148.7 \pm 12.1$ & $151.0 \pm 11.3$ \\
\hline \multirow[t]{2}{*}{ TMCSA } & ISOK & $171.0 \pm 9.6$ & $173.4 \pm 10.2$ & $170.1 \pm 9.9$ & $175.4 \pm 11.3$ \\
\hline & CONT & $151.4 \pm 9.9$ & $151.8 \pm 8.4$ & $153.0 \pm 9.3$ & $153.8 \pm 7.8$ \\
\hline
\end{tabular}

$\mathrm{BM}=$ body mass $; \mathrm{BF} \%=$ body fat percentage; $\mathrm{TF} \%=$ thigh fat percentage; $\mathrm{TLM}-$ thigh lean mass; TMCSA = thigh muscle cross-sectional area; ; ISOK = isokinetic; $\mathrm{CONT}=$ control

*Denotes significant change from pre- to post-assessment 1 
Table 4. Means $( \pm \mathrm{SE})$ for isokinetic strength testing.

\begin{tabular}{|c|c|c|c|c|c|c|c|}
\hline \multirow{13}{*}{$\begin{array}{c}\mathrm{PT} \\
(\mathrm{N} \cdot \mathrm{m})\end{array}$} & & & & $\begin{array}{l}\text { Pre-Training } \\
\text { Assessment } 1\end{array}$ & $\begin{array}{l}\text { Post-Training } \\
\text { Assessment } 1\end{array}$ & $\begin{array}{l}\text { Post-Training } \\
\text { Assessment } 2 \\
\end{array}$ & $\begin{array}{c}\text { Post- Training } \\
\text { Assessment } 3\end{array}$ \\
\hline & \multirow{4}{*}{ DCER } & \multirow{2}{*}{ Right } & $90^{\circ} \cdot \mathrm{s}^{-1}$ & $184.0 \pm 11.4$ & $188.3 \pm 13.1$ & $185.3 \pm 11.0$ & $186.4 \pm 10.2$ \\
\hline & & & $180^{\circ} \cdot \mathrm{s}^{-1}$ & $131.5 \pm 10.1$ & $139.2 \pm 11.6$ & $133.9 \pm 11.8$ & $142.1 \pm 8.4$ \\
\hline & & \multirow{2}{*}{ Left } & $90^{\circ} \cdot \mathrm{s}^{-1}$ & $173.0 \pm 11.7$ & $168.1 \pm 13.7$ & $171.9 \pm 13.5$ & $168.3 \pm 12.3$ \\
\hline & & & $180^{\circ} \cdot \mathrm{s}^{-1}$ & $131.8 \pm 10.0$ & $133.7 \pm 12.1$ & $137.2 \pm 11.9$ & $133.3 \pm 13.4$ \\
\hline & \multirow{4}{*}{ ISOK } & \multirow{2}{*}{ Right } & $90^{\circ} \cdot \mathrm{s}^{-1}$ & $196.1 \pm 13.3$ & $207.0 \pm 13.7$ & $197.9 \pm 14.5$ & $200.8 \pm 15.2$ \\
\hline & & & $180^{\circ} \cdot \mathrm{s}^{-1}$ & $136.9 \pm 8.1$ & $154.0 \pm 9.3$ & $145.5 \pm 9.7$ & $184.7 \pm 11.6$ \\
\hline & & \multirow{2}{*}{ Left } & $90^{\circ} \cdot \mathrm{s}^{-1}$ & $187.0 \pm 10.6$ & $185.1 \pm 12.5$ & $183.1 \pm 11.3$ & $145.6 \pm 10.5$ \\
\hline & & & $180^{\circ} \cdot \mathrm{s}^{-1}$ & $141.5 \pm 8.1$ & $144.2 \pm 7.6$ & $139.5 \pm 7.5$ & $144.8 \pm 7.2$ \\
\hline & \multirow{4}{*}{ CONT } & \multirow{2}{*}{ Right } & $90^{\circ} \cdot \mathrm{s}^{-1}$ & $159.6 \pm 9.2$ & $159.1 \pm 10.5$ & $152.9 \pm 11.6$ & $155.2 \pm 9.5$ \\
\hline & & & $180^{\circ} \cdot \mathrm{s}^{-1}$ & $127.9 \pm 7.9$ & $128.7 \pm 11.9$ & $114.6 \pm 8.5$ & $121.8 \pm 7.9$ \\
\hline & & \multirow{2}{*}{ Left } & $90^{\circ} \cdot \mathrm{s}^{-1}$ & $157.8 \pm 9.6$ & $146.5 \pm 8.9$ & $139.2 \pm 7.4$ & $134.7 \pm 4.9$ \\
\hline & & & $180^{\circ} \cdot \mathrm{s}^{-1}$ & $124.3 \pm 7.2$ & $125.2 \pm 9.4$ & $117.8 \pm 9.5$ & $116.6 \pm 6.8$ \\
\hline
\end{tabular}

$\mathrm{PT}=$ peak torque; DCER $=$ dynamic constant external resistance; $\mathrm{ISOK}=$ isokinetic; $\mathrm{CONT}=$ control

*Denotes significant change from pre-assessment 
Table 5. Means ( \pm SE) for dynamic constant external resistance 1-RM.

\begin{tabular}{|c|c|c|c|c|c|c|}
\hline & & & $\begin{array}{l}\text { Pre-Training } \\
\text { Assessment } 1\end{array}$ & $\begin{array}{l}\text { Post-Training } \\
\text { Assessment } 1\end{array}$ & $\begin{array}{l}\text { Post-Training } \\
\text { Assessment } 2\end{array}$ & $\begin{array}{l}\text { Post-Training } \\
\text { Assessment } 3\end{array}$ \\
\hline \multirow{6}{*}{$\begin{array}{l}1 \mathrm{RM} \\
(\mathrm{kg})\end{array}$} & \multirow{2}{*}{ DCER } & Right & $43.2 \pm 2.7$ & $52.4 \pm 3.4^{*}$ & $50.3 \pm 3.1 *$ & $50.8 \pm 3.0^{*}$ \\
\hline & & Left & $42.3 \pm 2.5$ & $48.93 .8^{*}$ & $48.93 .5^{*}$ & $48.93 .2 *$ \\
\hline & \multirow{2}{*}{ ISOK } & Right & $46.4 \pm 4.2$ & $49.5 \pm 4.3$ & $49.7 \pm 4.3$ & $48.0 \pm 4.7$ \\
\hline & & Left & $45.5 \pm 4.0$ & $47.7 \pm 4.0$ & $48.4 \pm 4.1$ & $46.5 \pm 4.0$ \\
\hline & \multirow{2}{*}{ CONT } & Right & $40.5 \pm 2.3$ & $40.8 \pm 2.1$ & $40.7 \pm 2.3$ & $41.7 \pm 1.7$ \\
\hline & & Left & $40.7 \pm 2.3$ & $40.3 \pm 2.2$ & $40.2 \pm 2.3$ & $41.1 \pm 1.8$ \\
\hline
\end{tabular}

$1 \mathrm{RM}=1$ repetition maximum; DCER = dynamic constant external resistance; ISOK = isokinetic; CONT $=$ control

*Denotes significant change from pre- to post-assessment 1 
Table 6. Means ( \pm SE) for isometric maximal voluntary contraction. Pre-Training Post-Training Post-Training Post-Training Assessment 1 Assessment 1 Assessment 2 Assessment 3

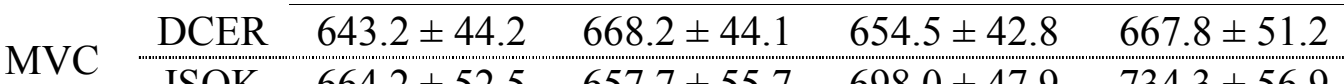

$\begin{array}{lllllll}\text { (N) } & \text { ISOK } & 664.2 \pm 52.5 & 657.7 \pm 55.7 & 698.0 \pm 47.9 & 734.3 \pm 56.9\end{array}$

(N) $\quad \begin{array}{llllll}\text { CONT } & 463.3 \pm 32.9 & 479.4 \pm 35.6 & 493.7 \pm 28.6 & 502.8 \pm 27.9\end{array}$

$1 \mathrm{RM}=1$ repetition maximum; DCER $=$ dynamic constant external resistance;

$\mathrm{ISOK}=$ isokinetic $; \mathrm{CONT}=$ control; $\mathrm{MVC}=$ maximal voluntary contraction 
Table 7. Means $( \pm \mathrm{SE})$ for mechanomyographic amplitude.

\begin{tabular}{|c|c|c|c|c|c|c|}
\hline & & & $\begin{array}{l}\text { Pre-Training } \\
\text { Assessment } 1\end{array}$ & $\begin{array}{l}\text { Post-Training } \\
\text { Assessment } 1 \\
\end{array}$ & $\begin{array}{l}\text { Post-Training } \\
\text { Assessment } 2 \\
\end{array}$ & $\begin{array}{l}\text { Post-Training } \\
\text { Assessment } 3 \\
\end{array}$ \\
\hline \multirow{4}{*}{ DCER } & \multirow{2}{*}{$\mathrm{RF}$} & $90^{\circ} \cdot \mathrm{s}^{-1}$ & $3.2 \pm 0.7$ & $3.4 \pm 0.7$ & $2.8 \pm 0.6$ & $2.9 \pm 0.6$ \\
\hline & & $180^{\circ} \cdot \mathrm{s}^{-1}$ & $7.5 \pm 1.7$ & $8.0 \pm 1.6$ & $7.8 \pm 2.1$ & $7.8 \pm 2.4$ \\
\hline & \multirow{2}{*}{ VL } & $90^{\circ} \cdot \mathrm{s}^{-1}$ & $2.6 \pm 0.4$ & $3.2 \pm 0.6$ & $2.9 \pm 0.5$ & $2.9 \pm 0.6$ \\
\hline & & $180^{\circ} \cdot \mathrm{s}^{-1}$ & $5.3 \pm 1.2$ & $5.8 \pm 1.2$ & $6.6 \pm 1.3$ & $5.3 \pm 0.9$ \\
\hline \multirow{4}{*}{ ISOK } & \multirow{2}{*}{$\mathrm{RF}$} & $90^{\circ} \cdot \mathrm{s}^{-1}$ & $2.3 \pm 0.2$ & $2.1 \pm 0.7$ & $2.9 \pm 1.1$ & $2.2 \pm 0.4$ \\
\hline & & $180^{\circ} \cdot \mathrm{s}^{-1}$ & $5.7 \pm 1.1$ & $5.1 \pm 1.1$ & $5.4 \pm 1.3$ & $5.8 \pm 1.2$ \\
\hline & \multirow{2}{*}{ VL } & $90^{\circ} \cdot \mathrm{s}^{-1}$ & $3.5 \pm 1.2$ & $3.1 \pm 0.5$ & $3.5 \pm 0.8$ & $3.2 \pm 0.6$ \\
\hline & & $180^{\circ} \cdot \mathrm{s}^{-1}$ & $7.3 \pm 2.4$ & $6.8 \pm 2.1$ & $5.8 \pm 1.2$ & $6.0 \pm 1.6$ \\
\hline \multirow{4}{*}{ CONT } & \multirow{2}{*}{ RF } & $90^{\circ} \cdot \mathrm{s}^{-1}$ & $2.4 \pm 0.4$ & $2.3 \pm 0.4$ & $2.3 \pm 0.6$ & $4.3 \pm 1.6$ \\
\hline & & $180^{\circ} \cdot \mathrm{s}^{-1}$ & $5.8 \pm 2.1$ & $5.6 \pm 1.7$ & $5.6 \pm 1.4$ & $5.6 \pm 1.4$ \\
\hline & \multirow{2}{*}{ VL } & $90^{\circ} \cdot \mathrm{s}^{-1}$ & $4.2 \pm 0.7$ & $3.0 \pm 0.3$ & $3.2 \pm 0.8$ & $4.3 \pm 1.2$ \\
\hline & & $180^{\circ} \cdot \mathrm{s}^{-1}$ & $7.4 \pm 1.8$ & $8.5 \pm 2.3$ & $7.8 \pm 1.6$ & $6.0 \pm 1.0$ \\
\hline
\end{tabular}

$\mathrm{RF}=$ rectus femoris; $\mathrm{VL}=$ vastus lateralis; $\mathrm{DCER}=$ dynamic constant external resistance; $\mathrm{ISOK}=$ isokinetic; $\mathrm{CONT}=$ control 
Table 8. Means $( \pm \mathrm{SE})$ for electromechanical delay.

\begin{tabular}{cccccc}
\hline & & Pre-Assessment 1 & Post-Assessment 1 & Post-Assessment 2 & Post-Assessment 3 \\
\cline { 3 - 5 } EMD & DCER & $4.4 \pm 0.3$ & $4.5 \pm 0.1$ & $4.8 \pm 0.2$ & $4.7 \pm 0.4$ \\
\cline { 3 - 5 }$(\mathrm{ms})$ & ISOK & $4.5 \pm 0.3$ & $4.5 \pm 0.4$ & $4.3 \pm 0.1$ & $4.1 \pm 0.2$ \\
\hline & CONT & $4.6 \pm 0.4$ & $5.2 \pm 0.5$ & $4.3 \pm 0.2$ & $4.7 \pm 0.2$ \\
\hline
\end{tabular}

$1 \mathrm{RM}=1$ repetition maximum; DCER $=$ dynamic constant external resistance; $\mathrm{ISOK}=$ isokinetic; $\mathrm{CONT}=$ control; EMD = electromechanical delay 


\section{APPENDIX B:}

\section{FIGURES}

Figure 1. Study design flowchart.

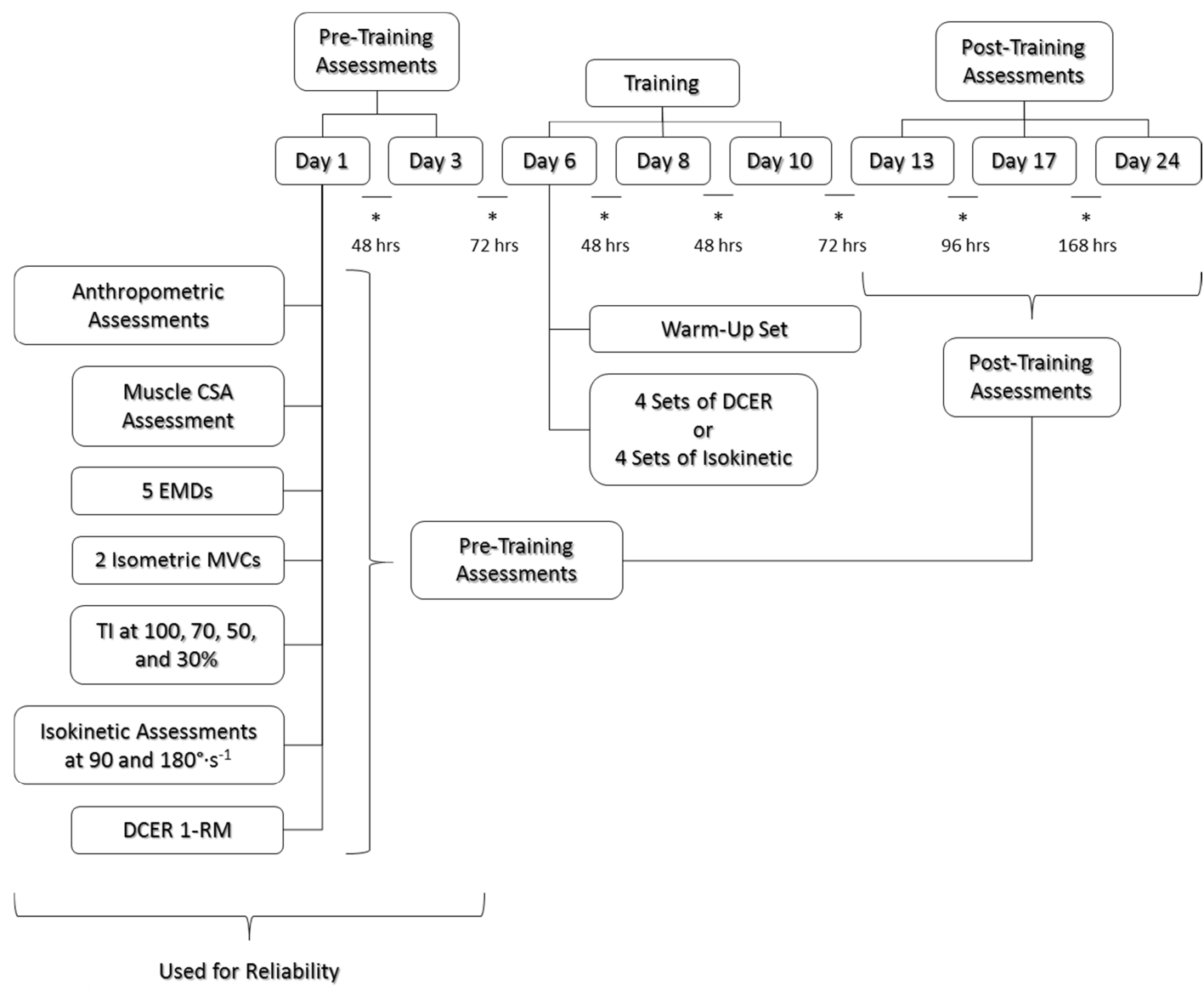


Figure 2. Region of interest around the right thigh.

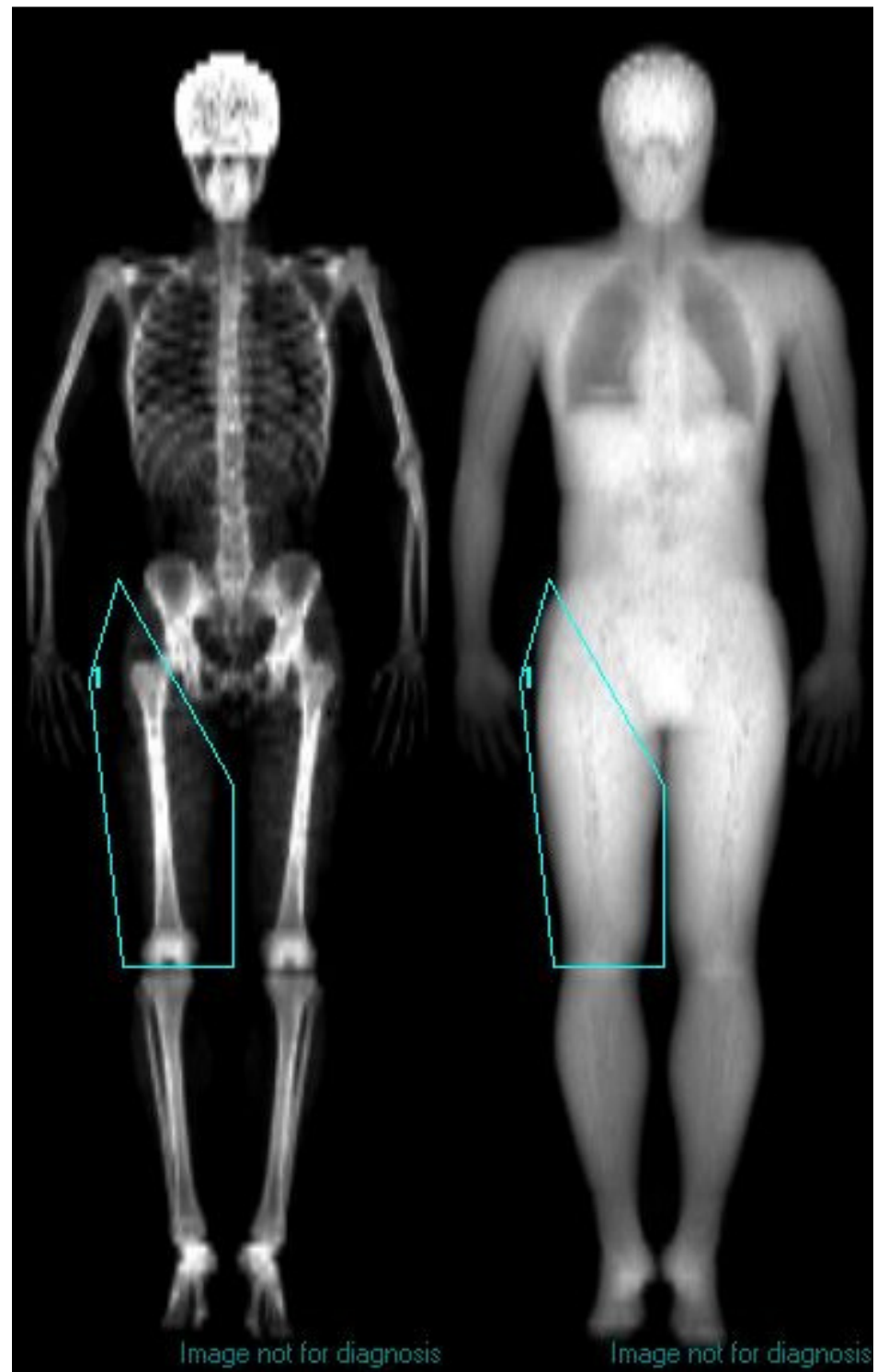


Figure 3. Isokinetic assessment set-up.

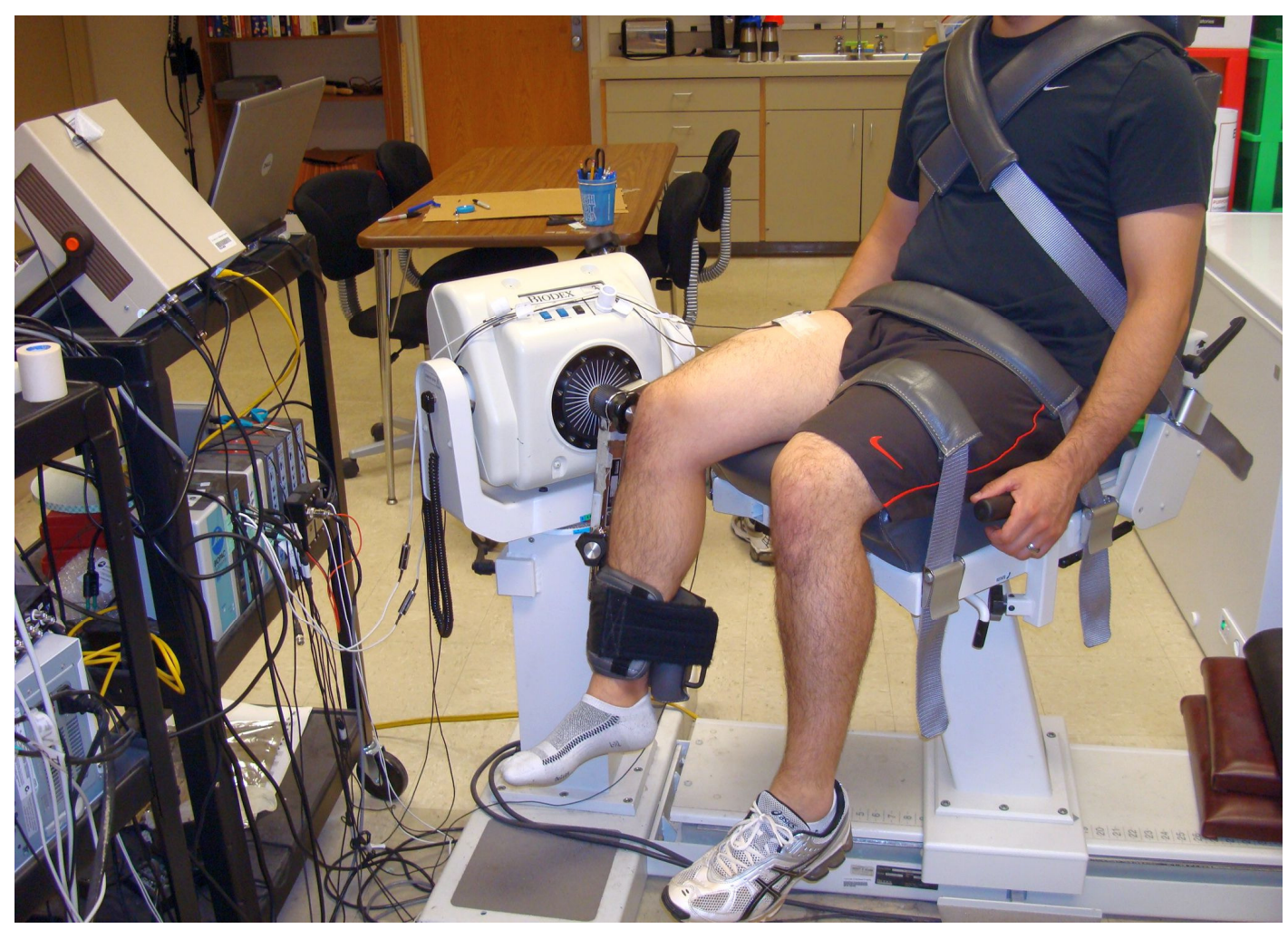


Figure 4. Dynamic constant external resistance assessment set-up.

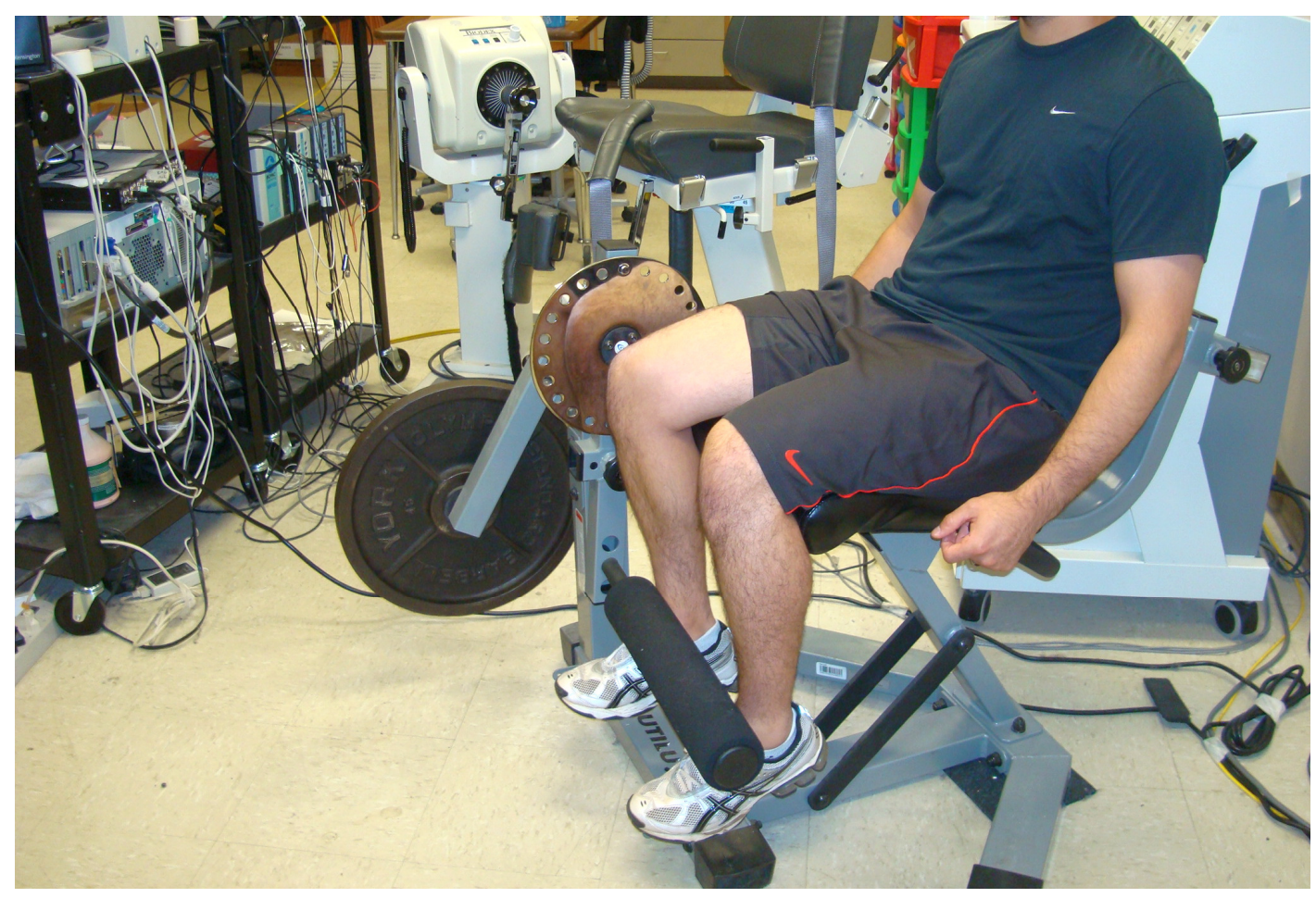


Figure 5. Electromyography electrodes and mechanomyography accelerometers placements.

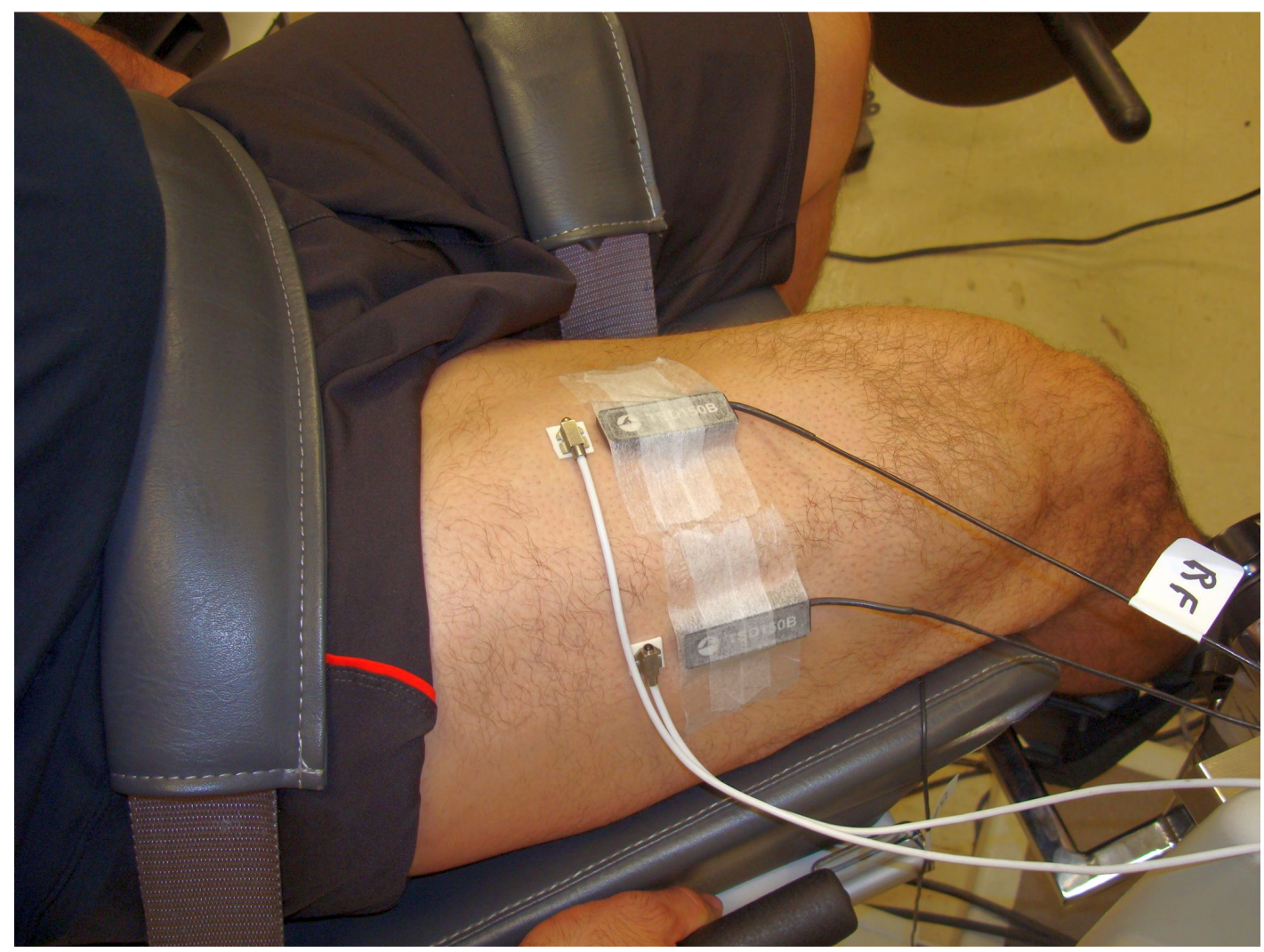


Figure 6. Isometric force assessment set-up.

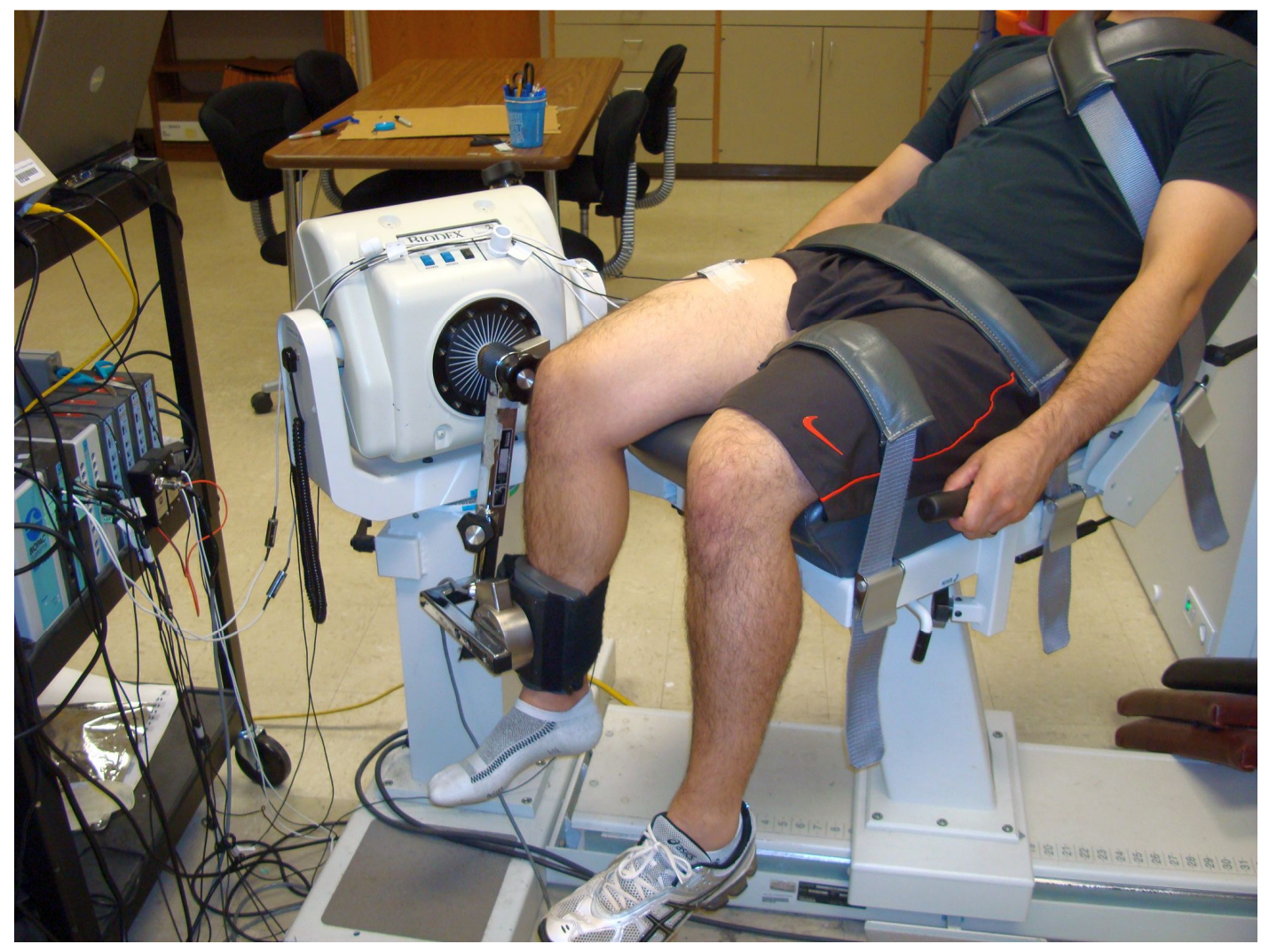


Figure. 7. Category-Ratio scale rating of perceived exertion.

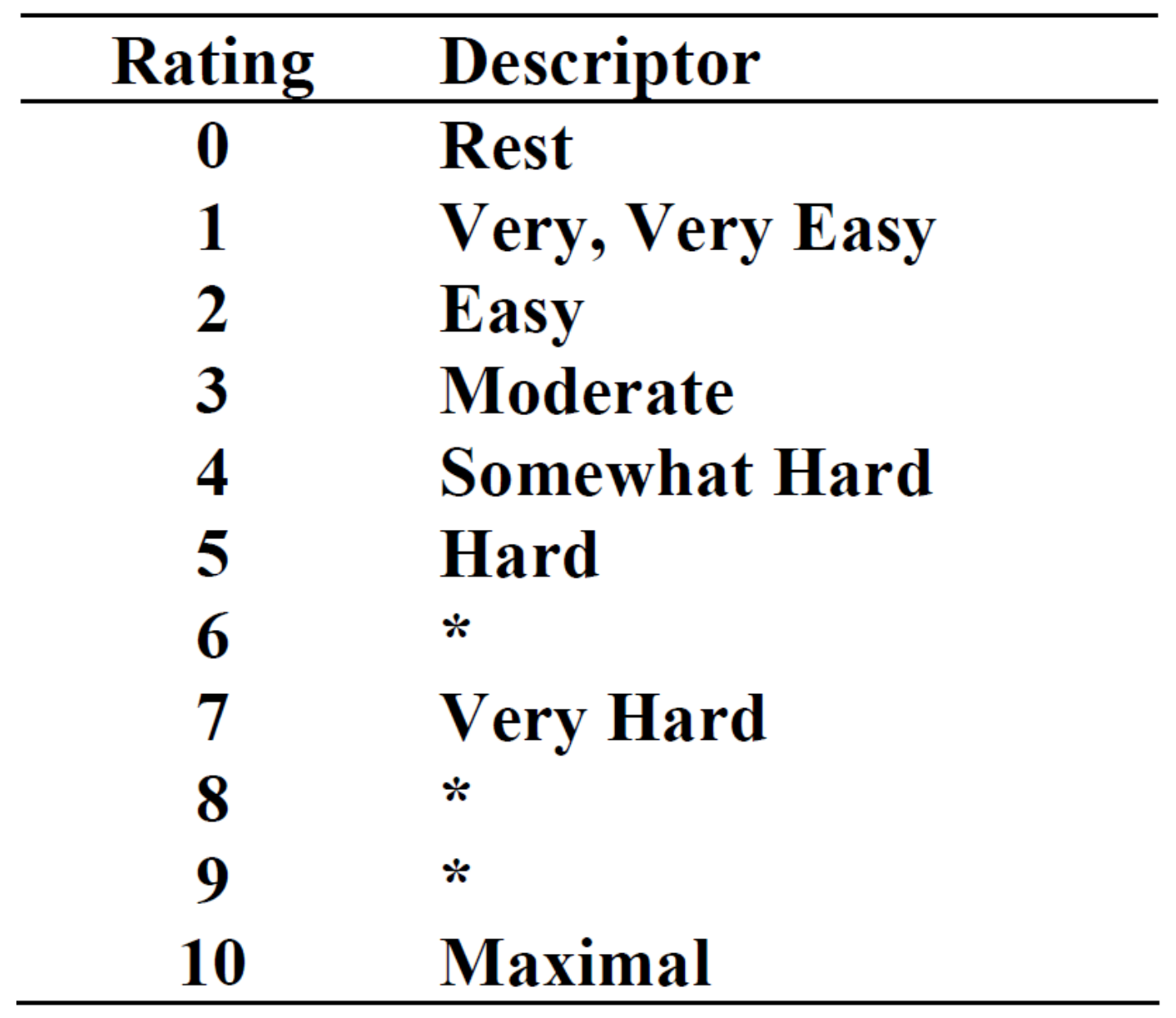


Figure 8. Means of percent change for leg extension isokinetic PT for the right (A) and left (B) leg at $90^{\circ} \cdot \mathrm{s}^{-1}$.

DCER $=$ dynamic constant external resistance; $\mathrm{ISOK}=$ isokinetic $;$ CONT $=$ control

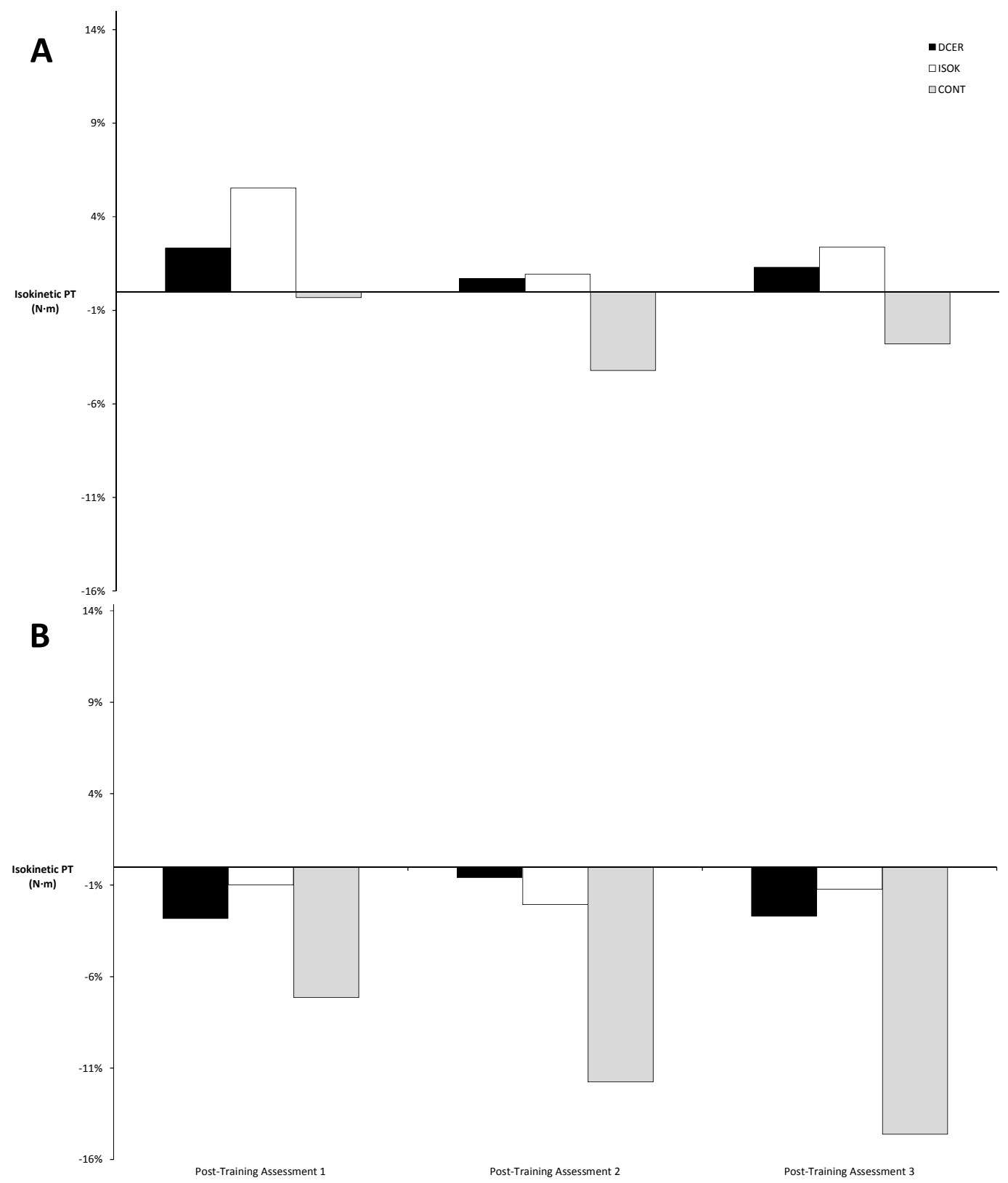


Figure 9. Means of percent change for leg extension isokinetic PT for the right (A) and left (B) leg at $180^{\circ} \cdot \mathrm{s}^{-1}$.

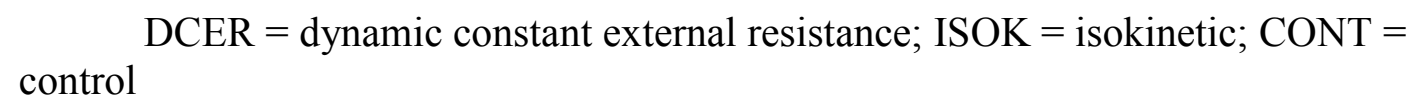$$
\text { DCER }=\text { dynamic constant external resistance; } \text { ISOK }=\text { isokinetic; } \text { CONT }=
$$
control

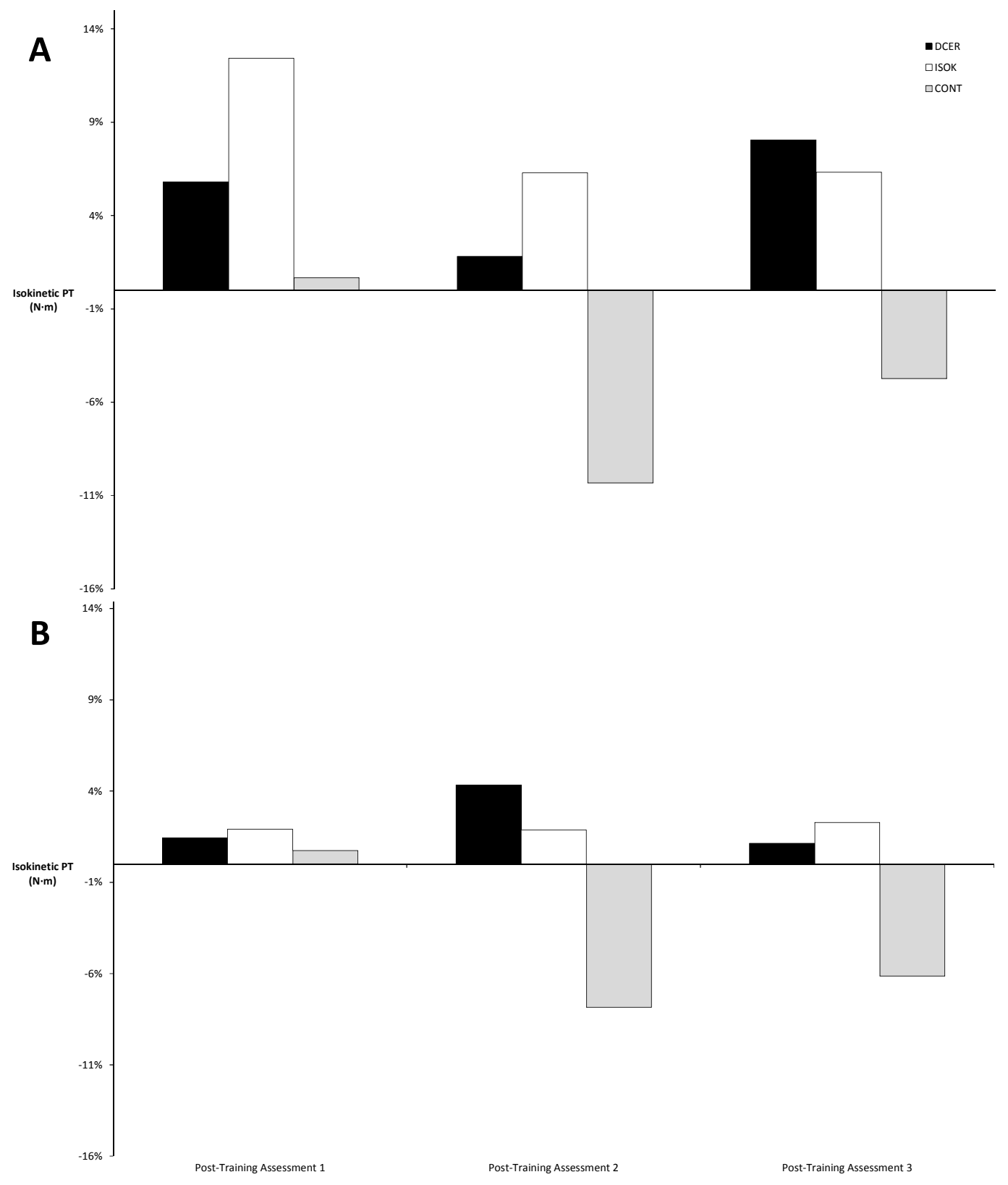


Figure 10. Mean $( \pm \mathrm{SE})$ isokinetic peak torque $(\mathrm{N} \cdot \mathrm{m})$ collapsed across time, group, and velocity.

*Denotes significant difference between legs

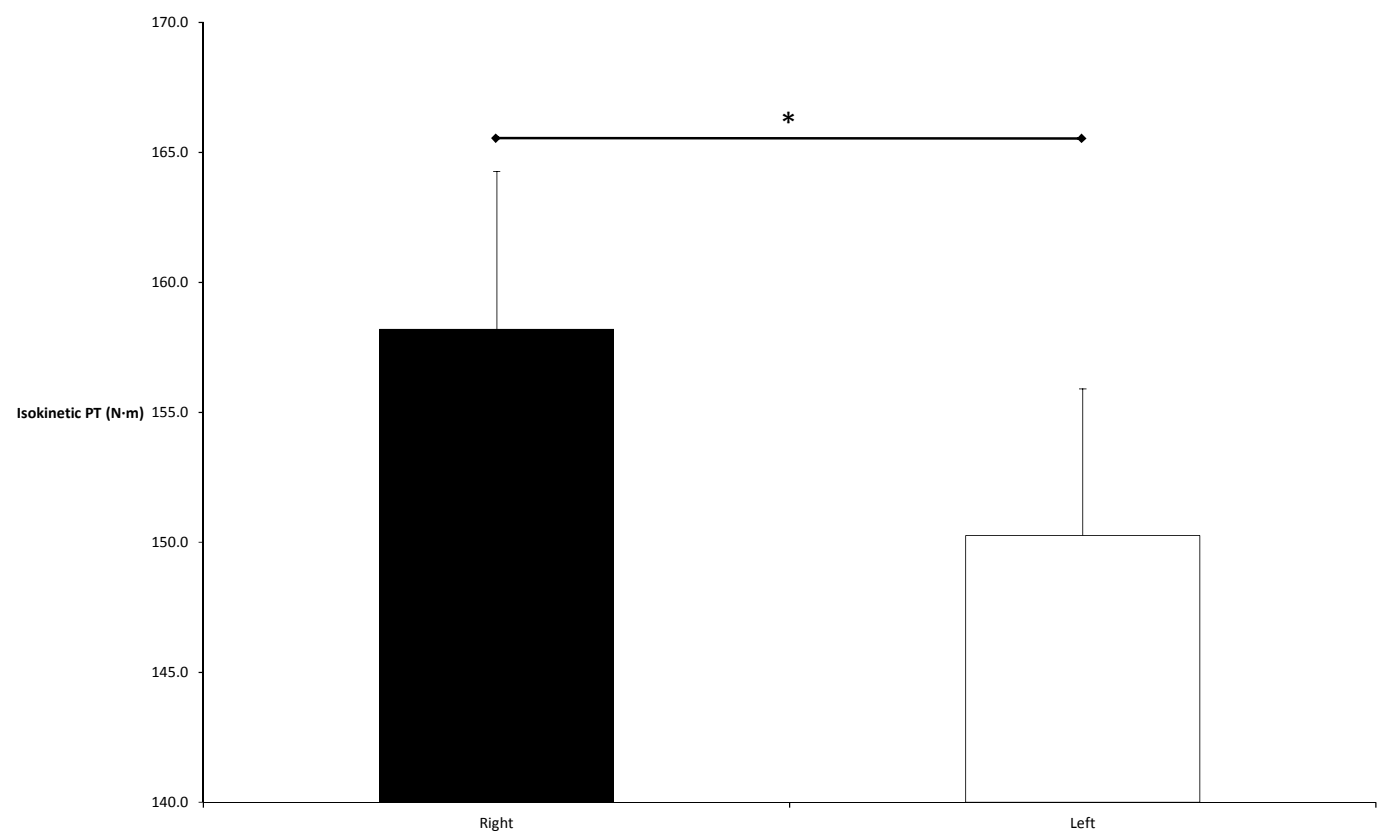


Figure 11. Means $( \pm \mathrm{SE})$ isokinetic peak torque $(\mathrm{N} \cdot \mathrm{m})$ collapsed across time, group, and limb.

*Denotes significant difference between velocities

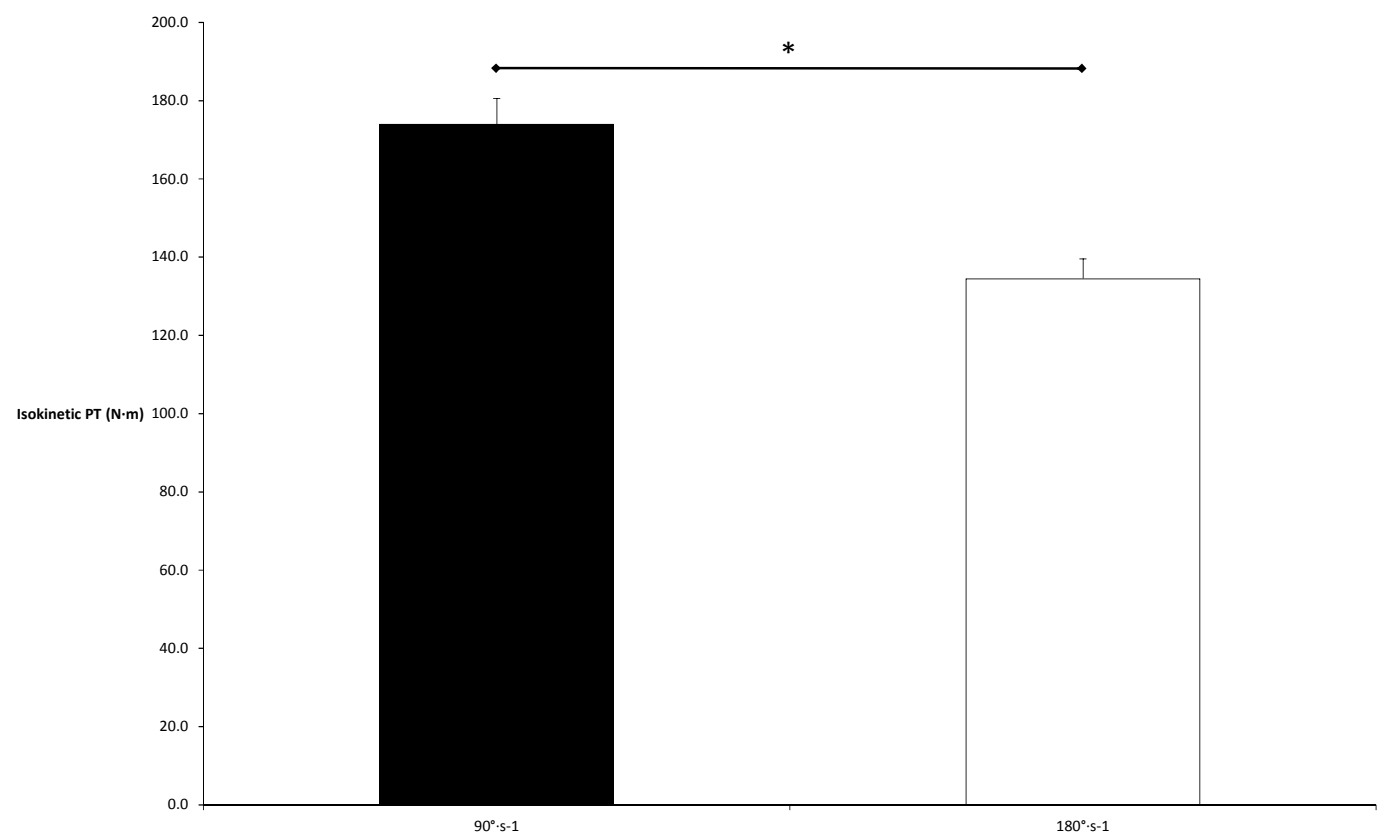


Figure 12. Means of percent change for leg extension (kg) 1-RM for the right (A) and left (B) leg.

* Denotes significant difference from the pre-test for the DCER group

DCER $=$ dynamic constant external resistance; $\mathrm{ISOK}=$ isokinetic $;$ CONT $=$ control

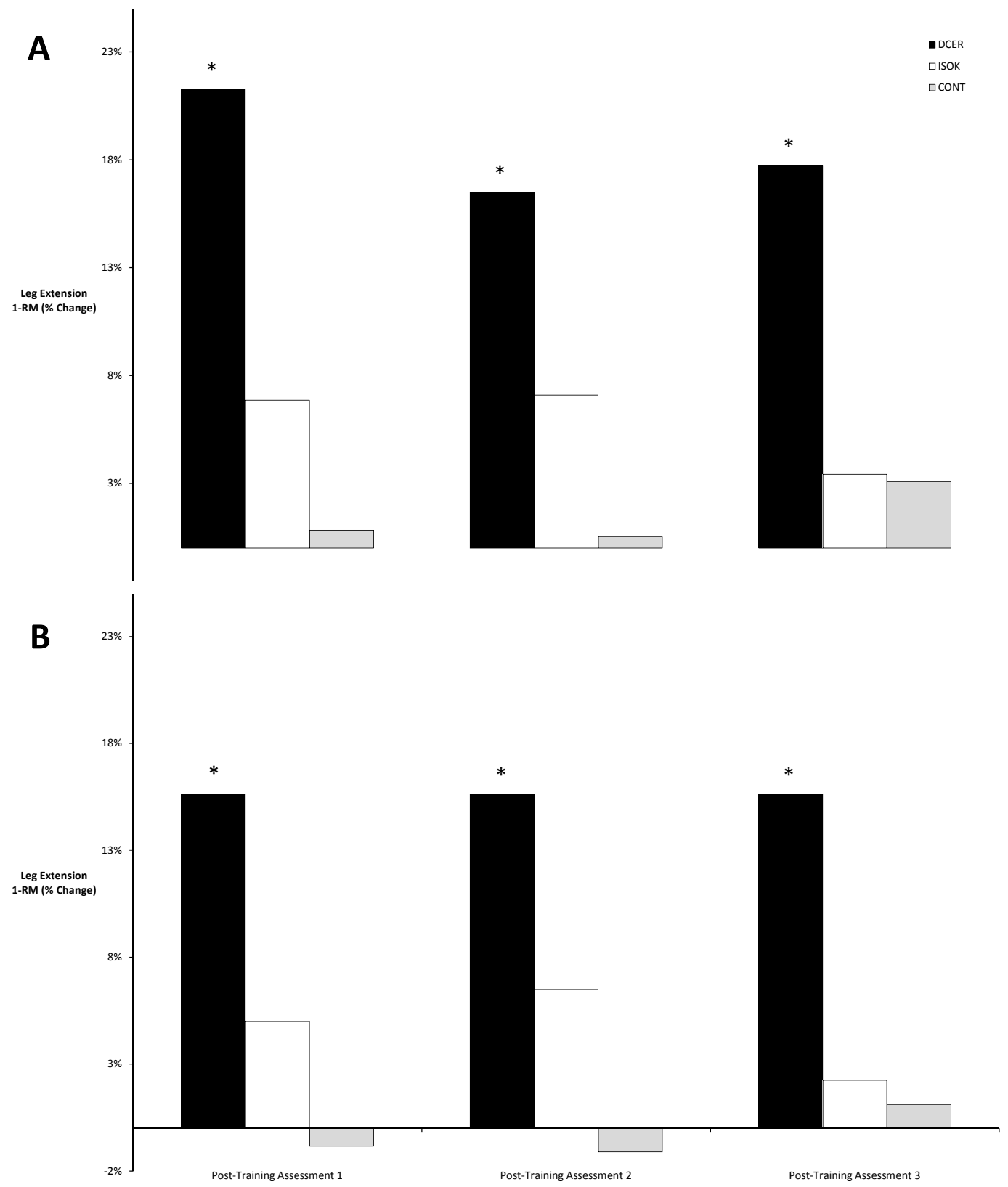


Figure 13. Means ( \pm SE) for electromyographic amplitude collapsed across quadriceps muscles, group, and time.

*Denotes significant difference between velocities
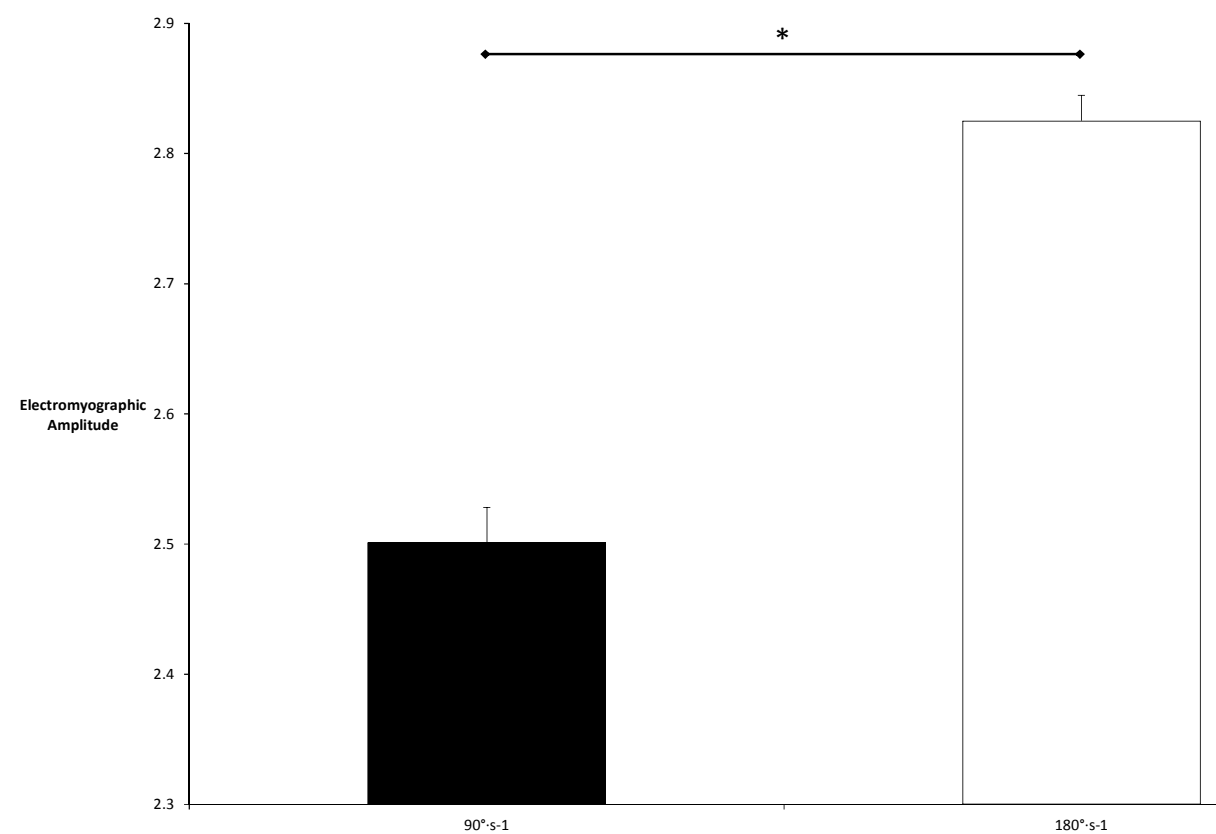
Figure 14. Mean $( \pm \mathrm{SE})$ for electromyographic amplitude collapsed groups and velocities for the BF muscles.

*Denotes significant difference between tests

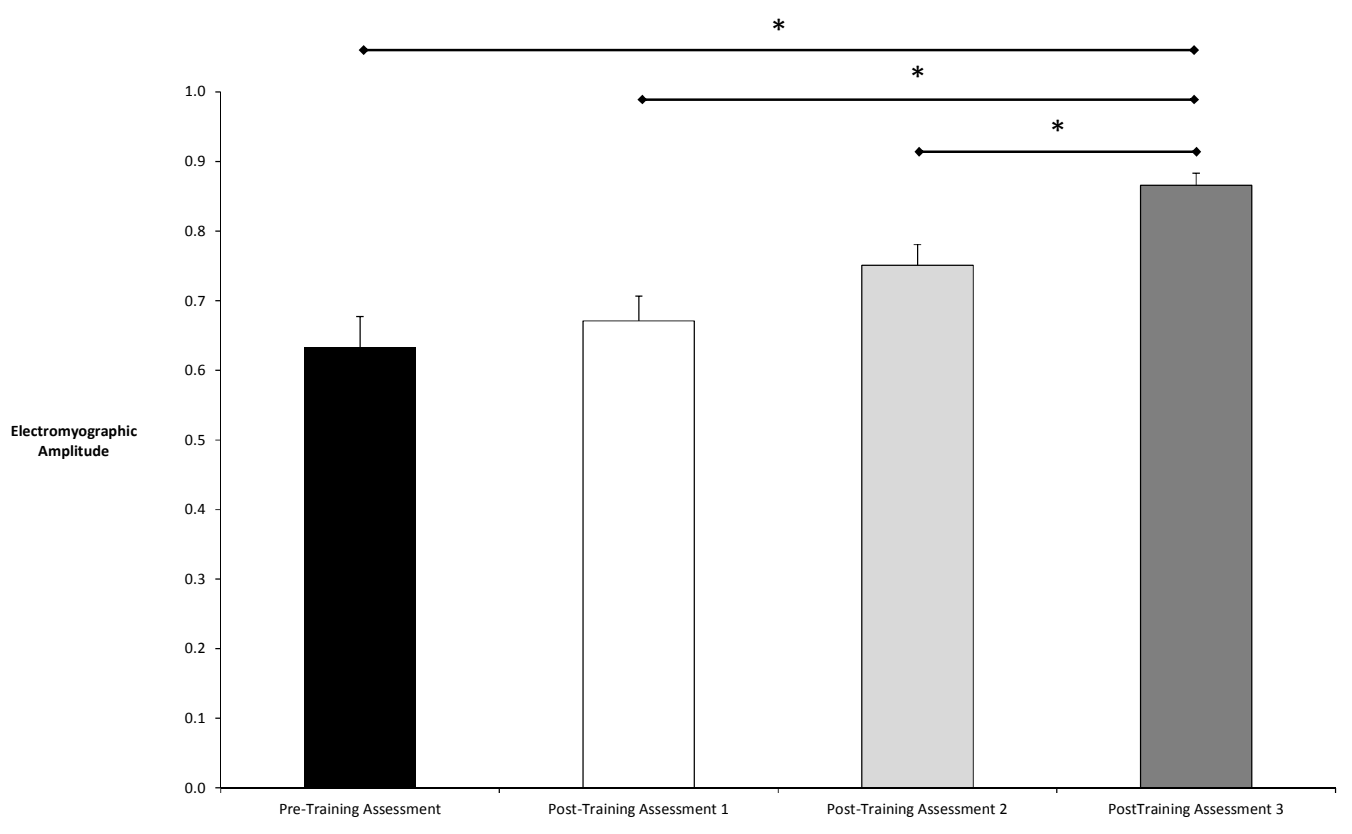


Figure 15. Mean $( \pm \mathrm{SE})$ for electromyographic amplitude collapsed across group and time for the BF muscles.

*Denotes significant difference between velocities

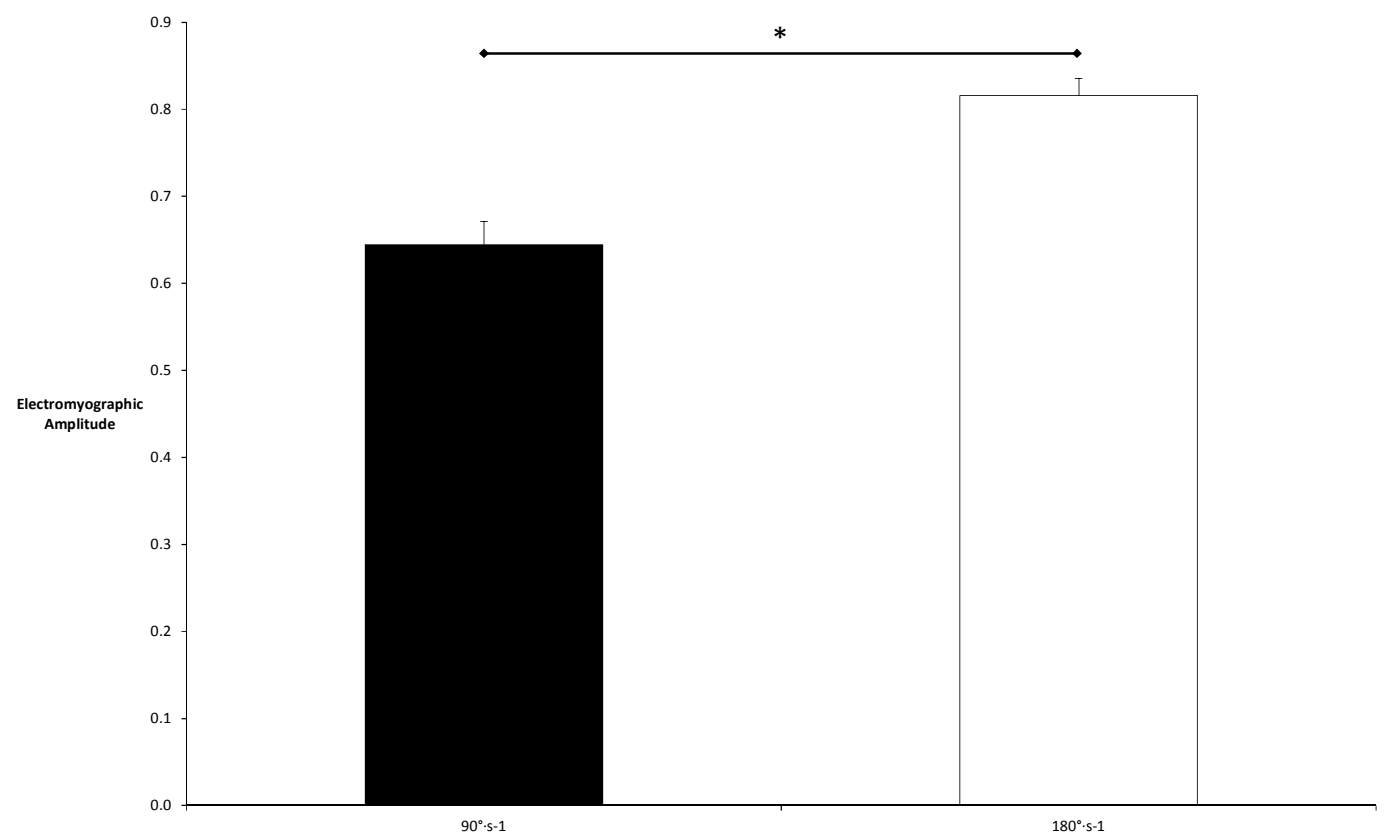


Figure 16. Mean $( \pm \mathrm{SE})$ for voluntary activation collapsed across group and time. *Denotes significant difference between percentages of maximum voluntary contraction

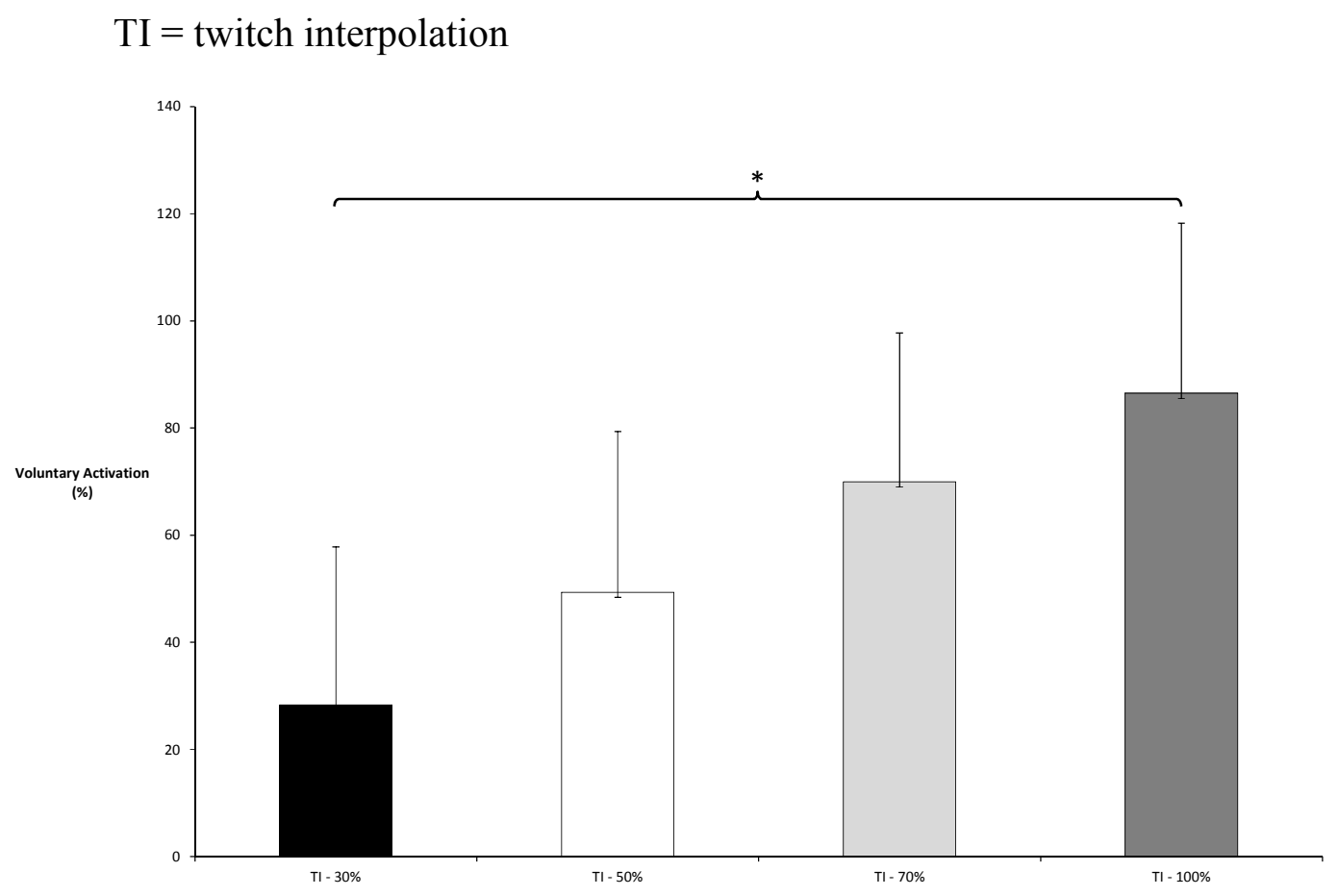


Figure 17. Mean $( \pm \mathrm{SE})$ for set rating of perceived exertion collapsed across both training groups.

* Denotes significant change over sets within each training session

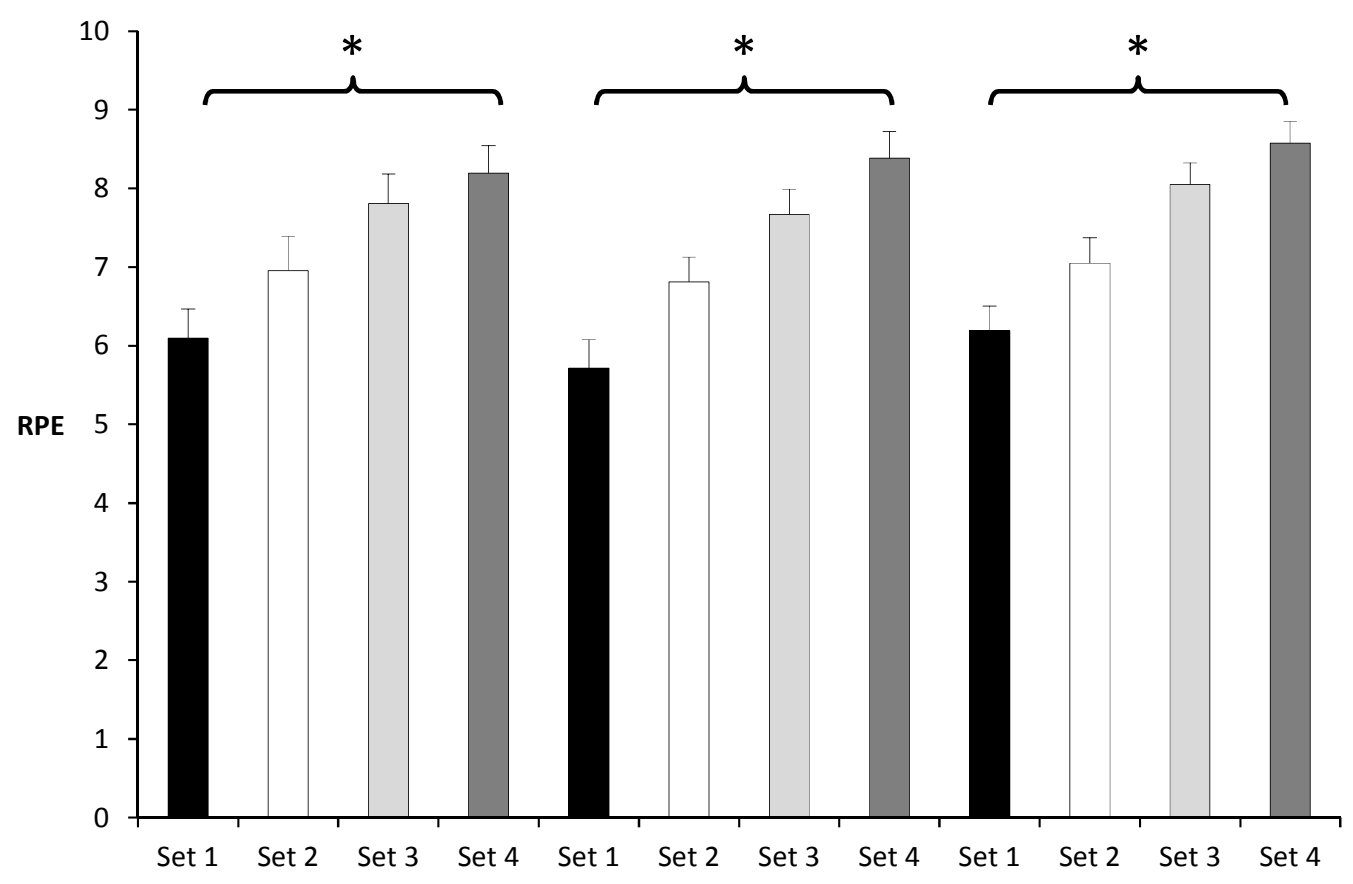


Figure 18. Mean ( \pm SE) for session rating of perceived exertion collapsed across both training groups.

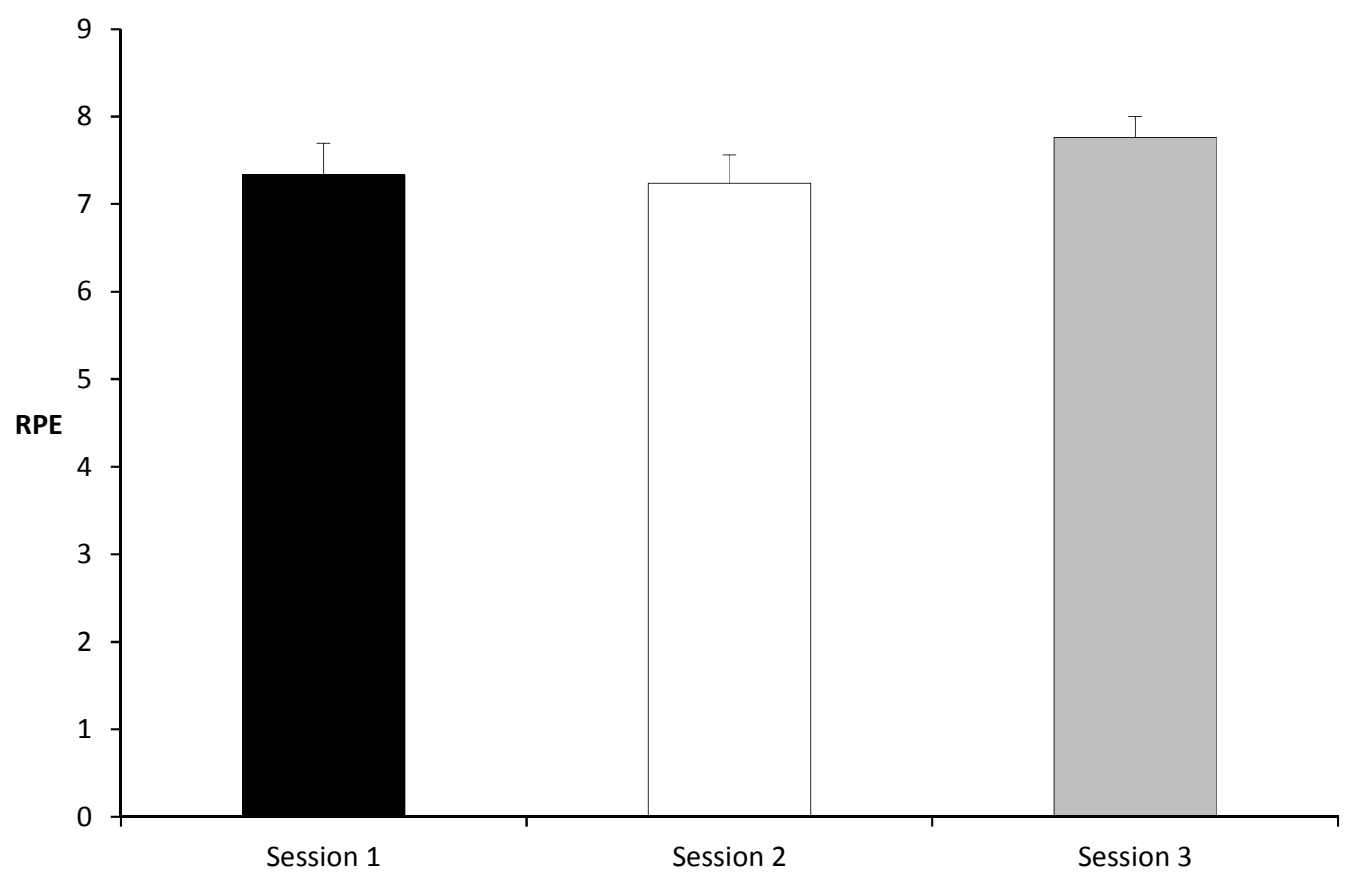




\title{
University of Oklahoma Institutional Review Board Informed Consent to Participate in a Research Study
}

\author{
Project Title: The effects of short-term resistance training and subsequent \\ detraining on neuromuscular performance \\ Principal Investigator: Pablo B. Costa, M.S. \\ Department: Health and Exercise Science
}

You are being asked to volunteer for this research study. This study is being conducted at the University of Oklahoma, Biophysics Laboratory. You were selected as a possible participant because you met the criteria of a healthy, sedentary or minimally-active adult between the ages of 18 and 35 years.

Please read this form and ask any questions that you may have before agreeing to take part in this study.

\section{Purpose of the Research Study}

The purpose of this study is to examine the effects of three days of resistance training on quadriceps muscle strength, neuromuscular function, and muscle size.

\section{Number of Participants}

About 60 people will take part in this study.

\section{Procedures}

If you agree to be in this study, you will be asked to do the following:

1. Fill out a PRE-EXERCISE TESTING HEALTH \& EXERCISE STATUS QUESTIONNAIRE, which may determine your ability to participate in this study.

2. Sign and date an Informed consent document (this document) indicating you understand all procedures and your rights as a research subject.

3. Set a schedule for 7 (five) additional laboratory visits. The visits will be in the Department of Health and Exercise Science Biophysics Lab (this lab).

4. You will lie down and your body composition will be assessed using a Dual-Energy X-ray Absorptiometry (DEXA). One scan will be performed per testing visit and each test will take about 10 minutes to complete. The DEXA scan results in $\mathrm{x}$-ray exposure that is similar to the radiation exposure Americans receive in several days from natural background radiation (being in the sun and radioactivity in the soil). The DEXA is essentially a padded table with a mechanical arm that uses low-dose radiation to measure bone mineral density. The "arm" of the DEXA will slowly move over your body, without contact. This test will be used to assess total bone mineral density and upper and lower body muscle mass. You will be required to wear either a bathing suit or tight-fitting clothing, such as Spandex, during this test.

5. Skinfold and circumference measurements of the dominant leg will be taken using skinfold calipers and metric tape.

6. Leg volume will be measured by placing your leg in a water-filled container. 
1. Sensors will be taped to your skin over areas that have been shaved and cleaned with alcohol during the laboratory visit.

2. A third electrode for nerve stimulation will be placed on the front of the hip area. This stimulation electrode may be stimulated up to 50 times.

3. Your quadriceps muscles will be electrically stimulated while performing isometric contractions where you will be kicking against an immovable lever.

4. You will perform 18-20 maximal muscle contractions for the quadriceps. You will be given several rest periods to avoid fatigue.

5. You will be randomly assigned to one of the two training groups or a control group. Training consists of leg extension exercises typically seen at a gym or physical therapy facility.

6. If assigned to a training group, you will take part in 3 training sessions. A training session consists of a warm-up and 4 sets of 10 repetitions in each day of leg extension exercise similar to what is seen at a gym or physical therapy facility.

7. On 3 separate visits, after the training program ends, you'll be asked to repeat the same tests (previously described in numbers 4 through 9 above).

\section{Length of Participation}

Your participation in the study will take place over the course of 24 days. You will visit the laboratory on 8 occasions (only 5 if assigned to the control group), separated by 2-7 days. The first 2 visits will be for pre-testing. The next 3 visits will be for training sessions and the last 3 visits will be for post-testing. Each training visit will last about 30 minutes and each testing sessions will last about 90 minutes.

This study has the following risks:

This study has the following risks: Possible muscle strain or injury during testing. Repeated muscle contractions may also lead to muscle soreness. There is a possibility that surface sensors may leave a minor abrasion on the skin's surface. Your physical risks will be minimized by having each testing session conducted by the qualified investigators. All testing procedures will be done in a controlled manner. All additional research staff members directly involved with testing of the subjects are familiar with the American College of Sports Medicine standards and protocols for exercise testing and emergency management.

This research study involves exposure to radiation from (5) DEXA scans, which is a type of $x$-ray procedure. This radiation is not necessary for medical care and is for research purposes only. You will receive radiation exposure of less than $2 \mathrm{mrem}$ from each scan and a total dose of (10 mrem), which is less than the radiation received in 12 days from natural background radiation ( $300 \mathrm{mrem} / \mathrm{yr})$, such as naturally occurring radioactivity in soil. Any risk from this amount of radiation is too small to measure directly, and is small when compared to every day risks. Although the amount of radiation you will receive in this study is minimal, it is important for you to be aware that the risk from radiation exposure is cumulative over your life time.

\section{Benefits of being in the study are}

None. 


\section{Injury}

In case of injury or illness resulting from this study, emergency medical treatment is available. However, you or your insurance company may be expected to pay the usual charge from this treatment. The University of Oklahoma Norman Campus has set aside no funds to compensate you in the event of injury.

\section{Confidentiality}

In published reports, there will be no information included that will make it possible to identify you without your permission. Research records will be stored securely and only approved researchers will have access to the records.

There are organizations that may inspect and/or copy your research records for quality assurance and data analysis. These organizations include the OU Institutional Review Board.

\section{Compensation}

You will not be reimbursed for you time and participation in this study.

\section{Voluntary Nature of the Study}

Participation in this study is voluntary. If you withdraw or decline participation, you will not be penalized or lose benefits or services unrelated to the study. If you decide to participate, you may decline to answer any question and may choose to withdraw at any time.

\section{Contacts and Questions}

If you have concerns or complaints about the research, the researcher(s) conducting this study can be contacted at 405-325-1368 or via email: pcosta@ou.edu or jcramer@ou.edu.

Contact the researcher(s) if you have questions or if you have experienced a research-related injury.

If you have any questions about your rights as a research participant, concerns, or complaints about the research and wish to talk to someone other than individuals on the research team or if you cannot reach the research team, you may contact the University of Oklahoma - Norman Campus Institutional Review Board (OU-NC IRB) at 405-3258110 or irb@ou.edu.

You will be given a copy of this information to keep for your records. If you are not given a copy of this consent form, please request one.

\section{Statement of Consent}

I have read the above information. I have asked questions and have received satisfactory answers. I consent to participate in the study. 


\section{APPENDIX D}

PRE-EXERCISE

TESTING HEALTH \&

EXERCISE STATUS

QUESTIONNAIRE

\section{The University of Oklaboma}

DFPARTMFNT OF HFAL TH AND EXFRCISE SCIENCE

Name

Date

Home Address

Work Phone

Home Phone

Person to contact in case of emergency

Emergency Contact Phone

Birthday (mm/dd/yy)

Personal Physician

Physician's Phone

Gender

Age

(yrs)

Height

(ft)

(in) Weight

(lbs)

Does the above weight indicate: a gain

If a change, how many pounds?

a loss

no change in the past year?

A. JOINT-MUSCLE STATUS ( $\checkmark$ Check areas where you currently have problems)

Joint Areas
( ) Wrists
( ) Elbows
( ) Shoulders
( ) Upper Spine \& Neck
( ) Lower Spine
( ) Hips
( ) Knees
( ) Ankles
( ) Feet
( ) Other

Muscle Areas

( ) Arms

( ) Shoulders

( ) Chest

( ) Upper Back \& Neck

( ) Abdominal Regions

( ) Lower Back

( ) Buttocks

( ) Thighs

( ) Lower Leg

( ) Feet

( ) Other

B. HEALTH STATUS ( $\checkmark$ Check if you currently have any of the following conditions)

( ) High Blood Pressure

( ) Heart Disease or Dysfunction

( ) Peripheral Circulatory Disorder

( ) Lung Disease or Dysfunction

( ) Arthritis or Gout

( ) Edema

( ) Epilepsy

( ) Multiply Sclerosis

( ) High Blood Cholesterol or Triglyceride Levels

( ) Allergic reactions to rubbing alcohol
( ) Acute Infection

( ) Diabetes or Blood Sugar Level Abnormality

( ) Anemia

( ) Hernias

( ) Thyroid Dysfunction

( ) Pancreas Dysfunction

( ) Liver Dysfunction

( ) Kidney Dysfunction

( ) Phenylketonuria (PKU)

( ) Loss of Consciousness

* NOTE: If any of these conditions are checked, then a physician's health clearance will required. 


\section{PHYSICAL EXAMINATION HISTORY}

Approximate date of your last physical examination

Physical problems noted at that time

Has a physician ever made any recommendations relative to limiting your level of physical exertion? YES $\mathrm{NO}$

If YES, what limitations were recommended?

D. CURRENT MEDICATION USAGE (List the drug name and the condition being manas MEDICATION CONDITION

E. PHYSICAL PERCEPTIONS (Indicate any unusual sensations or perceptions. $\checkmark$ Check have recently experienced any of the following during or soon after physical activity (PA) during sedentary periods (SED))

$\begin{array}{ll}\text { PA } & \text { SED } \\ \text { ( ) } & \text { ( ) Chest Pain } \\ \text { ( ) } & \text { ( ) Heart Palpitations } \\ \text { ( ) } & \text { ( ) Unusually Rapid Breathing } \\ \text { ( ) } & \text { ( ) Overheating } \\ \text { ( ) } & \text { ( ) Muscle Cramping } \\ \text { ( ) } & \text { ( ) Muscle Pain } \\ \text { ( ) } & \text { ( ) Joint Pain }\end{array}$

$\begin{array}{ll}\text { PA } & \text { SED } \\ \text { ( ) } & \text { ( ) Nausea } \\ \text { ( ) } & \text { ( ) Light Headedness } \\ \text { ( ) } & \text { ( ) Loss of Consciousness } \\ \text { ( ) } & \text { ( ) Loss of Balance } \\ \text { ( ) } & \text { ( ) Exs of Coordination } \\ \text { ( ) } & \text { ( ) Numbness } \\ \text { ( ) } & \text { ( ) Mental Confusion }\end{array}$

F. FAMILY HISTORY ( $\checkmark$ Check if any of your blood relatives ... parents, brothers, sisters uncles, and/or grandparents ... have or had any of the following)

( ) Heart Disease

( ) Heart Attacks or Strokes (prior to age 50)

( ) Elevated Blood Cholesterol or Triglyceride Levels

( ) High Blood Pressure

( ) Diabetes

( ) Sudden Death (other than accidental)

\section{G. RADIATION EXPOSURE}

Have you received any of the following procedures, within the last year? If yes, indicate $h$ ( ) Chest X-ray

( ) Dental X-ray ( ) Mammogram

( ) PQCT scan

( ) DEXA scan

( ) Other 


\section{H. EXERCISE STATUS}

Do you regularly engage in aerobic forms of exercise (i.e., jogging, cycling, walking, etc.)? YES

How long have you engaged in this form of exercise? years months

How many hours per week do you spend for this type of exercise? hours

Do you regularly lift weights?

YES

How long have you engaged in this form of exercise? years months

How many hours per week do you spend for this type of exercise? hours

Do you regularly play recreational sports (i.e., basketball, racquetball, volleyball, etc.)?

How long have you engaged in this form of exercise? years months

How many hours per week do you spend for this type of exercise? hours 